\title{
AN INVESTIGATION INTO THE EFFICACY OF THE ALGEBRA PROJECT
}

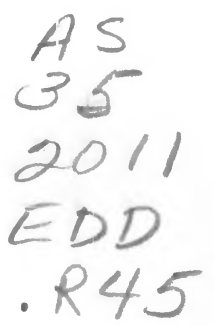

A dissertation submitted to the faculty of

San Francisco State University

In partial fulfillment of

The Requirements for

The Degree

\author{
Doctor of Education \\ In \\ Educational Leadership
}

by

Michael John Reimer

San Francisco, California

November, 2011 
Copyright by

Michael John Reimer

2011 
To my wife Katherine -

I love you. 


\section{CERTIFICATION OF APPROVAL}

I certify that I have read An Investigation into the Efficacy of the Algebra Project by Michael John Reimer, and that in my opinion this work meets the criteria for approving a dissertation submitted in partial fulfillment of the requirements for the degree: Doctor of Education in Educational Leadership at San Francisco State University.

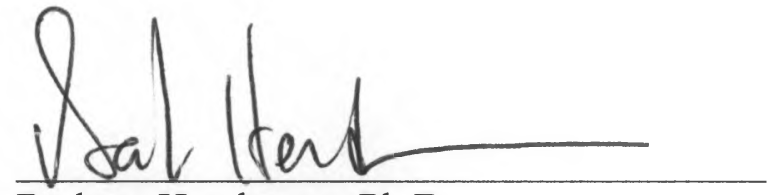

Barbara Henderson, Ph.D.

Professor

Department of Elementary Education

San Francisco State University

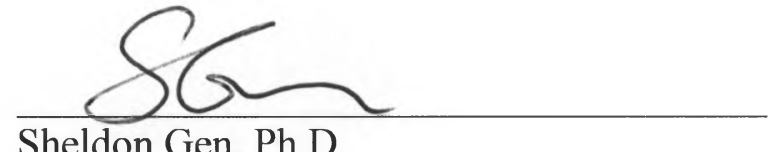

Sheldon Gen, Ph.D.

Assistant Professor

Department of Public Administration

San Francisco State University

Eric Hsu, Ph.D.

Professor

Department of Mathematics

San Francisco State University 


\section{AN INVESTIGATION INTO THE EFFICACY OF THE ALGEBRA PROJECT}

This research employed a quasi-experimental, sequential, explanatory, mixed-methods study design to investigate the efficacy of Robert Moses' Algebra Project. Frequently cited in the literature as an example of a curriculum grounded in culturally relevant and critical pedagogies, the program's effects on students were compared to several control groups. The study was conducted at a high school that served a diverse student body in Northern California and centered on answering three questions relative to: a) students' academic performance, as measured by the Algebra I California Standards Test (CST); b) students' affective response, as measured by Sandman's (1973) Mathematics Attitudinal Inventory (MAI); and c) the identification of additional factors that impacted students' feelings towards mathematics, via a set of semi-structured questions offered during two focus group sessions. Results did not reveal a statistically significant effect in favor of the Algebra Project on the Algebra I CST or on the MAI assessment. Subsequent teacher interviews suggested that poor articulation between the curriculum, the state's algebra content standards, and the standardized assessments contributed to the negative findings. While some students described being more engaged by the experiential activities employed in the Algebra Project curriculum, they were also cognizant of differences in the content of the course, compared to their experiences in traditional algebra classes. Finally, the Algebra Project cohort members displayed a higher degree of relational equity amongst one another. This was particularly apparent when contrasted with the interactions in the Non-Algebra Project cohort, which were punctuated by several instances of microaggressions between the participants, and served to highlight the underlying tension that existed in their more racially polarized classroom.

I certify that the Abstract is a correct representation of the content of this dissertation.

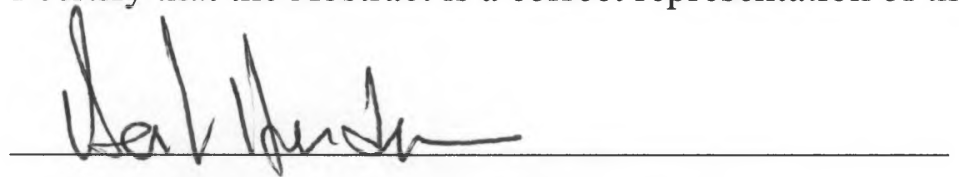

Barbara Henderson, Ph.D., Committee Chair

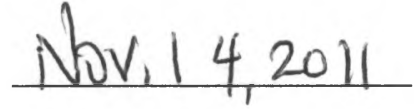

Date 


\section{ACKNOWLEDGEMENTS}

This research would not have been possible without the help and support of a number of individuals.

At the district level I would like to thank Dr. Ritu Khanna, from the Research, Planning and Accountability Department, for her assistance in obtaining the students' test score data. Thank you also to Stephen Kelley, for his help with the development of the MAI inventory and the processing of the student Scantron forms. At the site level I would like to thank the principal for granting me permission to conduct the study at his site; the counseling staff for their help in collecting the student and guardian permission forms; the mathematics teachers who shared their practice and insights and welcomed me into their classrooms; and finally, to the many students who took part in the study. Thank you, as well, to Assistant Superintendent Jeannie Pon, who allowed me to leave my school site during the day to conduct the research, and my Assistant Principal, Teresa Kohler, who capably managed the school in my absence.

Thank you to my committee members, Dr. Barbara Henderson, Dr. Sheldon Gen, and Dr. Eric Hsu, for your patience and guidance. While the finished product is still lacking in many ways, your comments and suggestions honed my thought process and have strengthened this research significantly. Thank you very much for being so willing to meet with me, for the time you spent reviewing the drafts of this document, and for your thoughtful comments and critiques. I sincerely appreciate all of your efforts and assistance.

Finally, thank you to my wife, Katherine, for all of your love and support along the way. There is no way I could have completed this research without you. 


\section{TABLE OF CONTENTS}

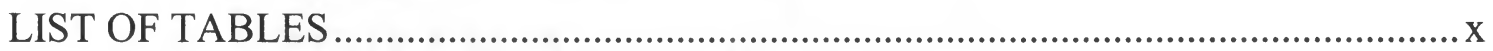

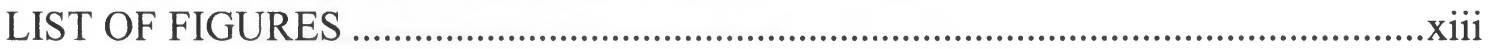

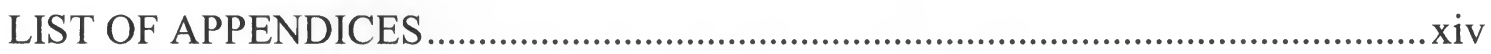

Chapter One: Purpose of the Study ..................................................................... 1

Introduction and Problem Statement .................................................................... 1

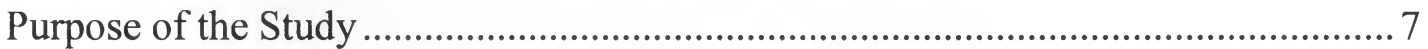

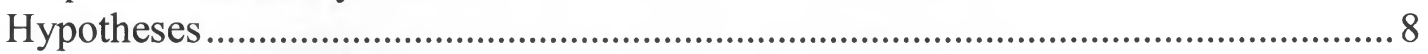

Conceptual Framework ................................................................................ 8

Operational Definitions of Key Terms ............................................................ 10

Statement of Delimitations and Scope of Study .................................................. 11

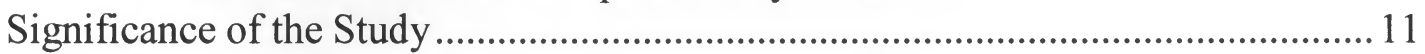

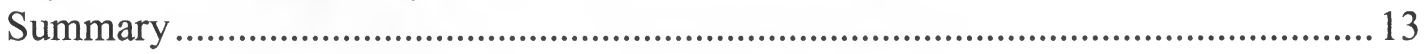

Chapter Two: Literature Review ................................................................. 15

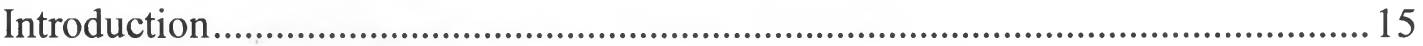

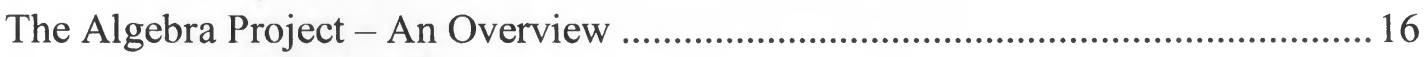

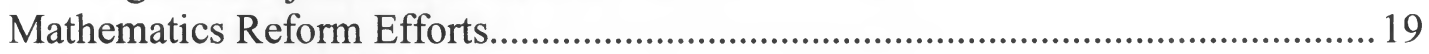

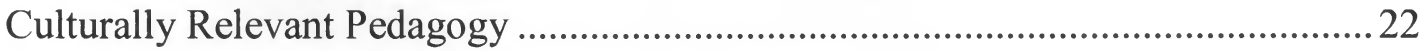

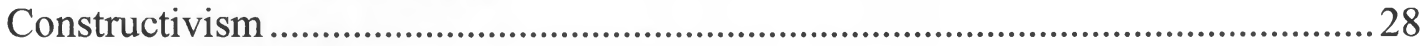

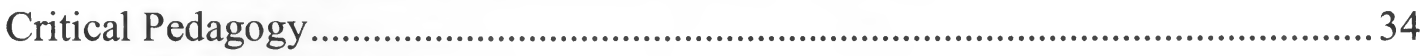

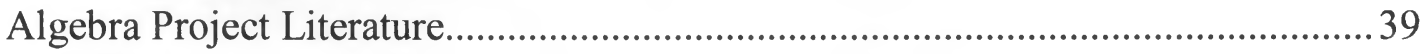

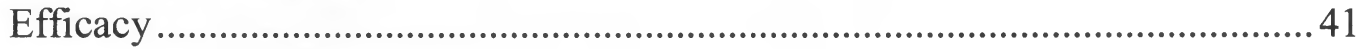

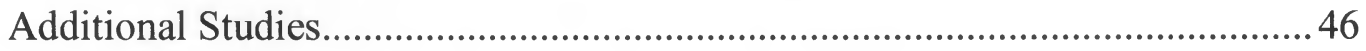

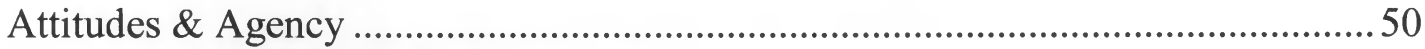

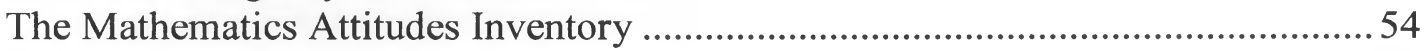

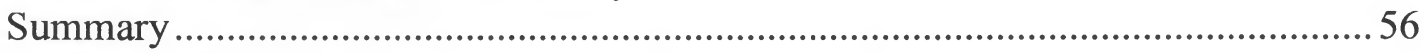

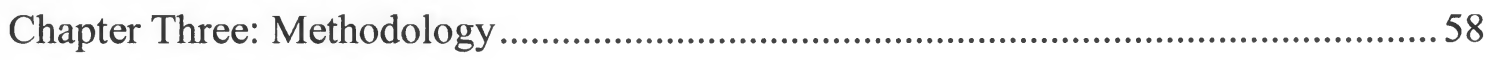

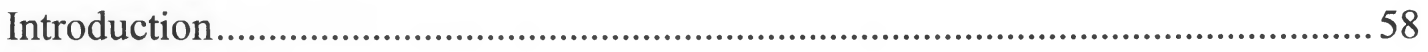

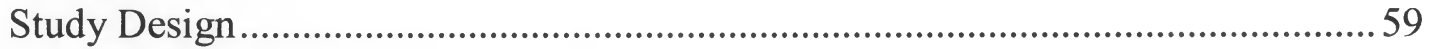

Role of the Researcher .................................................................................6 61

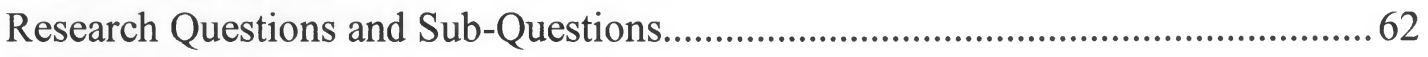

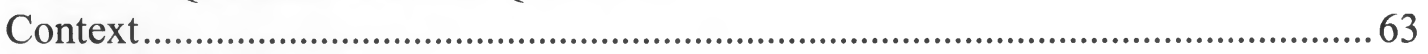

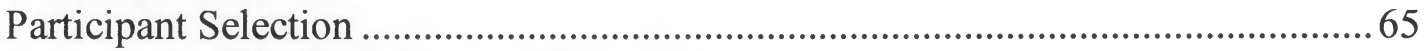

Ethics and Protection of Human Subjects............................................................6 69

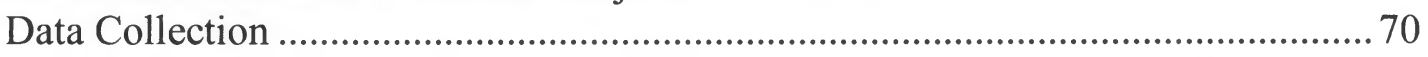

vii 


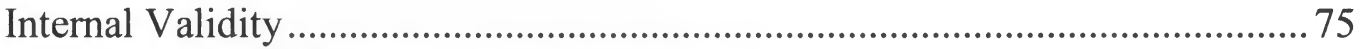

Spurious Effects \& Confounding Variables .......................................................76

External Validity ............................................................................................ 77

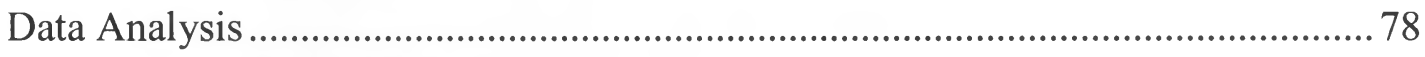

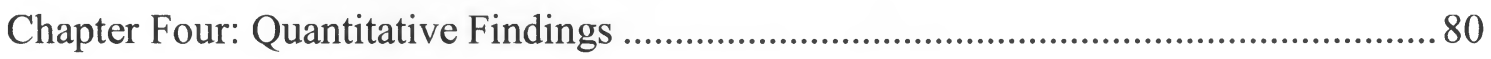

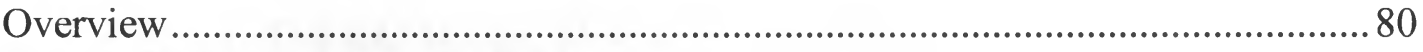

The Findings - Research Question \#1 .................................................................... 81

Student Samples Investigations ……………………….................................. 81

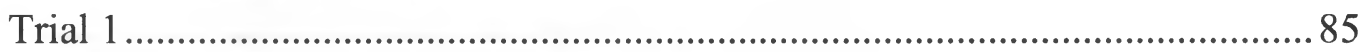

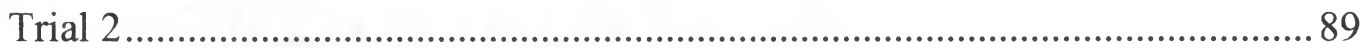

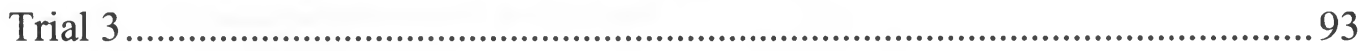

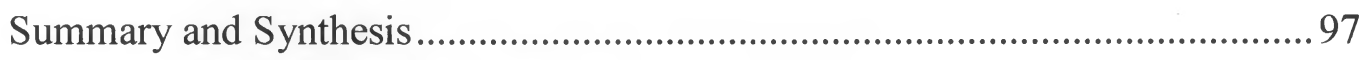

The Findings - Research Question \#2 ................................................................. 100

Student Samples.............................................................................................. 101

Raw Data Comparisons................................................................................. 102

Construct Comparisons.................................................................................... 104

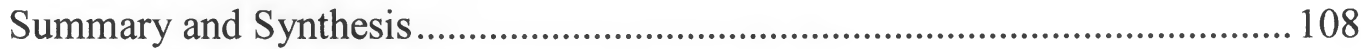

Chapter Five: Qualitative Findings ............................................................................ 110

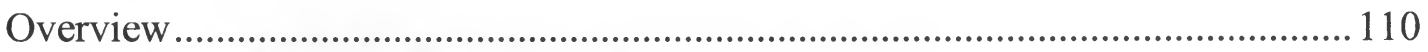

The Findings - Research Question \#3 ......................................................................111

Teacher Portraitures ……………………......................................................... 111

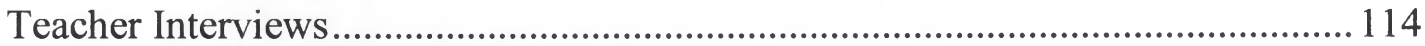

Reshaping the prescribed curriculum.............................................................. 118

Investing and taking a personal responsibility in students' success ................... 129

Summary and Synthesis ................................................................................ 133

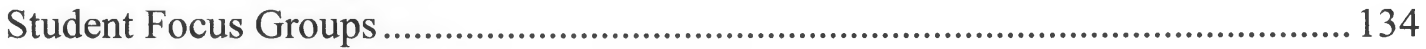

Student Affect \& Voice ................................................................................ 136

Curriculum \& Instruction................................................................................ 141

Student Discipline \& Equity ............................................................................... 145

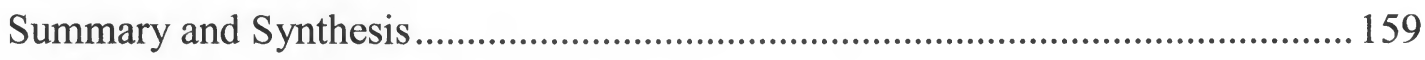

Chapter Six: Discussion and Recommendations .......................................................... 161

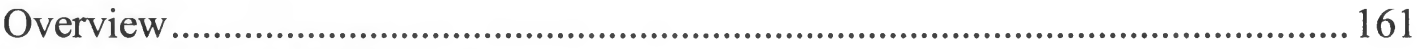

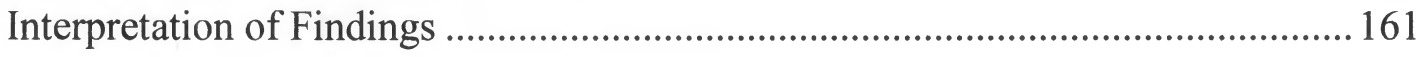

viii 


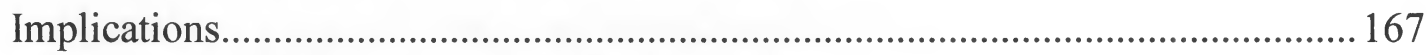

Recommendations for Action and Further Study ............................................ 168

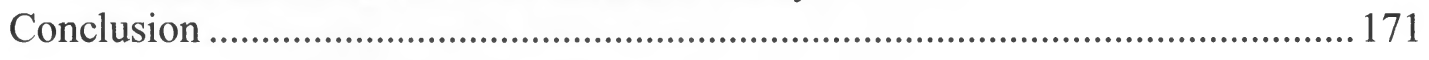

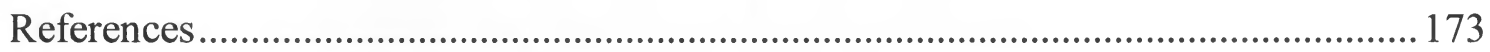

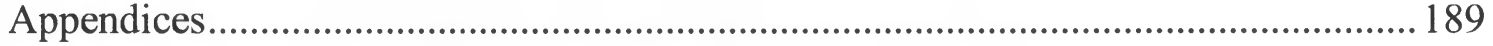




\section{LIST OF TABLES}

Table

Page

1. Percentage of $9^{\text {th }}$ Grade Students Testing At or Above Proficient on the Algebra I CSTs from a California School District by Race/Ethnicity

2. Change in $9^{\text {th }}$ Grade Students Testing At or Above Proficient on the Algebra I

CSTs from a California School District by Race/Ethnicity

3. African American Achievement Gap Between $9^{\text {th }}$ Grade Students Testing At or Above Proficient on the Algebra I CSTs from a California School District ... 192

4. Racial composition of Eastwood High School in 2009 64

5. Student composition of Eastwood High School in 2009 64

6. Algebra I CST Scaled-Scores and Proficiency Levels .72

7. Contingency Table for Gender and Instructional Support at Eastwood High ... 82

8. Contingency Table for Gender and Instructional Support at other district high schools

9. Contingency Table for Race and Ethnicity and Instructional Support at Eastwood High

10. Contingency Table for Race and Ethnicity and Instructional Support at other district high schools

11. Comparison of Algebra Project students' Algebra I CST scores between the $8^{\text {th }}$ and $9^{\text {th }}$ grade at Eastwood High

12. Paired samples t-test for Algebra Project students' Algebra I CST scores between the $8^{\text {th }}$ and $9^{\text {th }}$ grade at Eastwood High

13. Comparison of Non-Algebra Project students' Algebra I CST scores between the $8^{\text {th }}$ and $9^{\text {th }}$ grade at Eastwood High

14. Paired samples t-test for Non-Algebra Project students' Algebra I CST scores between the $8^{\text {th }}$ and $9^{\text {th }}$ grade at Eastwood High

15. Mean Differences between $8^{\text {th }}$ and $9^{\text {th }}$ grade mathematics CST Means at

Eastwood High

16. Independent samples t-test (Assuming Unequal Variances) of Mean Differences in students' Algebra I CST Scaled Scores at Eastwood High

17. Comparison of Algebra Project students' Algebra I CST scores between the $8^{\text {th }}$ and $9^{\text {th }}$ grade at Eastwood High 90 
18. Paired samples t-test for Means for Algebra Project students' Algebra I CST scores between the $8^{\text {th }}$ and $9^{\text {th }}$ grade at Eastwood High

19. Comparison of Non-Algebra Project students' Algebra I CST scores between the $8^{\text {th }}$ and $9^{\text {th }}$ grade at District High Schools

20. Paired samples t-test for Means for Non-Algebra Project students' Algebra I CST scores between the $8^{\text {th }}$ and $9^{\text {th }}$ grade at District High Schools

21. Mean Differences between $8^{\text {th }}$ and $9^{\text {th }}$ grade Algebra Scaled Scores - District Non-Algebra Project v. Algebra Project Cohorts

22. Independent samples t-test (Assuming Unequal Variances) of Mean Differences of students' Algebra Scaled Scores - District v. Algebra Project Cohorts .........92

23. Comparison of African American Algebra Project students' Algebra I CST scores between the $8^{\text {th }}$ and $9^{\text {th }}$ grade at Eastwood High

24. Paired samples t-test for Means for African American Algebra Project students' Algebra I CST scores between the $8^{\text {th }}$ and $9^{\text {th }}$ grade at Eastwood High 95

25. Comparison of African American Non-Algebra Project students' Algebra I CST scores between the $8^{\text {th }}$ and $9^{\text {th }}$ grade at District High Schools

26. Paired samples t-test for Means for African American Non-Algebra Project students' Algebra I CST scores between the $8^{\text {th }}$ and $9^{\text {th }}$ grade at District High Schools

27. Mean Differences between $8^{\text {th }}$ and $9^{\text {th }}$ grade African American Algebra Scaled Scores - District v. Algebra Project Cohorts 96

28. Independent samples t-test (Assuming Unequal Variances) of Mean Differences of students' Algebra Scaled Scores - District v. Algebra Project Cohorts ........ 96

29. Research Question \#1 Trial Summaries .............................................................. 98

30. Demographic profiles of Completed MAI Surveys - Non-Algebra Project and Algebra Project Classes .................................................................................. 101

31. Student Demographics of Algebra Project Classes at Eastwood High ............ 102

32. Student Demographics of Non-Algebra Project Classes at Eastwood High .... 102

33. Independent t-test of individual questions from MAI - Non-Algebra Project (Non-AP) v. Algebra Project (AP) ................................................................. 216

34. Independent samples t-Test (Assuming Unequal Variance) Results of Mean Construct Scores Between Non-Algebra Project (Non-AP) and Algebra Project (AP) Students 
35. Independent samples t-Test (Assuming Unequal Variance) Results of Mean Construct Scores Between Non-Algebra Project (Non-AP) and Algebra Project (AP) Students - English Language Versions Only ............................................... 107

36. Frequencies of Morrison's CRP elements from teacher interviews .................116 


\section{LIST OF FIGURES}

Figure Page

1. Conceptual Framework Schema …............................................................. 10

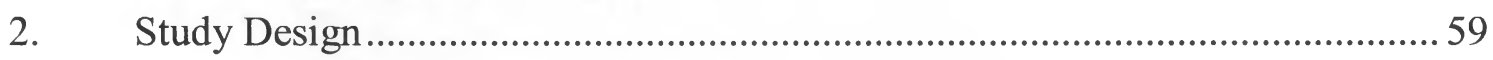

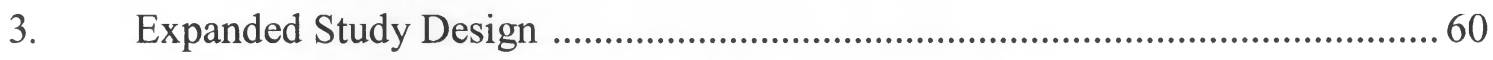

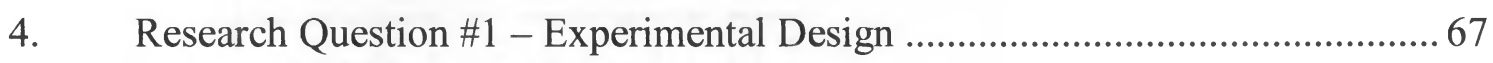

5. Research Question \#2 - Experimental Design ................................................. 68 


\section{LIST OF APPENDICES}

Appendix Page

A. $\quad 9^{\text {th }}$ Grade Algebra I CST Test Scores from a California School District ........ 190

B. Mathematics Attitudinal Inventory (MAI) Survey ....................................... 193

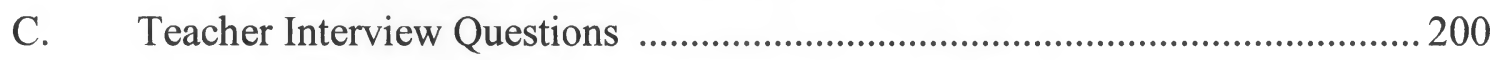

D. Student Focus Group Questions ............................................................. 204

E. Algebra I CST Technical Report ........................................................... 211

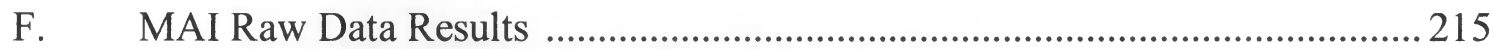

G. Student Focus Groups Data Indexing .................................................... 219 
Chapter One: Purpose of the Study

I am convinced, you know ... that doing something different is valid, and it's also necessary ... I just don't think we're serving students. And this goes beyond just math too. I think what we're doing in schools, if it's not working with our students, then we really need to re-evaluate what's broken. Because up 'til now, it's always the students are broken, you know, and there's no sense in continuing that flawed reasoning, if we're saying that we value all students.

\section{$9^{\text {th }}$ Grade Algebra Project teacher}

\section{Introduction and Problem Statement}

A critical and well documented problem in American public schools involves the wide discrepancies in students' mathematics test scores. This problem is particularly acute for African American students studying algebra, widely cited in the literature as being a "gatekeeper" subject (Esmonde, 2009; Gutstein \& Peterson, 2006; Jacobson, 2000; Kamii, 1990; Ladson-Billings, 1997; Lubienski \& Bowen, 2000; Moses, Kamii, Swap, \& Howard, 1989). A review of national and state test score data reveals significant gaps between groups of students and highlights a number of the challenges for practitioners and researchers. For example, the results from the National Assessment of Educational Progress (NAEP) $8^{\text {th }}$ grade mathematics test ${ }^{1}$, an assessment emphasizing algebraic skills, showed that African American students had the lowest average scaled-score $(\mu=261)$ of the major racial/ethnic groups, with Hispanics $(\mu=$ 266), Whites $(\mu=293)$ and Asians $(\mu=301)$ all scoring substantially higher (National

\footnotetext{
' The NAEP assessment reports student test score results using a scale from 0-500.
} 
Center for Education Statistics, 2009). The California results for this assessment revealed a similar picture, with African American students $(\mu=250)$ trailing behind all other groups (Hispanics, $\mu=256$; Whites, $\mu=289$; Asians, $\mu=294$ ).

However, the test score discrepancies are not limited to national tests. Regional assessments provide corroborating evidence of the existence of a significant algebra achievement gap. According to a recent study on student achievement in the state of California, African American students are less likely to be successful on the Algebra I California Standards Test (CST) with 9\% scoring at the Proficient level, as compared to their Hispanic (11\%), White (27\%) and Asian (43\%) peers (EdSource, 2008).

At the local level, an analysis of the 2010 Algebra I CST test scores, from a diverse, metropolitan school district in Northern California, revealed even more striking disparities, including a gap of 27 percentage points between African American students and White students and a $45 \%$ point difference with Chinese students. Further study of this district's data indicated: a) a 7\% point gap between African American and Latino students, b) zero growth $(0.0 \%)$ in the African American test scores during the past seven years; and c) when compared to several other racial/ethnic groups, the algebra achievement gap is actually widening for African American students (California School District, 2010). ${ }^{2}$ In fact, the situation has become so severe in this district that special

\footnotetext{
${ }^{2}$ See Appendix A - Tables 1-3 for additional details.
} 
education students (7\%) outscored African American students (6\%) on this statewide assessment at the $9^{\text {th }}$ grade level in 2010.

While some argue that socio-economic status (SES) serves as a confounding variable in the investigation into race and mathematics achievement (Kamii, 1990; Lubienski, 2002a; Lubienski \& Bowen, 2000), a preliminary small scale investigation at one of the district's high schools suggested that there was no relationship between the students' SES status and their mathematics test scores (Reimer, 2009a). A subsequent paper also ruled out gender as a dependent factor, but at the same time showed that race was related to the school's mathematics test scores results $\left(\chi^{2}(12)=106.2206, p<\right.$ 0.0001) (Reimer, 2009b).

Generally speaking, a review of the data at the national, state and local levels indicates that the achievement gap in algebra has remained essentially unchanged for years. Additionally, it appears that current practices have continued to produce significantly different results on these standardized assessments and have had limited impact in terms of narrowing the gap.

Of added concern are data from a recent study that indicated that different groups of students do not receive the same academic benefit as a result of taking algebra at the $9^{\text {th }}$ grade level. In a large-scale, quantitative investigation into students' academic performance, Riegle-Crumb (2006) investigated the benefit differentials that students received as a result of taking algebra at high school. One of the major findings from 
this study was that African American and Latino male students benefited significantly less as a result of studying algebra, compared to their Asian and White peers. Additionally, the researcher proved that this return differential remained, even when students began the study of algebra from the same relative academic position.

In her explanation of the results, Riegle-Crumb noted the importance of the underlying connections between the algebra curricula, students' sense of agency, and the development of their mathematical identities. Particularly germane for this study, Riegle-Crumb noted that the lack of relevant curriculum contributed to the results, arguing that the content and form of mathematics curricula often has little connection and relevance for minority students. Of additional concern from her study was the suggestion that elements of oppositional culture may have influenced the results for the African American and Latino males. Evidence to support several of her claims was also found in a recent small scale study into students' attitudes in algebra classes at the local level (Reimer, 2009c).

At the same time, while there is ample statistical evidence to show that African American students struggle to achieve at comparable rates to their peers, there remains relatively little research into equity issues in the mathematics classroom (Brenner; 1998; Gutierrez, 2008; Stinson, 2008). In a broad survey of mathematics education literature published between 1982 and 1998, Lubienski \& Bowen (2000) highlighted this lack of research. Whittling the 510, 241 abstracts from the ERIC data-base to just over 3,000 
articles specific to mathematics education, the authors categorized the articles according to various equity related topics, noting that gender received the most attention $(n=323)$, with ethnicity $(n=112)$ and class $(n=52)$ lagging far behind.

In their critique of this literature these researchers noted that, "...there were particular topics that seemed strangely lacking in attention ... (including) ... the special strengths and needs ethnic or class groups have in relation to various topics, such as statistics, algebra, and calculus (which often serve as gatekeepers)." (p. 630) While the researchers noted that test scores were often compared between student groups in these research articles, they also noted particularly poor connections to classroom practices, writing:

The data also reveal a large, overall emphasis on student cognition (yet usually not in conjunction with ethnicity, class or gender) and achievement and a relatively small emphasis on classroom processes, or on equity groups in relation to these processes. (p. 630)

The researchers concluded that much of the mainstream mathematics research has often focused on "cognition without context or culture" (p. 632). Although a handful of articles have recently focused on the importance of students' mathematical experiences in classrooms (Boaler \& Staples, 2008; Boaler, William, \& Zevenbergen, 2000; Gutstein, 2007; Kress, 2005; Martin, 2009; Schoenfeld, 2002; Stinson, 2008), the field is largely devoid of research that investigates the efficacy of specific curricular programs, or instructional practices, designed to address the inequities represented in 
the mathematics test score data (Brenner, 1998; Gay, 2000; Kamii, 1990; Lubienski \& Bowen, 2000; Morrison, Robbins, \& Rose, 2008), particularly for students studying algebra (Kamii, 1990; Morrison et al., 2008; Riegle-Crumb, 2006).

An earlier pilot study into the Algebra Project at a local high school seemed to offer a promising alternative for narrowing the algebra achievement gap (Reimer, 2009d). Developed by Robert Moses, the program centers on the implementation of a curriculum designed to be more closely connected to the students' daily experiences. The study revealed that the Algebra Project, frequently cited in the literature as an example of culturally relevant and critical pedagogies (Davis \& Martin, 2008; Kress, 2005; Lee, 1998; Leonard, Brooks, Barnes-Johnson, \& Berry, 2010; Martin, 2009), incorporated a number of supports that assisted students in their acquisition of the algebraic concepts. Specifically, these supports included: the incorporation of experiential and constructivist-based activities; an emphasis on the connections between language and mathematics; and broad community support from a variety of stakeholders (Reimer, 2009d). However, while this qualitative study was able to identify a number of strengths related to the program, it did not investigate the effects in two important domains: a) students' performance, as measured by the Algebra I California Standards Test, and b) students' affective response.

Summarizing, the situation could not be more critical for students in diverse algebra classrooms. While there is little debate regarding the importance of algebra for 
students, at the same time the disparities in the test results underscore the fact that educators have been unable to engage all students in the learning process in classrooms. In part, this research hopes to address these concerns.

With the weight of the evidence suggesting that traditional instructional methodologies have had little impact on engaging and motivating minority students in the study of algebra (Boaler \& Staples, 2008; California School District, 2010; Corey \& Bower, 2005; EdSource, 2008; Lubienski \& Bowen, 2000; National Center for Education Statistics, 2009; Stinson, 2008), I have hypothesized that the Algebra Project's strong foundation in culturally relevant pedagogy (CRP) and critical pedagogy (CP), makes it more likely to elicit a positive effect for students studying algebra in these two key domains.

\section{Purpose of the Study}

The purpose of this paper is to investigate the efficacy of the Algebra Project on students' acquisition of algebra. Justification for the study stems from the urgent need to identify instructional practices and related curricular materials that result in: a) increased rates of student success and b) a narrowing the algebra achievement gap for African American students. To do this the study employed a quasi-experimental, sequential, explanatory mixed-methods design to address three research questions: 
1. Are there differences in students' performance between the instructional methodologies (Non-Algebra Project v. Algebra Project) as measured by the Algebra I CST?

2. Are there differences in students' mathematical attitudes between the instructional methodologies (Non-Algebra Project v. Algebra Project) as measured by Sandman's $(1973,1979)$ Mathematics Attitude Inventory (MAI) survey?

3. What additional factors impact the way students feel about the study of mathematics?

\section{Hypotheses}

Based on the literature and the results of the pilot study, I hypothesized the following:

1. A statistically significant difference on the Algebra I CST will be established in favor of the experimental (Algebra Project) group.

2. A statistically significant difference on the MAI will be established in favor of the experimental (Algebra Project) group.

3. Students will identify race as a factor related to their achievement and developing mathematical identities.

\section{Conceptual Framework}

Because the Algebra Project is grounded in the theories of culturally relevant and critical pedagogy, these two theories were employed as the conceptual frameworks for this study. Specifically, the frameworks were used: a) as a means of guiding and 
informing the study's design and research questions, and b) as lenses through which the data was subsequently analyzed and interpreted.

Wanting to firmly ground the investigation of the Algebra Project within the existing literature, and at the same time operationalize particular elements of the conceptual framework, the research questions were developed as a means of investigating the connections between culturally relevant pedagogy (CRP), critical pedagogy $(\mathrm{CP})$ and the students' acquisition of algebra in the various classroom settings. The theoretical underpinnings of CRP were employed to help interpret the existing standardized test scores, as well as the existing literature on mathematics reform. Both frameworks were used as a means of evaluating the degree to which the program contributed the students' academic success, as well as the development of their mathematical identities and sense of agency. A conceptual framework schema for the study is provided in Figure 1.

While this schema provides a conceptual map of the theoretical connections and relationships between the major components of CRP and CP, set within the context of the study of algebra, it was not designed to be exhaustive. As will be presented, data collected over the course of the study drew upon understandings and connections to a number of other frameworks and theories of learning; most notably these included constructivism (cognitive and socio-cultural) and relational equity (Boaler, 2002). 


\section{Algebra Project \\ (acquisition of algebra)}

Culturally Relevant Pedagogy

(Ladson-Billings, 1995)

Central tenets include:

- High Academic Expectations

- Cultural Competence

- Critical Consciousness
Critical Pedagogy

(Freire, 2009)

Central tenets include:

- Banking to Problem Posing

- Oppression to Liberation

- Conscientização
Constructivism

(cognitive and socio-cultural)

Figure 1. Conceptual Framework Schema

\section{Operational Definitions of Key Terms}

Key terms and definitions have been borrowed from the works of Stinson (2008) and Martin (2009), and include the following: mathematics identity, defined as students' beliefs about their mathematics abilities, their understanding of the opportunities and constraints that exist to participate in mathematics, and their 
motivation to study mathematics; discourses, defined as capital-D discourse (Gee, 2005) referring to a variety of socio-cultural factors that "are always language plus other 'stuff'" (Stinson, p. 977); agency, defined as the participants' ability to accommodate, reconfigure, or resist the available socio-cultural discourses that surround minority students in order for them to effectively negotiate the dominant discourse patterns in their pursuit of success; and finally curriculum, defined broadly as the combined experiences (cognitive and affective), resources (physical and intellectual) and instructional methodologies used to transmit information between groups of people.

\section{Statement of Delimitations and Scope of Study}

Delimitations to the study include: the short history of the program at the study site, the fact that the results rested on the efforts of a small group of teachers, and that the study was centered at a single school. Additionally, data accessibility issues prevented a more detailed exploration into related factors and variables, including students' socio-economic status (SES), attendance rates, discipline and transcript data, and level of parents' education.

\section{Significance of the Study}

Since algebra is widely considered to be a gatekeeper subject, closing the algebra achievement gap is an important step to empowering historically disenfranchised communities (Esmonde, 2009; Gutstein \& Peterson, 2006; Moses et al., 1989). On the surface, the significance of the study rests with its potential to identify an 
algebra curriculum, and set of related instructional practices, that provides diverse student groups with access to algebra - which Moses refers to as the "new civil right" (Greeno, 2002; Kress, 2005; Moses \& Cobb, 2001 a, 2001b; Moses et al., 1989).

Additionally, a review of the related research suggests that this study may also serve to bridge a number of gaps in the existing literature. Specifically, the study stands to contribute to the following four broad areas. First, there has been limited application of $\mathrm{CRP}$ and $\mathrm{CP}$ as conceptual frames in mathematics research. While the study probes the efficacy of the Algebra Project on students' acquisition of the concepts in algebra, it also stands to contribute to these two larger bodies of work. Second, despite the challenges represented in the student test score data, there remains little research into programs designed specifically to meet minority students' needs as they study algebra. Highlighting the dearth of research, a query for the terms "African American" and "algebra" into the online ProQuest database produced a total of 29 articles only. Third, while Moses' Algebra Project employs a culturally responsive approach, there has been little formal empirical study into the program's efficacy and the student agency that it claims to foster. As will be detailed in the literature review, although the Algebra Project is frequently referenced in the literature as a successful instructional approach, there exists little research into the program, particularly in relation to student performance on standardized exams. Fourth, few of the empirical studies that do exist have employed independent, scientifically field tested and validated assessments against 
which the effects of the program can be measured. By investigating the standardized test scores and affective responses from students who are enrolled in the Algebra Project, it is hoped that researchers and practitioners will gain a better understanding of the types of curricular approaches that contribute towards successfully engaging students in the study of algebra.

\section{Summary}

Data from a variety of tests and assessments points to the continued existence of an achievement gap in mathematics - particularly in algebra. Additionally, studies have shown that current practices result in significant return differentials for particular groups of students. Despite these challenges and concerns, the existing literature reveals that there has been limited investigation into issues related to establishing more equitable mathematics classrooms. In the past decade, several researchers have suggested that an approach grounded in culturally relevant and critical pedagogies might prove to be beneficial for students. Because the Algebra Project is grounded in both of these theories, and has received relatively limited study, this research has proposed a more formal investigation into the program. Therefore, this study has proposed a detailed investigation into the efficacy of the Algebra Project in two key domains: a) students' academic performance, as measured by the Algebra I California Standards Test, and b) students' affective response. 
Chapter 2 provides a review of the related literature, including sections on culturally relevant pedagogy, constructivism, critical pedagogy, as well as an overview of the existing research into the Algebra Project. Chapter 3 offers the complete set of research questions and explains the study's design and methodology. The results from the quantitative portion of the study are presented and discussed in chapter 4 , with the qualitative results detailed and developed in chapter 5. Finally, implications, recommendations and conclusions are offered in chapter 6. 
Chapter Two: Literature Review

Introduction

This chapter reviews the literature related to the study and is divided into several sections. The chapter begins with an overview and description of the Algebra Project. Next, the results and conclusions of a recent large scale study into curricular reforms in mathematics are presented and discussed. After noting fundamental philosophical and epistemological considerations that are frequently absent in such studies, the related literature on culturally relevant, constructivist and critical pedagogical approaches are reviewed and developed. Selected readings on students' attitudes and construction of agency are also reviewed. Subsequently, a review of the existing literature and research on the Algebra Project itself is presented. The chapter concludes by highlighting existing gaps in the literature base.

Independent online searches were conducted using the ProQuest and ERIC online journal databases and employed several key words and phrases, including: algebra \& African American, algebra \& Latino, algebra \& constructivism, Algebra Project, problem solving, algebra \& attitudes and mathematics \& attitudes. Additional searches were conducted on the phrases culturally relevant pedagogy and critical pedagogy. Due to the lack of empirical research on the Algebra Project, subsequent searches were also performed in the ProQuest Interdisciplinary Dissertations \& Theses 
database. Finally, data-mining techniques were employed throughout the course of the study to ensure that relevant documents were reviewed.

\section{The Algebra Project - An Overview}

The Algebra Project was developed by Robert Moses in the early 1980's, and was specifically designed to help African American students at middle school successfully complete and pass algebra. Building on his experience as a veteran civil rights activist and community organizer from the 1960's, Moses created the Algebra Project to assist historically disenfranchised students gain access to more rigorous mathematics classes, by helping them succeed in their algebra classes (Kamii, 1990; Moses \& Cobb, 2001a, 2001b; Moses et al.,1989; Roach, 2004). Partly rooted in the belief that students must master basic mathematics to successfully participate in a modern and technologically based economy, Moses notes that algebra is a gatekeeper course, one whose mastery is necessary for continued study in mathematics and science classes (Moses \& Cobb, 2001a, 2001b; Moses et al., 1989; Reeves, 2002). Drawing on his experiences in the 1960's, Moses reframes disenfranchised populations' struggle for full citizenship and equality around literacy in mathematics - beginning with algebra (Kamii, 1990; Kress, 2005; Moses \& Cobb, 2001a, 2001b; Moses et al., 1989; Silva \& Moses, 1990). In recent years, the Algebra Project has expanded its focus to include other traditionally underserved groups of students (mostly Latinos), and has branched out to include collaborative partnerships with high schools across the country. 
From Moses' experiences in the civil rights movement, the Algebra Project is rooted in three organizing traditions. They include: the importance of families in the work of organizing; empowerment of grassroots groups and recruitment for leadership; and organizing in the context in which one lives and works (Moses \& Cobb, 2001a, $2001 \mathrm{~b}$; Moses et al., 1989). As a result, community and youth development represent key components that support the instructional strategies and teacher training that takes place at the school site.

Central to the Algebra Project is a unique pedagogical approach, sometimes referred to as the "five step curricular process" (Greeno, 2002; Moses \& Cobb, 2001a; Moses et al., 1989; Silva \& Moses, 1990). The multi-step process draws heavily on the basic tenets of Dewey, Piaget, and Lewin and the constructivist and experiential learning movements (Davis, 2004; Greeno, 2002; Kamii, 1990; Kress, 2005; Moses \& Cobb, 2001a; West \& Davis, 2005). This five step process is described as follows: a) participation in a physical event; b) a picture or model of the event; c) the use of intuitive language to describe the event; d) a description of the event in regimented English; and e) a symbolic representation of the event. As Moses and his colleagues explain, the students benefit from the model's movement from the experiential and tactile to the abstract conceptualization of numbers and algebraic concepts. Additionally, the program emphasizes the use of natural language as an intermediary step to develop students' understanding of problems, as they work towards a more 
formal mathematical representation of the activities (Kamii, 1990). The Algebra Project is grounded in the belief that connecting experiences and language with the underlying concepts of numeracy and mathematical operations is essential to helping students become successful in algebra.

In addition to being experiential in nature, Moses also notes that the curriculum is culturally centered, with the activities situated within the daily experiences of the students' lives and cultures (Davis \& Martin, 2008; Kress, 2005; Lee, 1998; Leonard et al., 2010; Martin, 2009; Moses \& Cobb, 2001a, 2001b; Moses, et al., 1989). Levine (2001) provided a succinct summary the Algebra Project's approach explaining, "To help African-American students master mathematics literacy, the program has replaced traditional, rote-bound instruction with imaginative activities that engage student creativity and encourage sophisticated mathematical reasoning" (p. 2).

In addition to the prescribed 5 step instructional lesson delivery, the Algebra Project is supported by a variety of other important components, including: asking students to dedicate themselves to rigorous study; committing students to at least 90 minutes of mathematics everyday (double the normal daily amount of instructional time); encouraging students to take four years of mathematics at high school; and including students' families in their mathematics development. To foster the connections to the wider community, in some cities the Algebra Project has also created youth action cohorts (known as the Young Peoples' Project) that focus on the 
development of tutoring and leadership opportunities, with an eye towards improving the mathematical skills and awareness of the local community (Cervone, 2002; Kress, 2005; Moses \& Cobb, 2001a; Moses et al., 1989; Normore, Rodriguez, \& Wynne, 2007; Roach, 2004).

\section{Mathematics Reform Efforts}

A review of the historical data and literature reveals that many of the mathematics reform initiatives to date have had little impact in narrowing the achievement gap in mathematics. In a recent large-scale RAND study that investigated the effectiveness of reform-oriented instructional practices in mathematics classrooms, the researchers discovered only marginal gains in students' academic performance (Le et al., 2006). In their longitudinal study these researchers noted that exposure to reform oriented instruction “...generally had nonsignificant or weak positive relationships to student achievement in both mathematics and science..." (Le et al., 2006, p. xvii).

Conducted in several school districts working on a systemic change initiative in conjunction with the National Science Foundation (NSF), Le's et al. research into instructional practices focused on tracking the achievement results of several cohorts over a three year period. These researchers employed a variety of measures to gauge teachers' implementation of instructional reform practices and then sought to establish the relationship of each factor to students' academic achievement. Notable results 
included statistically significant $(\mathrm{p}<0.03)$ positive effects $(0.1 \leq S D \leq 0.15)$ for all three indicators of group work on open ended assessments after cumulative exposure. Interestingly however, the researchers also found statistically significant $(\mathrm{p}<$ $0.03)$ negative effects $(S D=0.10)$ for two of the three indicators of group work when students' mathematical procedures were assessed using multiple choice assessments. Attempting to summarize their incongruous results, the researchers concluded that the relationship between instruction and achievement was at least partly dependent upon how achievement was measured and assessed.

However, although the research represented a detailed and comprehensive attempt to measure the effects of reform practices in mathematics classrooms, there were two important limitations to their study. The first was the use of the Stanford Achievement Test Series, Ninth Edition (SAT-9), a well known norm-referenced mathematics test, as a measure students' academic achievement. Although the study contributes towards the understanding of classroom practices that work to narrow the mathematics achievement gap, it remains unclear how the results of Le's et al. study may have been altered if the researchers had employed a criterion-referenced assessment. In recent years many states have shifted towards the use of criterion, as opposed to norm, referenced assessments.

As noted in the general media, California moved away from its use of the SAT-9 assessments in the late 1990's as it implemented a standards-based curriculum. Along 
with this curricular shift came assessments designed to measure students' achievement against a set of established benchmarks. While Le's et al. study was able to measure the efficacy of instructional practices, a replication study based upon a criterion-referenced assessment (such as the Algebra I CST or the proposed assessments for the new Common Core States' Standards) would be of interest, possibly providing additional insight into their mixed results. At the same time, such a shift would help to address the concerns from some researchers who argue that assessment results are employed too frequently to compare or rank groups of students against one another (Davis \& Martin, 2008; Martin, 2009; Tate, 1995).

Second, the results from Le's et al. study are tempered by the types of reforms that were considered. Close study of the report revealed the many of the practices investigated represented traditional reform techniques, several of which are often employed in mathematics classrooms on a regular basis. As noted in the study, the independent variables included measures of: instruction time per week, mathematical process, and amount of time spent on discussion, group work and seat work. While these factors are certainly related to student learning, at the same time describing these variables as reform practices seems to leave some room for further consideration. Additionally, many of the independent variables under investigation in the study relied on teacher reports of implementation, as opposed to direct observation by the researchers. 
Comparatively, Algebra Project's grounding in culturally relevant and critical pedagogical practices offers researchers several new avenues for investigation, and perhaps more importantly, provides a promising set of instructional techniques and strategies that explicitly confront the issues of race, student identity and success for students studying algebra.

\section{Culturally Relevant Pedagogy}

In the past 15 years, as researchers have investigated the development of student agency in connection to the learning process, the importance of presenting material in a manner that is congruent with students' lived experiences and cultures has been proposed as a means of providing more equitable learning experiences to diverse groups of students (Gay 2000; Ladson-Billings, 1995; Ladson-Billings \& Tate, 1995; Young, 2010). As this branch of research has developed and evolved, various terms have been introduced to describe the approach, including: multicultural, culturally-appropriate, culturally-centered, culturally-coherent, culturally-connected, culturally-mediated, culturally responsible, culturally responsive, socially just, Afro-centric, and ethnomathematics (Kress, 2005). Although these approaches vary subtly in their definitions and practice, in this work they are referred under the umbrella descriptor of “culturally relevant pedagogy," or CRP.

Generally speaking, much of the research into culturally relevant pedagogy has centered on the incorporation of particular strategies, instructional techniques and 
curricular materials designed to provide students with more entry points into the material in classrooms (Gay 2000; Ladson-Billings, 1995; Ladson-Billings \& Tate, 1995). As a result, researchers contend that students are more likely to: a) acquire the concepts presented during lessons, and b) feel more comfortable, confident and successful in the learning environment. Additionally, key to the culturally relevant approach are efforts to de-center the classroom from the largely White, middle-class Eurocentric worldview that typically describe many mathematics classes (Anderson, 1990; Kress, 2005), making them more likely to be receptive and inclusive for diverse student populations.

Originally defined by Ladson-Billings (1995) as she worked to develop a critical race theory for education and articulate best practices for practitioners (Gay 2000; Ladson-Billings, 1995; Ladson-Billings \& Tate, 1995), culturally relevant pedagogy (CRP) built upon several existing frameworks and theories of learning. Most notably, these included two variants of constructivism (cognitive and socio-cultural) (Kamii, 1990) and critical pedagogy (Freire, 1990). In the process of developing these connections, Ladson-Billings described CRP as similar to that of critical pedagogy (CP), noting that both approaches focus on the development of empowerment and agency within learners. However, as she noted, the two theories differ in their intended audiences, with CRP centered on the development of groups of learners, while CP centers primarily on the individual (Ladson-Billings, 1995). 
In building upon her theoretical frame, Ladson-Billings explained that culturally relevant pedagogy rests upon three propositions: a) students must experience academic success, b) students must develop and/or maintain cultural competence, and c) students must develop a critical consciousness through which they challenge the status quo of the current social order (Gay, 2000; Ladson-Billings, 1995; Ladson-Billings \& Tate, 1995; Leonard et al., 2010; Young, 2010). Although CRP has been applied to a variety of disciplines, domains and grade levels in the research literature, what is common to all of these works is their foundation upon these three key pillars.

More recently, Morrison et al. (2008) conducted a meta-analysis of 45 studies on the implementation of culturally relevant practices in classrooms from 1995-2008. In doing so, the researchers developed an expanded, practical definition of CRP, and provided specific links between theory and practice. Although not focused exclusively on mathematics education, Morrison's et al. work provides an important framework for the operationalization of culturally relevant pedagogy for researchers and practitioners. In their development of a research-based taxonomy grounded in Ladson-Billings' three pillars, these researchers outlined the following tenets of culturally relevant pedagogy, citing specific examples of each from the existing research:

\section{High Academic Expectations}

A. Modeling, scaffolding, \& clarification of the challenging curriculum

B. Using students' strengths as instructional starting points 
C. Investing and taking personal responsibility for students' success

D. Creating and nurturing cooperative environments

E. High Behavioral Expectations

2. Cultural Competence
A. Reshaping the prescribed curriculum
B. Building on students' funds of knowledge
C. Encouraging relationships between school and communities

\section{Critical Consciousness}
A. Critical literacy
B. Encouraging students in social justice work
C. Making explicit the power dynamics of mainstream society
D. Sharing power in the classroom

In addition to the documentation and classification of the existing research on culturally relevant pedagogy, the researchers also called for continued study into its implementation and effects. Particularly germane to this research here was their point that many studies on the implementation of CRP have employed homogenous student populations only (typically African American). As will be described in chapter 3, this research intends to measure the efficacy of a particular culturally relevant approach on a more racially diverse group of students. Finally, Morrison et al. strengthened the theoretical underpinnings and connections between various theories of learning. Weaving several related threads of CRP, CP and constructivism together, the researchers wrote: 
Beyond transgressing the hegemonic structural and organizational aspects of school, culturally relevant pedagogy also calls into question the hegemonic epistemological assumptions about knowledge, teaching and learning. Culturally relevant pedagogy is ultimately a constructivist pedagogy. Schools are currently set up to privilege the transmission theory of learning over the constructivist theory, and the rise of standardized curriculum and high-stakes tests has only tipped the scales more toward this transmission theory. (p. 444)

Framed back in terms of this study, a number of researchers have suggested that the implementation of culturally relevant pedagogical approaches could result in increased student performance (Gay, 2000; Kamii, 1990; Lee, 1998; Leonard et al., 2009; Tate, 1995). Several of these researchers have also specifically pointed to the Algebra Project as an example of a culturally relevant program likely to increase students' academic performance, as measured by various types of assessments (Kamii, 1990; Lee, 1998). Carol Lee (1998) stated:

... evidence from the ... Algebra Project (Moses, Kamii, Swap, \& Howard, 1989; Silva, Moses, Rivers, \& Johnson, 1990) strongly suggests that traditionally underachieving students can perform to rigorous standards, as demonstrated both through standardized and performance-based measures, when instruction they experience is culturally responsive. (p. 275)

However, while researchers note the benefits of a culturally relevant pedagogical approach, at the same time a growing body of evidence has highlighted a number of underlying tensions and inherent conflicts that remain, particularly for 
mathematics teachers (Brenner, 1998; Cahnmann \& Remillard, 2002; Enyedy \& Mukhopadhyay, 2007; Gutierrez, 2009; Leonard et al., 2009; Leonard et al., 2010; Tate, 1995; Young, 2010). As noted by these researchers, the list of factors complicating the implementation of culturally relevant pedagogy in the mathematics classroom includes: a) difficulty defining and identifying CRP; b) challenges reconciling CRP with teachers' existing belief systems; c) teachers' difficulties in implementing CRP practices with the mathematical content; d) systemic emphasis on improving students' test scores within schools and districts; and e) lack of appropriate training and support during pre-service teacher training.

Finally, while some have suggested that reform-based instructional approaches such as IMP (Clarke, Breed \& Fraser, 2004) and Complex Instruction (Boaler \& Staples, 2008), offer meaningful avenues of mathematics reform, it is important to note that their largely constructivist-centered approaches lack the explicit cultural emphasis and theoretical foundation upon which the Algebra Project is based. That is to say, few algebra curricula explicitly incorporate the type of culturally relevant pedagogy (CRP) that Ladson-Billings and others have postulated as being essential to engaging minority student populations. Although such approaches and curricula represent a departure from traditional instructional techniques, too often they remain part of a curricular paradigm that serves to reify existing disparities, with little large-scale impact in altering the status quo in terms of student performance on standardized tests. 


\section{Constructivism}

The connections between constructivism and educational reform have a long history in the literature. As researchers have applied the theory to a variety of situations and contexts, the field has evolved and experienced several schisms. The most notable of these has separated constructivists into one of two major camps: a) those who believe that learning is primarily an individual cognitive act (Kamii, 1990), from those who b) believe that learning is better described in a social and cultural context (Weinstein, 2004).

Constructivism has its origins in the work of cognitive psychologists on Developmental Theory during the early to mid-twentieth century. Generally, constructivism asserts that the acquisition of new knowledge is an ongoing process, in which the learner interacts with ideas on a conceptual level and attempts to assimilate and incorporate them into already existing schemas of understanding (Gadanidis, 1994; Kamii, 1990). Building on the notion that experience and interaction are critical components of human learning, cognitive psychologists began to explore the underlying connections between human developmental stages, learning, and the nature of the learning environment. Funkhouser (2003) noted that this led early cognitive theorists, including Piaget, to stress the active involvement of the students in the learning process. According to Jones \& Southern (2003) one of the basic principles of constructivist theory is that knowledge cannot be transmitted directly from the teacher to the student. 
In explaining this constructivist tenet, Andrew (2007) summarized the constructivist approach by stating, "It calls for teachers to spend less time lecturing, drilling students on basic facts, and rote learning. Instead students are encouraged to construct their own knowledge ..." (p. 157).

Over time, constructivism garnered attention from a variety of mathematics reformers, many of whom argue that the traditional methods used to teach mathematics are no longer effective. White-Clark, DiCarlo \& Gilchriest (2008) noted that, "Many high school students feel disconnected from their math instruction and perceive it as irrelevant to their lives, impacting their levels of interest and mathematics achievement" (p. 40). Citing several studies, Andrew (2007) concluded, "Frequently, students successfully pass through more than 20 years of formal schooling and still have deep misconceptions regarding the most fundamental of mathematics operations" (p. 159). He referenced studies which indicated that many students have only a cursory understanding of math concepts, and that they often lack the deeper understanding necessary to transfer their learning to out-of-school settings. Additionally, empirical evidence from the United States presented by White-Clark et al. (2008) pointed to low percentages of students who are proficient in basic math nationwide; with anecdotal evidence from Carson \& Rowlands (2007) suggesting that a general sense of "resistance and ennui" are increasingly found in certain students as a result of the traditional approaches used to teach to mathematics. 
A number of researchers have suggested that the use of constructivism in mathematics instruction may engage students in more meaningful learning. This includes many of the Algebra Project researchers and proponents (Greeno, 2002; Gresalfi, Martin, Hand \& Greeno, 2008; Kamii, 1990; West \& Davis, 2005) who have noted that the basic elements of the constructivist and experiential learning movements are embedded into the Algebra Project's five-step instructional methodology and the student-centered activities used in the classes. Constructivists believe that shifting from direct instruction towards more interactive and engaging learning environments creates a change in the student-teacher roles within the classroom, and increases the attention and focus of the learner. As White-Clarke et al. stated, the resulting activities and learning experiences created in such classrooms “... places greater responsibility of discovering and learning information on the students. The teacher, as "the guide on the side," facilitates the students' construction of meaning and the understanding of the content” (p. 41). In their work, these researchers referenced a number of studies that confirmed that a constructivist approach improved mathematics learning at the secondary level. Additional evidence was provided by Funkhouser (2003) whose study showed that "Students who receive a constructivist instructional approach to geometry using computer-augmented activities would achieve stronger gains in knowledge of geometry than would students who receive a more traditional approach" (p. 170-171). 
The literature on constructivism in mathematics also points towards a number of specific, recommended instructional techniques, including: questioning students' answers to help determine if they were right or wrong, an emphasis on explanations, providing basic levels of guidance and support for small groups of students, and stressing the importance of self-evaluation of student work (Gadanidis, 1994). Additionally, constructivist teaching often includes the use of mathematical tools and instruments (compass, straight-edge, protractor, the use of graphing calculators and other computer technologies, and the incorporation of manipulatives) into the hands-on activities in lessons (White-Clark et al., 2008). Gadanidis wrote that such activities “...offer students the opportunity to speculate, explore, criticize, and justify. They let students experience the high-level processes of knowledge creation rather than the lowlevel skills used to complete school-work" (p. 94). Of note here is the fact that the Algebra Project incorporates these types of instructional strategies and approaches into the core of its instructional program and methodologies.

However, the literature on the constructivist approach in mathematics has not focused exclusively on students' cognitive development. It has also built upon the socio-cultural perspective. As Kamii (1990) detailed in her work, the cognitive theorist Vygotsky postulated that learning was fundamentally influenced by the social realm and that learning would take place only in situations in which the learner was properly situated in the "zone of proximal development" (ZPD). Vygotsky believed that learning 
was more appropriately described by this socio-cultural perspective and that learning took place in situations in which the learner was engaged with an expert or an advanced activity (such as those embedded in the Algebra Project). Although some scholars believe that differences between the cognitive and socio-cultural constructivist theories have been exaggerated (Matusov \& Hayes, 2000), what is of interest is the fact that Moses' Algebra Project incorporates elements from both of the cognitive and sociocultural constructivist camps (Greeno, 2002; Gresalfi et al., 2008; Horn, 2008; Kress, 2005; Silva \& Cobb, 1990; Telese, 1999b).

Underscoring the importance of the socio-cultural influence in the algebra classroom, Corey \& Bower (2005) noted that their African American male participant favored online instruction over the traditional classroom environment to learn algebra for two primary reasons. The first involved the student's perceived decreased emphasis on the "cultural content of the mathematics curriculum" (p. 328) in the online setting. Specifically the student referenced both linguistic and cultural barriers in the traditional classroom setting that impeded his understanding of the algebra content. The second reason revolved around the limited sense of agency in the traditional setting, as the student noted that the pace of instruction in the classroom environment did not provide enough opportunities to learn. Conversely, in the web-based platform, the flexible pace made the student more comfortable in his learning environment. 
The results of this case study suggest that some African American students may not feel comfortable in the traditional algebra classroom setting. Corey \& Bower (2005) documented how the prevailing classroom culture and curriculum limited the student's ability to feel included the learning process. Although limited in terms of its generalizability, the study highlighted the importance of socio-cultural influences on students' mathematical experiences. The researchers noted that the norms in the mathematics classroom were so powerful that the student felt forced to alter his speech, appearance and general classroom demeanor in his attempt to try to assimilate into the White classroom culture of the algebra class. According to the researchers, this concern was so preoccupying for this student that important subject matter content questions were sometimes left unanswered.

Although the participant's exam scores showed little change between the traditional classroom and the on-line learning forum, the authors concluded that the student's learning needs were best served by the alternative curriculum and instructional approach. This conclusion was based upon the positive change in the student's attitude towards the study of algebra and the fact that the innovative learning environment provided a less culturally foreign situation for the learner than the traditional classroom. However, while there is evidence to suggest that the implementation of a constructivist-based approach can lead to improved learning results, it also comes with some additional challenges. Several researchers have noted that that a lack of time can 
influence the success of constructivist-based activities in mathematics classrooms (Andrew, 2007; Carson \& Rowlands, 2007; Gadanidis, 1994; Kamii, 1990; Morrison et al., 2008; White-Clark et al., 2008). Other documented challenges include: a) the need for additional teacher pre-service and in-service training, $b$ ) the low tolerance of some students for trial-and-error learning, c) the difficulty in monitoring and providing feedback during instruction, and d) the fact that some of the concepts under investigation took extensive time to discover and develop (Andrew 2007; Carson \& Rowlands, 2007; Jones \& Southern, 2003). Finally, at least one set of researchers documented the concern that not all students have the necessary academic readiness to engage in some of the interactive activities, which can limit the effectiveness of the learning situations and activities if not monitored by the instructor (Carson \& Rowlands, 2007).

Despite these criticisms, the fact that the Algebra Project emphasizes both the cognitive and socio-cultural constructivist theories, while focusing on developing student agency (Greeno, 2002) via the incorporation of activities based on the students' daily experiences, forms a potentially powerful and engaging curriculum for diverse groups of students studying algebra.

Critical Pedagogy

The literature on critical pedagogy $(\mathrm{CP})$ also spans a range of educational levels, disciplines and research topics. Although $\mathrm{CP}$ has been applied widely in educational 
research, there has been only limited application in the field of mathematics educational research (Gutstein, 2007; Martin, 2009; Normore et al., 2007; Stinson, 2008). In this section of the paper the underlying connections between Freire's critical pedagogy and the Algebra Project are developed.

Developed by Paulo Freire as he worked to improve the educational opportunities for the poor in Brazil and Latin America, critical pedagogy maps out a philosophical disposition and approach in which education is radically transformed. Maintaining that traditional models of education revolve around the passive reception of material by students, frequently resulting in the dehumanization and subjugation of learners, Freire (2009) argued for an educational paradigm which emphasized emancipatory and liberatory ideologies that served to empower the disenfranchised.

Freire stressed the importance of the active involvement of the oppressed in changing the world, noting that critical pedagogy must be forged with (not for) the oppressed so that marginalized groups are able to regain their humanity (Freire, 2009; Leonard et al., 2010). Framed in terms of this study, it is important to note that, unlike many other models of mathematics reform, the Algebra Project was developed by an African American male. Freire wrote, "The oppressed can overcome the contradiction in which they are caught only when this perception enlists them in the struggle to free themselves" (p. 49). Unlike other mathematical reform efforts, the Algebra Project's root in the organizing tradition of the 1960's seeks to mobilize and empower African 
Americans around the study of algebra. Moses et al. (1989) espoused this

conceptualization of ownership and Freireian ideology in the following passage:

By linking the content of math education to the future prospects of inner-city children, Moses transformed what had previously been a purely curricular issue into a broader political question. Drawing on his experience as an organizer, educator, and parent, Moses transformed the dialogue in the Open Program (a pre-cursor to the Algebra Project) among parents, teachers, and school administrators into one that centered on questions that would get at the heart of educational practice: How can a culture be created in the Open Program in which every child is expected to be as good as possible in his or her mathematical development? What should the content of middle school mathematics be? What curricular processes make that content available to all students? (p. 428)

On the importance of the development of curriculum and pedagogical practices

by the oppressed, Freire wrote:

Pedagogy which begins with the egoistic interests of the oppressors (an egoism cloaked in the false generosity of paternalism) and make of the oppressed the objects of its humanitarianism, itself maintains and embodies oppression. It is an instrument of dehumanization. This is why, as we affirmed earlier, the pedagogy of the oppressed cannot be developed or practiced by the oppressors. It would be a contradiction in terms if the oppressors not only defended but actually implemented a liberating education. (p. 54)

Freire's passage suggests why many of the algebra reform efforts have failed to effect meaningful change for African American students, and highlights the need to involve the appropriate agents of change in the process. In this way, Moses' Algebra Project offers a unique Freireian approach to mathematics reform. 
Also infused in Moses' program, largely through the emphasis on the experiential and constructivist approach, is Freire's conceptualization of the problem posing (as opposed to banking) instructional methodology. Additionally, the Algebra Project's emphasis on use of language and communication (Kamii, 1990; Moses \& Cobb, 2001a, 2001b; Moses et al., 1989) literally draws upon Freire's call to "read and write the world" as students study mathematics (Freire, 2009; Gutstein, 2007).

Such an approach was detailed by Gutstein (2007). In his practitioner-research, Gutstein detailed the effects of teaching mathematics from a social justice and equity perspective to his seventh and eighth grade mathematics students. Heavily influenced by critical theory and the work of Freire, Gutstein shaped his pedagogical practice around developing emancipatory literacy skills and agency in his students. Stating that he "... wanted students to learn to read and write the world with mathematics," (p.426) Gutstein explained how he modified the traditional curriculum such that students worked on real-world mathematics projects, in a similar manner to the experiential approach used in the Algebra Project's curriculum. Gutstein detailed how such an approach could de-center the traditional mathematics curriculum and at the same time encourage students to tackle real-world mathematics projects and problems from their communities. In doing so, he argued, students felt a stronger connection to mathematics, seeing it as a tool to empower them in their struggle to change their lives, rather than viewing it simply as a foreign subject to be studied exclusively at school. 
In his work detailing the mathematical experiences of four academically successful African American students, Stinson (2009) offered a link between critical race, critical and post-structural theories. Arguing that multiple theories should be considered towards the development of what the Commission on Research in Black Education referred to as a "cultural praxis methodology," Stinson used an eclectic approach to document students' skill at negotiating discourse throughout their mathematics experiences.

Finally, in his work Martin (2009) noted that traditional studies that investigate race and student performance in mathematics often begin and end with static categories of race. According to Martin, this siloing, often used by researchers to disaggregate data, perpetuates the patterns of underachievement. Martin argued that such narrow conceptual frames further the racialization and stigmatization of underserved students, especially African Americans. Attempting to address this issue Martin sought to: alter the way race in conceptualized in mathematics education research; alter the ways in which policy makers conceptualize mathematics education for historically underserved student populations; and to influence day-to-day instructional practice in mathematics classrooms. He noted "that mathematics classrooms are highly racialized spaces and that color-blind, race-neutral approaches to student identities only perpetuate inequality" (p. 299). Martin concluded by calling for research that conceptualizes mathematics learning and participation as racialized forms of experience - consisting of 
unique affective responses from different groups of students. In connecting his work to the Algebra Project, Martin stated, "Moses (Moses et al., 1989, Moses \& Cobb, 2001) links the learning of algebra to the historical struggle for civil rights for African Americans. Future research and policy should explore the benefits of such approaches in recognition of the fact that students' lives and mathematics experiences unfold as racialized experiences" (p. 329).

\section{Algebra Project Literature}

Despite the Algebra Project's widespread acclaim in a number of large urban centers across the country, there has been little formal empirical research into the program. A query for the phrase "Algebra Project" on ProQuest, an online electronic database containing articles from over 745 educational journals, revealed a total of just 24 articles. Generally speaking, while many of these detailed the importance and strengths of the program (Anderson, 1990; Checkley, 2001; Davis, 2004; Greeno, 2002; Kamii, 1990; Moses \& Cobb, 2001a, 2001b; Roach, 2004; Silva \& Moses, 1990; West, 2007) analysis revealed that this literature consisted of interviews, the development or extension of theoretical frameworks, or case studies. Additionally, the data that have been reported tend to be summarized in such a way that a careful review of the results is not always possible (Sikorski, Wallace, Stariha \& Rankin, 1993; Carson \& Day, 1995; West, 2007). Multiple literature searches produced only a handful of empirical, peer 
reviewed articles. Furthermore, few of these papers centered on measuring the efficacy of the program as an instructional model with students.

In his review of Moses' work, Levine touched upon this lack of research stating, "While the vignettes and overall narrative thread give us a persuasive picture of an effective reform movement, the book would have been strengthened by more systematic documentation and analysis of the program's impact on student achievement" (p. 4). Attempting to explain the limited body of research, Kamii (1990) pointed to the grassroots nature of the program, writing:

Because the Algebra Project was at the outset a community-based rather than university-based endeavor, it has been and continues to be at its core an actionoriented undertaking. The correspondence between questions emanating from community-based endeavors and those framed by researchers is instructive, however, and it underscores the potential benefits of creating ongoing dialogues between communities and universities that could influence the ways in which each conducts its own business. (p. 395)

Additionally, a number of the existing research papers have been conducted by those who were either directly or indirectly associated with the Algebra Project (Cobb, 1994; West \& Davis, 2005; West, 2007), raising some concern about perspective and researcher bias.

Here, it is interesting to note that only one of the 24 journal articles represented primary, empirical research into the Algebra Project (Carson \& Day, 1995). Expanding the search to include additional studies from the ProQuest Interdisciplinary 
Dissertations \& Theses database resulted in only an additional six studies. While limited in number, they are reviewed in detail here to document their findings and to establish the gaps that might benefit from additional research.

The studies are separated into two major categories to aid with their description and analysis: a) those that investigated the efficacy of the Algebra Project as an instructional model for students studying algebra, and b) additional studies that probed other aspects of the program, including its historical development, implementation and affective response from students.

\section{Efficacy}

In one of the earliest attempts to document the Algebra Project's impact on student achievement, Sikorski et al. (1993) described the results of the program's implementation in the Chicago Public Schools. While summarized to a large extent, the authors presented data that questioned the overall efficacy of the Algebra Project in terms of improving students' test scores. In describing the program's impact from two phases of trials that involved multiple middle school sites, the authors reported students' results in terms of quartile scores on the Iowa Test of Basic Skills (ITBS).

In reporting the results from the first phase, they noted "The CAP (Chicago Algebra Project) schools had a higher percentage of students scoring in the bottom quartile than did the sixth-grade cohorts in non-CAP schools" (p. 90). Additionally, in phase 2, the researchers reported "All of the CAP schools had a higher percentage in the 
bottom quartile than did non-CAP schools" (p. 90). While noting that the results from phase 3 were still being analyzed, they concluded, "The results do not indicate a significant positive CAP (Chicago Algebra Project) impact on ITBS mathematics scores" (p.90). However, while these results were of interest, because they were published as part of a larger analysis of a number of reform efforts in the city during the early 1990's, a full presentation of the methodology and findings was not included in their work.

In one of only two empirical studies that attempted to investigate the efficacy of the Algebra Project on students' academic progress, Carson \& Day (1995) studied the program's effects on students' learning of integer operations. Arguing that students frequently exhibit difficulty in performing addition and subtraction with integer values after being taught with traditional techniques, the authors posited that the unique instructional approach employed by the Algebra Project would provide superior results. Employing a quasi-experimental, mixed method study that incorporated a pre/post test design, the researchers compared mean test scores between the experimental $(n=39)$ and control $(n=44)$ groups.

The assessment tool, developed by Algebra Project researchers from the Program and Evaluation Group (PERG) at Lesley University, consisted of five openended problems. Students were first presented with integer problems and asked to develop a story to describe each one. The subjects were then asked to solve the 
problem and explain their steps in the form of a word problem. Each student response was scored by both researchers using a four point rubric (0-3 points). Maximum point values were awarded in instances in which a student's word-problem produced the equation provided in the question, and also contained the correct computational response. Partial point values were awarded based upon the severity of the mistakes and the assessment's reliability was calculated with a Cronbach's alpha of 0.60 .

To ensure high reliability scores between the two raters, both researchers initially scored each test independently. Although differences in student scores were negotiated and agreed upon in a follow-up meeting, no inter-rater reliability quotient was reported, and it is unclear how many scoring discrepancies had to be reconciled. Employing Analysis of Variance (ANOVA), the researchers reported favorable results for the experimental group at a statistically significant level $\left(\mathrm{F}_{1,81}=33.77, \mathrm{p}<\right.$ .0001). After presenting the results, the authors concluded that the Algebra Project provided students with a deeper understanding of basic arithmetic operations with integer values, when compared to the techniques used in traditional algebra curricula.

Unfortunately however, bias was a concern in the research. In noting the purpose of their paper the researchers explained:

Instruction aimed at introducing students to algebra should provide students with experiences that require them to abstract more complex meanings from their own navigational knowledge. The purpose of this paper is to support this position by examining the conceptual understanding of students who received 
this type of curriculum, namely the Algebra Project Transition Curriculum, developed by Robert Moses. (p. 7-8) (italics added)

Interestingly, in the course of their investigation, the researchers employed experimental and control groups were significantly different. The experimental cohort consisted of $9^{\text {th }}$ grade (average age 14 years 3 months) inner-city students enrolled in Algebra Project classes. Approximately half of these students were Black while the other half were Hispanic, and all were described as taking algebra for the first time.

The control group differed in a number of ways. First, the students enrolled in the traditional algebra class were from a school in a predominantly White, middle-class, suburban neighborhood. Additionally, the students in the control group had previously been identified as "gifted" and had been placed in a high ability mathematics track. Finally the control group consisted of $6^{\text {th }}$ grade students (average age of 11 years 4 months).

While the study did show a difference in favor of the experimental cohort, the fact the researchers were not able to control for a number of important variables left some question as to why the experimental and control groups differed to such an extent. Although some have argued that these differences biased the research in favor of the comparison group, the study may have been strengthened had the researchers been able to control for additional variables, including age, locale, and academic placement. Unfortunately this made it difficult to determine the extent to which the results were due 
to differences in the instructional methodologies or influenced by other confounding variables. The most notable of these being: a) the 35 month average age difference between the experimental and control group, and b) the unequal mathematics exposure prior to the start of the experiment.

Finally, it was interesting to note that the primary skill measured in the study (subtraction of negative numbers) is best described as an arithmetic skill, not an algebraic skill. Although operations with integers are widely considered to be an important skill in algebra, the study may have benefited from assessing topics more commonly associated with the algebra curriculum, such as exponents \& roots, factoring, or quadratic equations.

The only other investigation into the efficacy of the Algebra Project consisted of larger scale study in which Adair (1996) was able to control for a number of key variables. Adair investigated the impact of the Algebra Project on student achievement in an experimental, quantitative study of 388 students. In addition to the development of a mathematical model using hierarchical linear modeling, the researcher was able to establish a statistically significant difference between the $6^{\text {th }}$ grade control and experimental groups; and that this difference persisted into the $7^{\text {th }}, 8^{\text {th }}$ and $9^{\text {th }}$ grades. Limiting her research however, was the fact that student achievement was measured through the MAT, a norm-referenced assessment that had not been re-calibrated since the mid 1980's. While these two researchers have been able to provide some evidence 
of the efficacy of the Algebra Project, others have framed their research and investigations around other unique attributes and outcomes related to the program.

\section{Additional Studies}

The second category consisted of empirical studies that centered on a variety of topics related to the Algebra Project and its implementation, and included investigations into: program comparison and evaluation, program development and implementation, and student perception and attitudes.

In her historical organizational case study, Nell Cobb (1994) traced the process by which the Algebra Project was established and operationalized in the Chicago Public School System in the 1990's. The qualitative investigation centered on interviews with 30 adult program participants regarding their experiences with the implementation of the Algebra Project, and did not collect any student data. Framing her study around organizational change literature, Cobb focused on three developmental stages, including: a) mobilization, b) implementation and c) institutionalization. After identifying 19 different factors impacting the three different domains, Cobb highlighted the importance the factors from the implementation domain, concluding that three components were critical to successful future programs, including: 1) the observation of the project in other settings; 2) teacher participation in project decisions; and 3) local material development. 
While primarily focused on documenting the program's development, Cobb noted that a primary reason for the Algebra Project's implementation was the fact that mathematics anxiety had been identified as a serious concern by students. Additionally, the researcher concluded that future Algebra Project startups would benefit from careful attention to implementation and continuation phases in order to ensure success. Finally, she identified five avenues for further research. Interestingly, none of these involved gathering student data or attempts to determine the program's efficacy related to student learning outcomes. Although valuable as an investigation into the implementation of a reform program centered around the organizational change literature, Cobb's findings were somewhat qualified by the fact that she served as an Algebra Project program administrator in the city - raising some concern regarding the possible influence of researcher bias.

In his dissertation on the impact of the Algebra Project on students at a middle school in San Francisco, Nelson (1997) employed a case study design in which he investigated participants' perceptions and affective responses to the program. Basing his study upon the analysis and interpretation of open ended interviews with four Algebra Project teachers and an attitudinal survey of 11 African American male students, Nelson's study sought to answer five broad research questions.

Of particular interest was his investigation into the last research question "How does the African American male perceive his participation in the Algebra Project 
to benefit him now and in the future?" In answering this question, Nelson employed a modified version of an attitudinal inventory provided by Algebra Project researchers at Lesley University. After re-grouping the student responses around four clusters (Participation, Confidence, Approaches to Math and Future Goals) Nelson interpreted the results.

While the researcher reported "no negative response" in the Participation domain and a "positive" response from the students in the Confidence domain, the small sample size prevented the use of several inferential tests. Additionally, the interpretation of the results from the other two domains (Approaches to Math and Future Goals) contained unclear and somewhat contradictory statements. Although the researcher found positive student attitudinal responses to the Algebra Project, the work lacked some controls and elements of study design necessary for a rigorous investigation. Other concerns included: the bias contained in the student attitudinal inventory, a lack of consistent statistical reporting procedures, the arbitrary grouping and identification of clusters, and the use of an attitudinal inventory that did not benefit from field testing or psychometric evaluation prior to its use.

Sanders' (1995) dissertation centered on the Algebra Project's community development component. Using a participant-observer lens this case study involved interviews with students, parents, teachers and principals at sites in both rural and urban school districts. Sanders' study revealed that the Algebra Project modeled the 
community involvement in the educational process, that the program fostered support that was actively developed and nurtured, and that the resulting increase in participation enabled staff to rally their communities around math education and other school activities. However, as with Nell Cobb's work, researcher bias was a concern as Sanders noted that he was a proponent of the program - and disclosed his involvement on the national Algebra Project's planning committee.

In a study that investigated mathematics programs designed to recruit and retain African American, Hispanic and female students in high school mathematics classes, Williams (1994) evaluated six instructional models, including the Algebra Project. After selecting 66 questions from the National Council of Teachers of Mathematics' (NCTM) Guide to Reviewing School Mathematics Programs, the researcher developed a four point rubric and rated each program. Ranking the Algebra Project third out of the six programs, Williams noted that one of the strengths of the program included the fact that the curriculum used cooperative and experiential instruction to motivate students and to enhance their social skills. However, the study was limited by the fact that the researcher was the sole rater involved in the classification and evaluation of each of the categories. Additionally, although the study was able to compare the Algebra Project to other alternative instructional models from theoretical and conceptual standpoints, the study's results would have been strengthened if they had been supported by additional student data. 
Finally, Gresalfi et al. (2008) investigated the development of students' competence in two mathematics classrooms, employing discourse analysis to compare student and teacher interactions in classrooms. In their study the researchers compared interactions in a $6^{\text {th }}$ grade mathematics classroom, taught by an Algebra Project trained teacher, with an $8^{\text {th }}$ grade algebra classroom led by a teacher without formal training in the program. Among their findings and conclusions, the authors noted that behaviors that are constructed as competent in one classroom can be significantly different from those in another classroom. Additionally, the researchers cautioned against attempting to determine whether students are learning without a critical analysis on what students might be able to learn in given settings.

Attitudes \& Agency

As mathematics researchers have attempted to broaden the set of tools used to evaluate different instructional methodologies, and at the same time address a number of important considerations raised by proponents of culturally relevant pedagogy, constructivism and critical pedagogy, (Boaler, 2008; Kamii, 2005; Weinstein, 2004), interest in measuring students' affective response has once again become an important consideration. Increasingly researchers have attempted to evaluate attitudes towards the study of mathematics as an important indicator (Boaler, William \& Zevenbergen, 1999; Clarke, Breed \& Fraser, 2004; Rech, 1994; Schoenfeld, 1985; Telese 1999a) into students' developing sense of agency. This includes the work of Algebra Project 
researchers, some of whom have suggested that the program's unique constructivist based curriculum motivates students to study algebra. Kamii (1990) stated, “...the Algebra Project uses a curriculum designed to foster motivation and self-esteem in children" (p. 394). While Nelson (1997) had previously investigated students' affective response to the Algebra Project, this aspect of the program's effect with students still remains to be rigorously investigated and measured.

Schoenfeld (1985) investigated the connections between students' attitudes and beliefs about mathematics and the relationship to academic performance. After developing an instrument consisting of 70 closed and 11 open ended questions, 230 students from three high schools in New York were surveyed. Analysis of the results led Schoenfeld to conclude that male and female students considered mathematics to be an objective subject whose content could be mastered if they worked hard enough. Additionally, the findings showed that students believed that native ability accounted for differences in student scores, especially when compared to other subject areas, including English and Social Studies $\left(\mathrm{F}_{2,230}=30.16, \mathrm{p}<.0001\right)$. However, unfortunately the results were not disaggregated by race or ethnicity and the study considered students' exposure to traditional instructional methodologies only. Finally, the results were difficult to analyze as the researcher developed the inventory himself and the survey instrument lacked field or validity testing. 
In another study of students' attitudes towards algebra, Telese (1999a) investigated the mathematical attitudes of 226 Latino high school students in Texas using a modified inventory. His results suggested that students' attitudes were not conducive to promoting algebra as the "new civil right" - finding a high occurrence of traditional instructional practices in the mathematics classrooms. Other notable conclusions from the study included the fact that algebra students had the lowest mean response scores for positive attitudes compared to other mathematics classes in the study, and that female students reported more negative mathematical attitudes compared to males. Unfortunately the study was primarily focused on the results of a single ethnicity and, as with the Schoenfeld study, did not attempt to investigate students' affective responses outside of traditional curricular models.

In a large-scale qualitative investigation into the factors that impacted students' success in secondary mathematics classes, Boaler, William \& Zevenbergen (2000) noted that students' developing mathematical identities are frequently overlooked by researchers. Commenting on the lack of research in this area they stated, "There are very few studies in mathematics education that explore the construction of identity in and through the practices of mathematics" (p. 5). They concluded by noting that students' attitudes towards mathematics were typically shaped by their inability to see success in mathematics as meaningful or relevant to their developing identities. 
Finally, in a more recent study into students' affective responses to their mathematical experiences, Clarke et al. (2004) compared results from students who were enrolled in a problem-based math reform curriculum (Interactive Mathematics Program or IMP) with those who took traditional mathematics classes. Employing modified forms of the Mathematics Belief Questionnaire and the Mathematics World Questionnaire in their quantitative study, the researchers surveyed 451 high school students in algebra, geometry and advanced algebra classes.

Among the findings were that the IMP students were significantly more likely to rate themselves as strong in algebra than the traditional group of students $(\mu=7.50 \mathrm{v} . \mu$ $=6.86, \mathrm{p}<0.0012$ ), were more likely to feel positive about their mathematics classes students $(\mu=0.97$ v. $\mu=-0.52, p<0.0001)$, and that the IMP students valued working with others at higher level than those students in the traditional algebra courses $(p<$ 0.0001). While the researchers concluded that students enrolled in the problem-solving curriculum had more positive attitudes than those in the traditional algebra classes, the researchers did not disaggregate the results by race/ethnicity or probe connections to student achievement on standardized assessments. Finally, as noted earlier, while the IMP program focuses on developing students' conceptual understanding, through an expanded curriculum based upon a problem centered approach, it lacks a specific grounding in culturally relevant pedagogy, distinguishing it from the Algebra Project. 
While these studies shed light on the connections between students' affective response to mathematics, its connection student engagement, and to some extent performance, they are limited by one of two problems. The first involves the use of assessment tools that were not properly validated or field tested. In many studies, researchers developed and deployed their own inventories without ensuring sufficient testing of the surveys - introducing the potential for researcher bias. In other cases existing surveys were modified or cobbled together and then implemented without additional testing.

The second difficulty revolved around the fact that few studies probed differences between traditional and reform methodologies. This prevented a more complete understanding into the relationships between curriculum, instructional practices and students' developing sense of agency between groups of students. While these studies provided important data into the various environmental and social variables that influence student learning, additional study into specific curricular approaches designed to meet the needs of historically underserved students might provide insight into the types of instructional techniques required to make algebra classrooms feel more inclusive for students.

\section{The Mathematics Attitudes Inventory}

Sandman's (1973) Mathematics Attitudes Inventory (MAI) was developed specifically to measure students' affective responses to the study of mathematics 
(Sandman, 1980). Unlike many of the mathematics attitudinal assessment instruments commonly in use, Sandman's inventory was designed to be used by students at the middle and high school levels. The 48 question instrument uses a 4 option Likert scale and is designed to provide information on six different affective domains: a) perception of the mathematics teacher, b) anxiety toward mathematics, c) value of mathematics in society, d) self-concept in mathematics, e) enjoyment of mathematics and f) motivation in mathematics (Sandman, 1973). The instrument was developed as part of National Science Foundation (NSF) study and was piloted and field tested in racially and ethnically diverse settings at two locations across the country. Additionally, in these development trials the MAI achieved high levels of reliability (alpha levels from 0.68 to 0.89 ) for each of the six different domains. Finally, factor analysis showed the six domains tested separate measures of students' attitudes and the results of the assessment tool are widely considered to be generalizable when used with large populations.

While originally developed over 35 years ago, the tool is still frequently employed by mathematics researchers as a measure of students' attitudes in mathematics classrooms (Lodree, 2005; O'Callaghan, 1998; Rech, 1994; Tanner \& Chism, 1996). Of particular note from this group of studies was Rech's (1994) work, in which she employed Sandman's MAI instrument to investigate the mathematics attitudes of African American students by grade level and by gender. Interestingly, the study found that higher achieving African American students in $8^{\text {th }}$ grade possessed 
poorer attitudes than lower achieving students in four of the six domains. Additionally when comparing gender differences, Rech found statistically significant differences in favor of males in the Self-Concept and the Enjoyment domains. Unfortunately however, Rech's work investigated the attitudes of African American students only, and was not able to probe how students from different racial and ethnic backgrounds felt about studying mathematics. Finally, the study did not investigate students' feelings towards any alternative, or reform-orientated instructional approaches.

A systematic investigation into students' affective response to an alternative instructional model that employed an independently field tested and validated assessment tool, would help to round out this existing literature. Additional gaps in the literature are noted in the final section.

\section{Summary}

A review of the related literature reveals several gaps. Specifically, the following four areas require further study and investigation. First, there has been limited application of culturally relevant pedagogy and critical pedagogy as conceptual frames in mathematics research. Investigation into the Algebra Project could help to narrow the algebra achievement gap while contributing to these larger bodies of work. Second, there is little research into curricular programs designed specifically to meet African American students' needs as they study algebra. Third, there has been little formal empirical research into Moses' Algebra Project, particularly in terms of the 
program's efficacy in regards to students' academic achievement or sense of agency. Fourth, of the studies that do exist, few have employed independent, scientifically validated assessments against which the program has been measured. This study hopes to address these gaps in an attempt to evaluate a specific curricular program for students studying algebra. 
Chapter Three: Methodology

\section{Introduction}

This study employed a quasi-experimental, sequential, explanatory mixedmethods study design. The research consisted of a retrospective analysis of standardized test scores, as well as an investigation into students' affective response to the study of algebra.

The rationale for the study's design was rooted in the nature of the three research questions. Specifically, the first two research questions investigated particular aspects of the Algebra Project's efficacy in terms of two pre-made, independently developed assessments (the Algebra I California Standards Test (CST) and Sandman's (1973) Mathematics Attitudinal Inventory (MAI)). While these two research questions focused on the results and interpretation of quantitative data, the third and final question attempted to delve deeper into related factors, while providing the opportunity for substantive participant voice. To do this, two different qualitative techniques were employed - interviews and focus groups. Personal interviews were held with the teachers, while student focus group sessions were conducted as a means of investigating the co-construction of beliefs, attitudes and norms within the groups.

In addition to providing data on the efficacy of the Algebra Project, in terms of both standardized test scores and students' affective response, the study provides insight into certain aspects of culturally relevant pedagogy and critical pedagogy, upon which 
the Algebra Project curriculum is based. Implications and recommendations, presented in chapter 6 , highlight additional avenues that would benefit from continued study and investigation.

\section{Study Design}

The study consisted of two stages. The first stage involved the collection and interpretation of quantitative data from the Algebra I CST and from the MAI survey. In the second stage, a number of semi-structured interview questions were selected for use in subsequent teacher interviews and student focus group sessions. The study's research design is depicted in Figure 2 as:

QUAN $\longrightarrow$ qual

Figure 2. Study Design

or in expanded form (Creswell \& Plano Clark, 2006) in Figure 3 as: 
Research question \#1

Research question \#2

Research question \#3

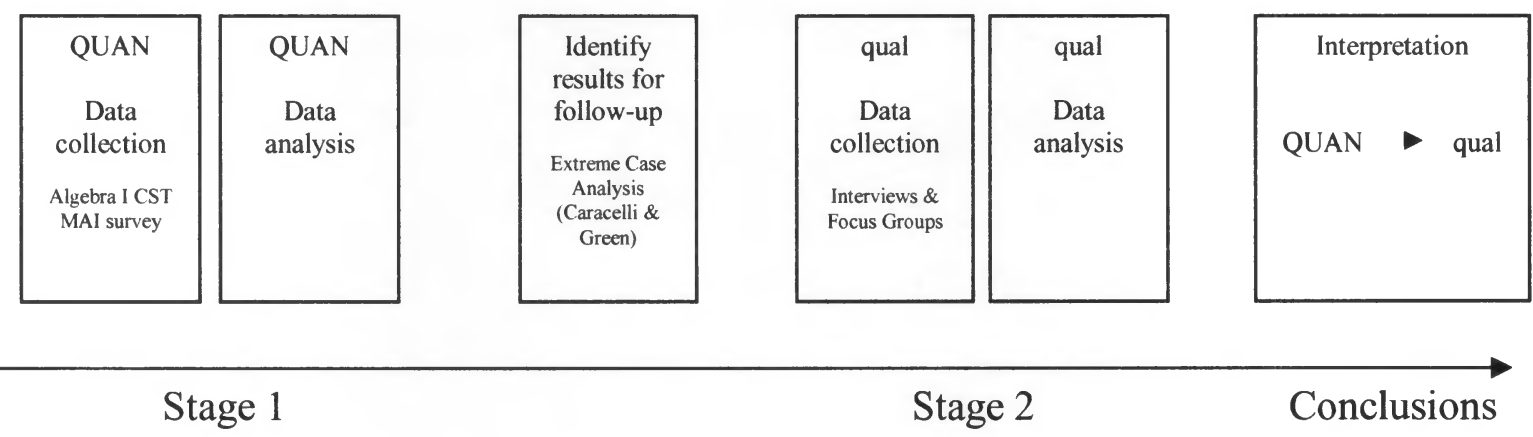

Figure 3. Expanded Study Design

After analyzing the quantitative results from Stage 1, Caracelli \& Green's (1993) Extreme Case Analysis was employed to narrow the focus of the investigation in the study's second stage. Described in their work as an integrative strategy for mixedmethods data analysis (Caracelli \& Green, 1993), Extreme Case Analysis provided the flexibility to focus on the discrepancies and salient points revealed in the quantitative data analysis for further investigation in stage 2. In defining this technique, the researchers explained:

"Extreme cases" identified from the analysis of one data type, and pursued via (additional data collection and) analysis of data of the other type, with the intent of testing and refining the initial explanation for the extreme cases. (p. 197) 
Framed in terms of the study, extreme cases were defined as statistically significant differences in the Algebra I CST or MAI data. After the results from the Algebra I CST and MAI survey were analyzed, a series of questions were selected for use in the subsequent interviews. These semi-structured, open-ended questions probed aspects revealed during the quantitative analysis, and elicited additional insights from the study's participants. Specifically, the qualitative data collected during Stage 2 came from personal interviews with two Algebra Project teachers and from two student focus group sessions (Non-Algebra Project, $\mathrm{n}_{1}=5$; Algebra Project, $\mathrm{n}_{2}=5$ ).

\section{Role of the Researcher}

My previous experience and position in the school district significantly contributed to my ability to conduct the study. Prior to becoming a school administrator, I taught mathematics at the middle and high school levels for 10 years. This classroom experience included several years of teaching algebra to diverse groups of students in a variety of settings (rural, sub-urban, and urban). Additionally, during this time period I also served as the Mathematics Department Chair at a high school. As part of my regular duties I was periodically asked to review and evaluate various instructional materials (texts, curriculum materials, computer-based intervention programs) and provide recommendations on their purchase and implementation.

In my current role, I serve as a principal of a middle school in the school district in which the study was conducted. As a result of my position, I benefited from unique 
access to the district gatekeepers, site administrators, and teachers involved in the study. Without their direct help and support at critical junctures along the way, it is likely that the study would not have been completed.

In situations in which studies are conducted in the researcher's own institution, bias becomes an important concern. Several steps were implemented to offset the possible effects of bias in the study, including: the use of standardized and independently field tested assessment tools (Algebra I CST and MAI), the coding of all quantitative data with dummy teacher and student identifiers prior to conducting the statistical tests, and gaining permission and consent from all study participants (administrators, teachers, students and their parents).

However, despite these efforts there remains a possibility that my experiences, or standing as a White male in a position of power and authority relative to a minority student population, may have influenced the results, or their interpretation, during the investigation. All final interpretations and conclusions should be viewed with this caveat in mind.

\section{Research Questions and Sub-Questions}

As noted in chapter 1 , the study consists of three primary research questions. These questions, along with all related sub-questions, are listed below:

1. Are there differences in students' performance between the instructional methodologies (Non-Algebra Project v. Algebra Project) as measured by the Algebra I CST? 
a) Are there differences between the instructional methodologies at the school site?

b) Are there differences between the instructional methodologies when compared to student results at other high schools that are not enrolled in the Algebra Project?

c) Are there differences between the instructional methodologies for the African American students when compared to student results at other high schools that are not enrolled in the Algebra Project?

2. Are there differences in students' mathematical attitudes between the instructional methodologies (Non-Algebra Project v. Algebra Project) as measured by Sandman's $(1973 ; 1979)$ Mathematics Attitude Inventory (MAI) survey?

a) Which of the six different affective domains measured by the MAI will detect a difference in students' attitudes between the two instructional methodologies?

3. What additional factors impact the way students feel about the study of mathematics?

\section{Context}

Since the Algebra Project was implemented at just one high school in the district, the study was conducted at a single site - Eastwood Academic High School (pseudonym). Founded in the 1990's, and located in a working class neighborhood in the southeastern section of a large metropolitan area in northern California, Eastwood Academic High School is a four-year college preparatory high school with a racially and ethnically diverse student body (see Table 4). 
Table 4

Racial composition of Eastwood High School in 2009

\begin{tabular}{|c|c|}
\hline Student Group & Percent of School Population \\
\hline African American & 24.7 \\
American Indian or Alaska Native & 0.6 \\
Asian & 51.0 \\
Filipino & 3.5 \\
Hispanic or Latino & 17.3 \\
Pacific Islander & 4.1 \\
White (Not Hispanic) & 0.8 \\
Multiple or No Response & 1.1 \\
\hline
\end{tabular}

Additionally, students came from a wide variety of backgrounds and ability levels (see Table 5).

\section{Table 5}

Student composition of Eastwood High School in 2009

\begin{tabular}{|c|c|}
\hline Student Group & Percentage of School Population \\
\hline English Language Learners & 34.2 \\
Special Education & 16.6 \\
Gifted and Talented & 13.4 \\
Free and Reduced Lunch & 59.7 \\
\hline
\end{tabular}


The school's website described the site as having a highly dedicated faculty, staff and active Parent, Teacher, Student Association (PTSA), listing one of the school's core beliefs as " $\ldots$ each student should be equipped with the essential skills, knowledge, and values needed to make wise college, career, and vocational decisions."

Finally, access to study participants was negotiated through the district's Research, Planning \& Accountability Department, the school's principal, and the teachers from the study site.

\section{Participant Selection}

\section{Research Question \#1}

The first research question involved a retrospective analysis of test score data from the 2008-2009 and 2009-2010 school years and consisted of three separate trials. After obtaining the raw test score data files from the district's Research and Accountability department, a comprehensive student test-score database was created. The original database consisted of 3,447 individual student entries and contained 19 unique fields. In addition to demographic data (including gender, race/ethnicity, grade level), the database consisted of CST mathematics test score data for all $9^{\text {th }}$ grade students from the district's high schools $(\mathrm{n}=14)$ during the two year period, as well as those students enrolled in the district's charter $(n=4)$ and alternative high schools $(n=$ 3). The test score data from one independent study school, and two continuation high schools were excluded from the database due to the unique program structures and 
student demographics at these schools. Finally, the data were coded to indicate which students had been enrolled in mathematics support classes, in addition to their algebra class, during $9^{\text {th }}$ grade.

In order to ensure accurate comparisons for the paired samples t-tests, students who did not have standardized test-scores in their $8^{\text {th }}$ or $9^{\text {th }}$ grade years were omitted from the database. Continued refinement of the database, to ensure that students had a comparable exposure to mathematics curricula in $8^{\text {th }}$ grade, further reduced the dataset to a final total of 1,484 students. $^{3}$ All data for the experimental and comparison groups were then drawn from this final sub-set from the database. The experimental group $(\mathrm{n}=$ 79) consisted of all students enrolled in the Algebra Project with CST test score data, over the two year period at Eastwood High School.

As noted earlier, various trials in research question \#1 employed different comparison groups. The comparison group for Trial $1(n=56)$ consisted of a sample from Non-Algebra Project classes at Eastwood High School. In order to account for the additional instructional time the Algebra Project cohort received, the comparison group for Trial 2 consisted of a synthetic cohort $(n=213)$ developed from students from other high schools across the district. The comparison group for Trial $3(n=37)$ consisted of a sample of students from other high schools across the district who met particular demographic characteristics. Additionally, all comparison groups were selected from

\footnotetext{
${ }^{3}$ At the time of the study students in $8^{\text {th }}$ grade had the option of enrolling in two different mathematics courses: General Mathematics or Algebra I. The final dataset of 1,484 students was created by querying the database for students who had taken Algebra I in their $8^{\text {th }}$ grade year.
} 
the same two year period as the experimental group and were controlled for grade level $\left(9^{\text {th }}\right.$ grade). Finally, the experimental design for the three trials in the first research question is depicted in Figure 4 below.

$\begin{array}{lll}\mathrm{O}_{\mathrm{el}} & \mathrm{X} & \mathrm{O}_{\mathrm{e} 2} \\ \mathrm{O}_{\mathrm{cl}} & & \mathrm{O}_{\mathrm{c} 2}\end{array}$

Figure 4. Research Question \#1 - Experimental Design

The null and research hypotheses for the paired samples t-tests in the first research question were:

$$
\begin{array}{ll}
\mathrm{H}_{0}: & \mu_{\mathrm{O} 2}=\mu_{\mathrm{O} 1} \\
\mathrm{H}_{\mathrm{a}}: & \mu_{\mathrm{O} 2}>\mu_{\mathrm{O} 1}
\end{array}
$$

\section{Research Question \#2}

The second research question involved the analysis of the results of a mathematics attitudinal inventory (MAI) conducted during the 2010-2011 school year. The experimental group consisted of the entire student population enrolled in the Algebra Project during the 2010-2011 school year $(n=35)$. A single comparison group $(n=40)$ of students was developed from three Non-Algebra Project classes at the study site using convenience sampling, and was considered to be representative of the populations from these classes. The student surveys were conducted approximately half 
way through the academic year (late January to early February). Finally, the experimental design for the second research question is depicted below in Figure 5.

$$
\begin{array}{ll}
\mathrm{O} & \mathrm{O}_{\mathrm{el}} \\
& \mathrm{O}_{\mathrm{cl}}
\end{array}
$$

Figure 5. Research Question \#2 - Experimental Design

The null and research hypotheses for the independent samples t-test in the second research question were:

$$
\begin{array}{ll}
\mathrm{H}_{0}: & \mu_{\text {Oel }}=\mu_{\text {Ocl }} \\
\mathrm{H}_{\mathrm{a}}: & \mu_{\text {Oel }} \neq \mu_{\mathrm{Ocl}}
\end{array}
$$

\section{Research Question \#3}

The third research question involved personal interviews with two Algebra Project teachers, and a pair of focus groups (Non-Algebra Project; $\mathrm{n}_{1}=5$, Algebra Project; $\mathrm{n}_{2}=5$ ) with students from the study site.

The teachers were selected for their experience teaching mathematics to diverse groups of students as well as their on-going work in implementing the Algebra Project curriculum. The focus group students were selected using a convenience sampling technique. Selected mathematics teachers (Non-Algebra Project and Algebra Project) at the site were asked to recruit a representative sample of students (based upon gender 
and race/ethnicity) who would be interested in providing feedback on the study of algebra. All students who participated in the focus group sessions also completed the MAI survey in stage 1 of the study.

Finally, the student participants ranged between 14-16 years of age, and as such, were considered to be a vulnerable population. While the researcher had pre-existing relationships with the Algebra Project teachers from an earlier pilot study, none of the students were known to the researcher.

\section{Ethics and Protection of Human Subjects}

Participation in the study involved minimal risk. The primary risk involved a loss of privacy (through the loss or theft of data) and maintaining confidentiality as a result of students' participation in the focus group sessions. To help ensure that the participants' privacy was not compromised, a number of preventative measures were integrated into the study.

Risks to loss of privacy were minimized by storing all data (CST scores, MAI results and transcriptions from interviews and focus groups) on a password protected laptop computer. Additionally, this computer was maintained in a locked room at all times and was secured when not in use by the researcher. After the raw data were collected, individual identifiers (including names and student/teacher identification numbers) were removed from the data. 
Risks associated with maintaining confidentiality were also minimized. As noted, all individual identifiers were removed from the data prior to their use, and only the researcher had access to the collected data. Additional measures were embedded into the study itself, including reminders to participants about the importance of the confidentiality agreements at the start and conclusion of the sessions. All digital recordings and transcripts from the focus group sessions and interviews are scheduled to be destroyed one year after the study's completion.

Finally, to help provide an additional layer of protection for participants, all policies and procedures related to working with human subjects were followed, including those stipulated by the Institutional Review Board at San Francisco State University, the school district in which the study was conducted, the principal of the site, and the participating teachers. All participating students were required to provide their assent prior to data collection and, because they were deemed to be a vulnerable population, their guardians were also required to provide consent. Pseudonyms have been used in place of the proper names for all individuals in this paper.

\section{Data Collection}

Three instruments were used to collect the data during the study. Because of their emphasis within schools and districts as the primary indicator of instructional reform efforts, the first was the Algebra I California Standards Test (CST) - a criterion referenced assessment that all algebra students in California are required to take each 
spring. The assessment is standards based, uniformly administered (with scripted, standardized instructions and time limits), and has high reliability and validity scores. For a complete overview of these measures please refer to Appendix E.

The Algebra I CST is broken down into the following four strands:

Number properties, operations \& linear equations Graphing \& systems of linear equations Quadratics and polynomials

Functions and rational expressions
17 questions 14 questions 21 questions $\underline{13 \text { questions }}$ 65 questions

Individual item responses are used to calculate a final scaled-score for each student. These scaled-scores range from 150 to 600 points, and are used to denote student mastery of the concepts in terms of five proficiency levels. The scaled-score range for each of the levels is shown in Table 6. Finally, the scaled-scores are designed to be comparable from year to year, with the Proficient level defined by the state as representing grade-level mastery of the essential concepts for all students on the CSTs.

Data collection for the CST scores was conducted in conjunction with the district's Research, Planning \& Accountability Department. As a result, the Algebra I CST test scores for all students from the district's high schools were made available to the researcher.

Included in the data request, the department provided related test score and student demographic information, including fields for: $8^{\text {th }}$ and $9^{\text {th }}$ grade mathematics 
Table 6

Algebra I CST Scaled-Scores and Proficiency Levels

\begin{tabular}{|l|c|}
\hline Proficiency Level & Scaled-Scores \\
\hline Advanced & $428-600$ \\
Proficient & $350-427$ \\
Basic & $300-349$ \\
Below Basic & $253-299$ \\
Far Below Basic & $150-252$ \\
\hline
\end{tabular}

scaled-scores, student identification number, school number, grade level, gender, race and ethnicity, and mathematics classes.

The raw Excel data files were then exported into Microsoft Access where they were combined, cleaned and manipulated. This database was subsequently queried for each trial, with the results being exported back into Microsoft Excel for all statistical calculations.

The second instrument was Sandman's (1973) Mathematics Attitudinal Inventory (MAI). Unlike many of the mathematics attitudinal assessment instruments commonly in use, Sandman's inventory was specifically designed for use by students in middle and high school. The 48 question instrument employs a 4 option Likert scale and provided information on six different affective constructs: 
Perception of the Mathematics Teacher Anxiety toward Mathematics

Value of Mathematics in Society

Self-concept in Mathematics

Enjoyment of Mathematics

Motivation in Mathematics
8 questions

8 questions

8 questions

8 questions

8 questions

8 questions

48 questions

As noted by Sandman (1979), the constructs measured the following:

1. Perception of the Mathematics Teacher - This scale reflects a student's view regarding the teaching characteristics of his or her mathematics teacher. A high score indicates a favorable view of the mathematics teacher.

2. Anxiety toward Mathematics - This scale reflects the uneasiness a student feels in situations involving mathematics. A high score indicates high anxiety toward mathematics.

3. Value of Mathematics in Society - This scale reflects a student's view regarding the usefulness of mathematical knowledge. A high score indicates high perceived value of mathematics.

4. Self-Concept in Mathematics - This scale reflects a student's perception of his or her own competence in mathematics. A high score indicates a favorable selfconcept in mathematics. 
5. Enjoyment of Mathematics - This scale reflects the pleasure a student derives from engaging in mathematical activities. A high score indicates high enjoyment of mathematics.

6. Motivation in Mathematics - This scale reflects a student's desire to do work in mathematics beyond the class requirements. A high score indicates high motivation in mathematics.

Developed in connection with a large scale evaluation project supported by the National Science Foundation, the MAI was field tested with 5,034 students in two diverse settings (economic and race/ethnicity) in the country. During these developmental trials the MAI achieved high levels of reliability (alpha levels from 0.68 to 0.89 ) for each of the six different constructs (Sandman, 1973). Finally, factor analysis indicated that the six constructs tested separate measures of students' attitudes and, when used with large, representative samples, the results of the tool are widely considered to be generalizable.

In order to survey the broadest cross-section of students at the site, the MAI survey instrument was translated into Spanish and Cantonese (employing one-way translation). Prior to conducting the survey, students were given the opportunity to select between the three language versions of the inventory. Translated copies of the MAI survey are included in Appendix B. 
Data collection for the MAI was conducted by the researcher, in cooperation with the site administrators and mathematics teachers. After the survey administrations, the bubble documents were scanned by the staff in the Research, Planning \& Accountability department at the district office. The raw data were exported into Microsoft Excel files where it was subsequently cleaned and manipulated (twenty-nine of the questions on the survey are reverse scored items). A total of 10 individual responses were left blank by the 75 students completing the survey, representing a response rate of $99.7 \%$. To help ensure appropriate comparisons for the subsequent computations, these blank fields were replaced with data in accordance with procedures outlined by Sandman (1979) during the MAI's development. All statistical tests were then performed in Microsoft Excel.

The third and final instrument was a series of semi-structured, open-ended questions used in the interviews and focus group sessions. Teacher interview questions are included in Appendix C, while the student focus group questions are presented in Appendix D. Data collection for the interviews and focus groups was conducted by the researcher. A transcription service was used to convert the digital audio files into electronic text documents for subsequent study and review.

\section{Internal Validity}

Study design and methodology were the primary tools used to minimize the effects of threats to the internal validity. As explained by Fraenkel \& Wallen (2009), 
these considerations are best accounted for prior to the collection of data to minimize the spurious effects of confounding variables. Depending on the research question, these steps included ensuring that appropriate demographic data fields were collected and subsequently controlled in an attempt to minimize the effects from threats due to: selection bias (based on grade level, prior mathematics performance on standardized exams, race/ethnicity, gender, language fluency); location; instrumentation; maturation; regression, and implementation.

\section{Spurious Effects \& Confounding Variables}

Although the study design and data collection techniques employed in the study attempted to control for as many of the spurious effects as possible, no study can eliminate their influence completely, and a number of limitations and qualifications exist in the study.

Most notably this includes the fact that some students attended different schools within the district (research question \#1 - trial 2 and trial 3 comparison groups). While the use of different comparison groups in the various trials attempted to address this threat, there remains the possibility that some unidentified confounding variable could have provided spurious results. Such an argument might proceed as follows - different high schools are known within the city for their particular curricular and academic programs. In most cases, families identify particular high schools on their registration forms; schools that they believe would best meet the needs of their children's interests, 
talents and academic strengths. Even though a number of variables were controlled for in the experimental and comparison groups (grade, exposure to $8^{\text {th }}$ grade mathematics, amount of seat time in $9^{\text {th }}$ grade algebra classes), there is no way to account for differences from the unforeseen effects from enrollment in different schools. To address this concern, the comparison group in trial 1 was created from students at the experimental site who were enrolled in Non-Algebra Project algebra classes.

Other notable threats to the validity of the results include: differences in the socio-economic status of students, the number of students in particular sections of algebra at different schools, English language proficiency of students, the experience and credentials of the teachers, as well as the unique programs offered at the different high schools across the district. All results and their interpretation should be viewed with these delimitations in mind.

\section{External Validity}

While a number of ethical and practical considerations precluded the possibility of conducting a truly randomized study, the quantitative findings are likely generalizability to similar student populations and settings. Results from the qualitative portion of the study (presented in Chapter 5) however are unique to the school site, particular classrooms and individual participants. In order to increase the overall generalizability of the results from the study, several steps were implemented to strengthen its external validity. This included the use of instruments (CST and MAI) 
with strong reliability and validity scores; the collection of data from a broad and representative group of students; the use of a matched pair study design for the CST test score analysis; the development of synthetic cohorts for particular comparison groups, and the implementation of triangulation techniques, as defined by Extreme Case Analysis.

\section{Data Analysis}

Data analysis varied depending upon the research question and specific investigative technique employed. Data from the Algebra I CST and the MAI survey were analyzed using descriptive and inferential statistics. Specifically, this included the use of chi-squared tests of independence to assist with the descriptions of the student samples, as well as the use of paired samples t-tests and independent student's t-tests to investigate the Algebra I CST and MAI data.

After analyzing the quantitative data from the first two research questions, several open ended questions were selected for subsequent teacher interviews and student focus groups. The digital recordings from these interviews were transcribed after each session and reviewed prior to coding.

Two separate coding procedures were used for analysis and interpretation of the qualitative data collected for research question \#3. The transcripts from the teacher interviews were coded against the framework developed by Morrison et al., in which 
the researchers operationalized 15 different elements of culturally relevant pedagogy. The two categories with the largest tally counts were then analyzed for further study. The student focus group transcripts were coded and analyzed using an open coding technique for emerging themes. After the digital recordings were transcribed, a comprehensive data index was developed through an iterative process in which transcripts were carefully reviewed, highlighted, coded, and finally indexed. Through several re-readings, overlapping categories were collapsed and combined until six unique categories were identified. Further pruning to three major themes was achieved by building on the connections to the quantitative data and the existing literature. Micro-analysis was used for portions of the investigation into the student discourse patterns.

Finally, the qualitative and quantitative data were integrated through the use of Caracelli \& Green's Extreme Case Analysis. As noted earlier, this allowed for a targeted approach to data collection in the final research question and served to bridge the quantitative and qualitative portions of the study. 
Chapter Four: Quantitative Findings

\section{Overview}

Because the study's three research questions investigated the effects of the Algebra Project on different dependent variables, and employed significantly different investigative techniques, the presentation of the study's findings are detailed over the course of two chapters. Results from the two quantitative research questions are presented and discussed independently in chapter 4. A presentation and discussion of the study's qualitative data from the third research question is offered in chapter 5 .

The first two research questions were as follows:

1. Are there differences in students' performance between the instructional methodologies (Non-Algebra Project v. Algebra Project) as measured by the Algebra I CST?

2. Are there differences in students' mathematical attitudes between the instructional methodologies (Non-Algebra Project v. Algebra Project) as measured by Sandman's (1973) Mathematics Attitude Inventory (MAI) survey?

As will be shown, the results of the CST investigation indicated that the Algebra Project showed comparable outcomes to the control group at the study site (trial 1). However, when compared to Non-Algebra Project students at other schools in the district, a statistically significant effect was noted in favor of the comparison group (trial 2). Finally, for African American students, the results showed no difference between the instructional methodologies (trial 3). 
Additionally, data collected from the MAI survey did not reveal differences between the cohorts; however, the subsequent qualitative investigation did suggest differences between the groups of students.

\section{The Findings - Research Question \#I}

\section{Student Samples Investigations}

In order to describe the student samples more completely, and to ensure comparable groups for subsequent t-tests, two related student placement investigations were conducted. As gender differences are frequently researched in relation to mathematics, the first investigation into the student samples analyzed placement into algebra support classes (either through the Algebra Project at Eastwood High or via an algebra support class at other district high schools) and gender. Over the two year period, results from a chi-squared test for independence confirmed that there was no relationship between gender and placement into support classes at Eastwood $\operatorname{High}(p=$ 0.5516, d.f. $\left.=1, \chi^{2}=0.3545\right)$, or at other district high schools $\left(p=0.9248, d . f .=1, \chi^{2}=\right.$ 0.0089). The contingency tables for both investigations are provided in Tables $7 \& 8$ below: 
Table 7

Contingency Table for Gender and Instructional Support at Eastwood High

\begin{tabular}{|c|c|c|c|}
\hline Methodology & Female & Male & Total \\
\hline Non-Algebra Project & $\begin{array}{c}29 \\
(30.6963)\end{array}$ & $\begin{array}{c}27 \\
(25.3037)\end{array}$ & 56 \\
\hline Algebra Project & $\begin{array}{c}45 \\
(43.3037)\end{array}$ & $\begin{array}{c}34 \\
(35.6963)\end{array}$ & 79 \\
\hline Totals & 74 & 61 & 135 \\
\hline
\end{tabular}

Note: Expected values in parentheses. $\alpha=0.05$.

\section{Table 8}

Contingency Table for Gender and Instructional Support at other district high schools

\begin{tabular}{|c|c|c|c|}
\hline Methodology & Female & Male & Total \\
\hline Algebra & $\begin{array}{c}556 \\
(556.6316)\end{array}$ & $\begin{array}{c}580 \\
(579.3684)\end{array}$ & 1136 \\
\hline Algebra \& Support & $\begin{array}{c}105 \\
(104.3684)\end{array}$ & $\begin{array}{c}108 \\
(108.6316)\end{array}$ & 213 \\
\hline Totals & 661 & 688 & 1349 \\
\hline
\end{tabular}

Note: Expected values in parentheses. $\alpha=0.05$.

These results from this first investigation indicated that gender and placement into mathematics support classes are not connected at a statistically significant level - at either Eastwood High or at other high schools across the district. This seems to be in line with much of the recent literature on gender and mathematics achievement, which, generally speaking, has shown a narrowing of the test score results between males and females over the past 30 years (Lauzon, 2001; Riegle-Crumb, 2006). 
The second investigation probed placement into algebra support classes (again, either by way of the Algebra Project or via an algebra support class) and students' race (based upon the target populations of African American and Latino students (Moses et al., 1989)). Over the two-year period, results confirmed that there was no relationship between race and ethnicity and placement into support classes at Eastwood High ( $p=$ 0.8065 , d.f. $=1, \chi^{2}=0.0600$ ). However, when the same test was conducted at the other high schools in the district, a statistically significant relationship was discovered ( $p<$ $0.0001, d . f .=1, \chi^{2}=88.6609$ ). The contingency tables for each test are shown in Tables 9 \& 10 below:

Table 9

Contingency Table for Race and Ethnicity and Instructional Support at Eastwood High

\begin{tabular}{|c|c|c|c|}
\hline Methodology & AA \& L & Other & Total \\
\hline Non-Algebra Project & $\begin{array}{c}35 \\
(35.6741)\end{array}$ & $\begin{array}{c}21 \\
(20.3259)\end{array}$ & 56 \\
\hline Algebra Project & $\begin{array}{c}51 \\
(50.3259)\end{array}$ & $\begin{array}{c}28 \\
(28.6741)\end{array}$ & 79 \\
\hline Totals & 86 & 49 & 135 \\
\hline
\end{tabular}

Note: Expected values in parentheses. $\alpha=0.05$. 
Table 10

Contingency Table for Race and Ethnicity and Instructional Support at other district high schools

\begin{tabular}{|c|c|c|c|}
\hline Methodology & AA \& L & Other & Total \\
\hline Algebra & $\begin{array}{c}502 \\
(565.0526)\end{array}$ & $\begin{array}{c}634 \\
(570.9474)\end{array}$ & 1136 \\
\hline Algebra \& Support & $\begin{array}{c}169 \\
(105.9474)\end{array}$ & $\begin{array}{c}44 \\
(107.0526)\end{array}$ & 213 \\
\hline Totals & 671 & 678 & 1349 \\
\hline
\end{tabular}

Note: Expected values in parentheses. $\alpha=0.05$.

The results from this second investigation indicated that while race and ethnicity are not connected to student placement into support classes in algebra at Eastwood High (via the Algebra Project), at the other district high schools the two categories are linked at a statistically significant level. Although the reason for this difference is unclear, high schools across the district appear to be employing different enrollment and scheduling practices with particular student groups. A full discussion is beyond the scope of this research; however, further study into this phenomenon is likely to highlight the critical role that counselors and student placement advisors play in helping to close the achievement gap in algebra. Also, as will be shown, this difference may provide some insight into the results of the inferential tests on the Algebra I CST scores in trial 2. 
Although useful as a method of helping to describe the student samples, additional analysis and discussion are left in favor of addressing the study's research questions. As noted, the first research question was:

Are there differences in students' performance between the instructional methodologies (Non-Algebra Project v. Algebra Project) as measured by the Algebra I CST?

To answer this question three separate trials were performed.

\section{Trial 1}

The first trial sought to establish if there were differences between the instructional methodologies (Non-Algebra Project v. Algebra Project) on the Algebra I CST at Eastwood High School. Interestingly, Eastwood High School offered both Algebra Project and traditional Non-Algebra Project courses to students at the site. Prior to the treatment, an independent samples t-test could not confirm a statistically significant difference between the two groups on their $8^{\text {th }}$ grade CST scores ${ }^{4,5}$.

The same student samples were then used to determine the Algebra Project's effect on the Algebra I CST test scores. Employing a paired samples t-test for the two cohorts, the students' $8^{\text {th }}-9^{\text {th }}$ grade Algebra I CST test scores were compared. The results for the Algebra Project group at Eastwood High School are shown in Tables 11 \& 12 below:

\footnotetext{
${ }^{4}$ An independent samples t-test (assuming unequal variance) resulted in: $p=0.1245, d . f .=102, t$ $=1.5490$.

${ }^{5}$ All independent samples t-tests conducted in the study assumed unequal variances, as recommended by Yates, Moore \& Starnes (2008).
} 
Table 11

Comparison of Algebra Project students' Algebra I CST scores between the $8^{\text {th }}$ and $9^{\text {th }}$ grade at Eastwood High

\begin{tabular}{|c|c|c|c|}
\hline Test & $\bar{X}$ & $n$ & $S D$ \\
\hline $\begin{array}{c}\text { 8th Grade } \\
\text { Algebra CST }\end{array}$ & 266.0633 & 79 & 35.9641 \\
\hline $\begin{array}{c}9^{\text {th }} \text { Grade } \\
\text { Algebra CST }\end{array}$ & 267.7468 & 79 & 42.9136 \\
\hline
\end{tabular}

Table 12

Paired samples t-test for Algebra Project students' Algebra I CST scores between the $8^{\text {th }}$ and $9^{\text {th }}$ grade at Eastwood High

\begin{tabular}{|c|c|c|c|c|}
\hline Test & $t$ & $r$ & d.f. & $p$ \\
\hline $8^{\text {th }}$ Grade v. $9^{\text {th }}$ Grade & -0.3751 & 0.5001 & 78 & 0.3543 \\
\hline
\end{tabular}

Note: $\alpha=0.05$

Although a slight increase in the mean scaled score was established on the $9^{\text {th }}$ grade assessment, as noted in Table 11 above, results from the paired samples t-test could not confirm a statistically significant increase for the Algebra Project group on the $9^{\text {th }}$ grade Algebra I CST $(p=0.3543, d . f .=78, t=-0.3751)$.

The results for the Non-Algebra Project cohort at Eastwood High School are shown in Table 13 and Table 14: 
Table 13

Comparison of Non-Algebra Project students' Algebra I CST scores between the $8^{\text {th }}$ and $9^{\text {th }}$ grade at Eastwood High

\begin{tabular}{|c|c|c|c|}
\hline Test & $\bar{X}$ & $n$ & $S D$ \\
\hline $\begin{array}{c}\text { 8th Grade } \\
\text { Algebra CST }\end{array}$ & 277.2143 & 56 & 44.5555 \\
\hline $\begin{array}{c}9^{\text {th }} \text { Grade } \\
\text { Algebra CST }\end{array}$ & 275.6429 & 56 & 43.0017 \\
\hline
\end{tabular}

Table 14

Paired samples t-test for Non-Algebra Project students' Algebra I CST scores between the $8^{\text {th }}$ and $9^{\text {th }}$ grade at Eastwood High

\begin{tabular}{|c|c|c|c|c|}
\hline Test & $t$ & $r$ & d.f. & $p$ \\
\hline $8^{\text {th }}$ Grade v. $9^{\text {th }}$ Grade & 0.2561 & 0.4502 & 55 & 0.3994 \\
\hline
\end{tabular}

Note: $\alpha=0.05$

As shown in Table 13, the comparison group performed slightly lower on the Algebra I CST at the end of $9^{\text {th }}$ grade. However, further testing revealed that this change was not statistically significant $(p=0.3994, d . f .=55, t=0.2561)$, as shown by the results of the paired samples t-test in Table 14 .

Taken together, the results of the paired samples t-tests seem to indicate that the Algebra Project may actually narrow the achievement gap (ever so slightly) at this site. In order to test this claim, a Difference In Differences (DID) test was conducted. This test first involved the computation of the differences (post-test - pre-test) in the scaled scores for each student in both cohorts. A subsequent independent t-test (assuming 
unequal variances) was then conducted on the average differences between the two groups. The results of this test are shown below in Table 15 and Table 16 below:

Table 15

Mean Differences between $8^{\text {th }}$ and $9^{\text {th }}$ grade mathematics CST Means at Eastwood High

\begin{tabular}{|c|c|c|c|}
\hline Group & $\bar{D}$ & $n$ & $S D$ \\
\hline $\begin{array}{c}\text { Non-Algebra } \\
\text { Project }\end{array}$ & -1.5714 & 56 & 45.9248 \\
\hline $\begin{array}{c}\text { Algebra } \\
\text { Project }\end{array}$ & 1.6835 & 79 & 39.8933 \\
\hline
\end{tabular}

Table 16

Independent samples t-test (Assuming Unequal Variances) of Mean Differences in students' Algebra I CST Scaled Scores at Eastwood High

\begin{tabular}{|c|c|c|c|c|}
\hline Group & $t$ & Critical Value & d.f. & $p$ \\
\hline $\begin{array}{c}\text { Non-Algebra Project } \\
\text { v. Algebra Project }\end{array}$ & -0.4281 & 1.9822 & 108 & 0.6694 \\
\hline
\end{tabular}

Note: $\alpha=0.05$

As indicated in Table 16, the results indicate that the difference in the differences between the two groups was not statistically significant $(p=0.6694, d . f .=$ $108, t=-0.4281)$. Finally, an independent samples t-test on the $9^{\text {th }}$ grade scaled scores could not establish a statistically significant difference between the two groups. ${ }^{6}$

${ }^{6}$ The results of an independent samples t-test (assuming unequal variance) between the NonAlgebra Project v. Algebra Project groups at Eastwood High School in $9^{\text {th }}$ grade produced the following results: $p=0.2949$, d.f. $=118, t=1.0520$. 
It is interesting to note that statistically significant differences were not detected between the cohorts, especially with the knowledge that the Algebra Project group received double the amount of instructional time compared to the Non-Algebra Project students. As explained in chapter 2, the Algebra Project students receive an additional mathematics support period each day in addition to their algebra class. According to the results from this first trial, the benefits from taking this additional support class at this site are not seen in the Algebra I CST scores. (Gutierrez, 2000)

\section{Trial 2}

While the first trial was designed to investigate the efficacy of the Algebra Project at the school site, it was unable to account for the additional instructional time between the two cohorts. In order to account for this significant variable a second trial was conducted.

This second trial compared the effects of Algebra Project at Eastwood to a synthetic cohort of Non-Algebra Project students at other high schools in the district on the Algebra I CST, and was able to account for this variable. This was done by querying the database for students at other high schools who were concurrently enrolled an algebra class and a mathematics support class during the same school year. Additionally, this comparison group was also controlled for the type of $8^{\text {th }}$ grade mathematics class (Algebra I). A total of 213 students met these criteria for the comparison group in the second trial. An independent samples t-test (assuming unequal 
variance) did not indicate a statistically significant difference in the $8^{\text {th }}$ grade mathematics CST scores between the student groups prior to the start treatment. ${ }^{7}$

Interestingly, after having established the two groups did not differ prior to the start of the experiment, the results of the paired samples t-tests, and the subsequent DID test, provided some surprising results.

While the Algebra Project cohort's results from Eastwood have already been presented in Trial 1, they are reprinted here in Table 17 and Table 18 for the reader's convenience:

Table 17

Comparison of Algebra Project students' Algebra I CST scores between the $8^{\text {th }}$ and $9^{\text {th }}$ grade at Eastwood High

\begin{tabular}{|c|c|c|c|}
\hline Test & $\bar{X}$ & $n$ & $S D$ \\
\hline 8th Grade & & & \\
Algebra CST & 266.0633 & 79 & 35.9641 \\
\hline $9^{\text {th }}$ Grade & & & \\
Algebra CST & 267.7468 & 79 & 42.9136 \\
\hline
\end{tabular}

${ }^{7}$ An independent samples t-test (assuming unequal variance) resulted in: $p=0.2125, d . f .=124, t$ $=1.2531$. 
Table 18

Paired samples t-test for Means for Algebra Project students' Algebra I CST scores between the $8^{\text {th }}$ and $9^{\text {th }}$ grade at Eastwood High

\begin{tabular}{|c|c|c|c|c|}
\hline Test & $t$ & $r$ & d.f. & $p$ \\
\hline $8^{\text {th }}$ Grade v. $9^{\text {th }}$ Grade & -0.3751 & 0.5001 & 78 & 0.3543 \\
\hline
\end{tabular}

Note: $\alpha=0.05$

The results of the pre/post paired samples t-test for the Non-Algebra Project synthetic cohort are shown in Table 19 and Table 20 below:

Table 19

Comparison of Non-Algebra Project students' Algebra I CST scores between the $8^{\text {th }}$ and $9^{\text {th }}$ grade at District High Schools

\begin{tabular}{|c|c|c|c|}
\hline Test & $\bar{X}$ & $n$ & $S D$ \\
\hline $\begin{array}{c}\text { 8th Grade } \\
\text { Algebra CST }\end{array}$ & 271.8028 & 213 & 31.3189 \\
\hline $\begin{array}{c}9^{\text {th }} \text { Grade } \\
\text { Algebra CST }\end{array}$ & 282.2347 & 213 & 43.6062 \\
\hline
\end{tabular}

Table 20

Paired samples t-test for Means for Non-Algebra Project students' Algebra I CST scores between the $8^{\text {th }}$ and $9^{\text {th }}$ grade at District High Schools

\begin{tabular}{|c|c|c|c|c|}
\hline Test & $t$ & $r$ & d.f. & $p$ \\
\hline $8^{\text {th }}$ Grade v. $9^{\text {th }}$ Grade & -3.9183 & 0.5025 & 212 & 0.0001 \\
\hline
\end{tabular}

Note: $\alpha=0.05$ 
As shown in Table 20, the results indicated a statistically significant improvement in the Algebra I CST scaled scores at the end of $9^{\text {th }}$ grade for the synthetic district group.

A subsequent DID comparison between the Algebra Project and district cohorts provided the following results:

Table 21

Mean Differences between $8^{\text {th }}$ and $9^{\text {th }}$ grade Algebra Scaled Scores - District NonAlgebra Project v. Algebra Project Cohorts

\begin{tabular}{|c|c|c|c|}
\hline Group & $\bar{D}$ & $n$ & $S D$ \\
\hline $\begin{array}{c}\text { Non-Algebra } \\
\text { Project }\end{array}$ & 10.4319 & 213 & 38.8563 \\
\hline $\begin{array}{c}\text { Algebra } \\
\text { Project }\end{array}$ & 1.6835 & 79 & 39.8933 \\
\hline
\end{tabular}

Table 22

Independent samples t-test (Assuming Unequal Variances) of Mean Differences of students' Algebra Scaled Scores - District v. Algebra Project Cohorts

\begin{tabular}{|c|c|c|c|c|}
\hline Group & $t$ & Critical Value & $d . f$. & $p$ \\
\hline $\begin{array}{c}\text { Non-Algebra Project } \\
\text { v. Algebra Project }\end{array}$ & 1.6764 & 1.9776 & 136 & 0.0960 \\
\hline
\end{tabular}

Note: $\alpha=0.05$

As indicated in Table 22, the results of the t-test indicated that there was a statistically significant difference in the differences in favor of the comparison group at the $\alpha=0.10$ level. This result is intriguing, especially when viewed in combination 
with the results of the student sample investigations at the start of the chapter (see Tables $9 \& 10$ ). Recall that these chi-squared tests indicated that students at other district high schools were more likely to be placed in algebra and an algebra support class if they were also African American or Latino. Taken together these results suggest that enrolling African American and Latino students in algebra and a support class is more likely to produce favorable results on the Algebra I CST compared to the Algebra Project. A final independent samples t-test at the end of $9^{\text {th }}$ grade confirmed a statistically significant difference between the two student cohorts. ${ }^{8}$

\section{Trial 3}

While the results in Trial 2 suggested that African American and Latino students were better served on the Algebra I CST by taking algebra and a support class (when compared to the Algebra Project), the third and final trial sought to determine the effect of the Algebra Project for African American students only. For this trial, purposive sampling was employed to restrict the samples for the experimental and comparison groups to African American students. The database was queried to control for: the type of $8^{\text {th }}$ grade mathematics CST test (Algebra I), the amount of mathematics instructionaltime in $9^{\text {th }}$ grade, and race (African American). An independent samples t-test (assuming unequal variances) of the $8^{\text {th }}$ grade Algebra scaled scores indicated that the

\footnotetext{
${ }^{8}$ The results of an independent samples t-test (assuming unequal variance) between the District Non-Algebra Project group v. Algebra Project group at Eastwood High School in $9^{\text {th }}$ grade produced the following results: $p=0.0118, d . f .=142, t=2.5516$.
} 
two samples did not differ at a statistically significant level prior to the start of the experiment. ${ }^{9}$

Somewhat surprisingly, after having established that a statistically significant difference between these two groups did not exist prior to the treatment, the results of the paired samples t-test, and the subsequent DID test, failed to indicate a statistically significant difference for either of the African American cohorts. The results are interesting as the Algebra Project was developed specifically to assist African American students in their acquisition of the algebraic concepts.

The results of the pre/post paired samples t-test for the African American Algebra Project cohort are provided in Table 23 and Table 24 below:

Table 23

Comparison of African American Algebra Project students' Algebra I CST scores between the $8^{\text {th }}$ and $9^{\text {th }}$ grade at Eastwood High

\begin{tabular}{|c|c|c|c|}
\hline Test & $\bar{X}$ & $n$ & $S D$ \\
\hline $\begin{array}{c}\text { 8th Grade } \\
\text { Algebra CST }\end{array}$ & 255.2162 & 37 & 27.1438 \\
\hline $\begin{array}{c}9^{\text {th }} \text { Grade } \\
\text { Algebra CST }\end{array}$ & 256.1622 & 37 & 31.1132 \\
\hline
\end{tabular}

${ }^{9}$ The results of an independent samples t-test (assuming unequal variance) could not confirm a statistically significant difference between the two groups $(p=0.1327, d . f .=68, t=1.5217)$. 
Table 24

Paired samples t-test for Means for African American Algebra Project students' Algebra I CST scores between the $8^{\text {th }}$ and $9^{\text {th }}$ grade at Eastwood High

\begin{tabular}{|c|c|c|c|c|}
\hline Test & $t$ & $r$ & d.f. & $p$ \\
\hline $8^{\text {th }}$ Grade v. $9^{\text {th }}$ Grade & -0.1435 & 0.0578 & 36 & 0.4433 \\
\hline
\end{tabular}

Note: $\alpha=0.05$

Results of the pre/post paired samples t-test for the African American Non-

Algebra Project district cohort are shown in Table 25 and Table 26 below:

Table 25

Comparison of African American Non-Algebra Project students' Algebra I CST scores between the $8^{\text {th }}$ and $9^{\text {th }}$ grade at District High Schools

\begin{tabular}{|c|c|c|c|}
\hline Test & $\bar{X}$ & $n$ & $S D$ \\
\hline $\begin{array}{c}\text { 8th Grade } \\
\text { Algebra CST }\end{array}$ & 265.2647 & 34 & 28.3809 \\
\hline $\begin{array}{c}9^{\text {th }} \text { Grade } \\
\text { Algebra CST }\end{array}$ & 265.3235 & 34 & 36.1040 \\
\hline
\end{tabular}

Table 26

Paired samples t-test for Means for African American Non-Algebra Project students' Algebra I CST scores between the $8^{\text {th }}$ and $9^{\text {th }}$ grade at District High Schools

\begin{tabular}{|c|c|c|c|c|}
\hline Test & $t$ & $r$ & d.f. & $p$ \\
\hline $8^{\text {th }}$ Grade v. $9^{\text {th }}$ Grade & -0.0081 & 0.1602 & 33 & 0.4968 \\
\hline
\end{tabular}

Note: $\alpha=0.05$ 
As shown in Table 24 and Table 26, neither of the results of the paired samples t-test for the African American cohorts indicated a statistically significant difference between the $8^{\text {th }}$ and $9^{\text {th }}$ grades on the Algebra I assessment. The Difference In Differences comparison between the two African American cohorts is shown below in Tables 27-28:

Table 27

Mean Differences between $8^{\text {th }}$ and $9^{\text {th }}$ grade African American Algebra Scaled Scores District v. Algebra Project Cohorts

\begin{tabular}{|c|c|c|c|}
\hline Group & $\bar{D}$ & $n$ & $S D$ \\
\hline $\begin{array}{c}\text { Non-Algebra } \\
\text { Project }\end{array}$ & 0.0588 & 34 & 42.1986 \\
\hline $\begin{array}{c}\text { Algebra } \\
\text { Project }\end{array}$ & 0.9459 & 37 & 40.0901 \\
\hline
\end{tabular}

Table 28

Independent samples t-test (Assuming Unequal Variances) of Mean Differences of students 'Algebra Scaled Scores - District v. Algebra Project Cohorts

\begin{tabular}{|c|c|c|c|c|}
\hline Group & $t$ & Critical Value & d.f. & $p$ \\
\hline $\begin{array}{c}\text { Non-Algebra Project } \\
\text { v. Algebra Project }\end{array}$ & -0.0906 & 1.9955 & 68 & 0.9281 \\
\hline
\end{tabular}

Note: $\alpha=0.05$

As indicated in Table 28, for African American students in the study, neither curricular approach produced a difference in the mean scaled scores that was statistically significant by the end of $9^{\text {th }}$ grade. Finally, an independent samples 
(assuming unequal variance) t-test failed to establish a statistically significant difference between the two groups at the end of $9^{\text {th }}$ grade. ${ }^{10}$

\section{Summary and Synthesis}

Summarizing the data from the three trials in research question \#1: at Eastwood High School there is no evidence to suggest that the Algebra Project produced statistically significant difference in the results on the Algebra I CST test when compared to the Non-Algebra Project approach; that when controlled for the amount of instructional time, Non-Algebra Project students at other high schools obtained a statistically significant higher test scores compared to Algebra Project students on the Algebra I CST assessment; and that when also controlled for race, African American students did not show a statistically significant difference on the Algebra I CST compared to those enrolled in a Non-Algebra Project curriculum. For convenience, the results from the three trials are summarized in Table 29.

The results from these three trials appear to confirm the findings on the Algebra Project's efficacy, as measured by standardized exams, published by Sikorski et al. (1993), while contradicting the more favorable results by Adair (1993). As noted in chapter 2, Sikorski et al. (1993) pointed to data suggesting that the Algebra Project produced inconclusive or unfavorable results, when compared to a cohort of students not enrolled in the Algebra Project classes, as measured by the Iowa Test of Basic Skills

\footnotetext{
${ }^{10}$ The results of an independent samples t-test (assuming unequal variance) between the African American groups at the end of $9^{\text {th }}$ grade produced the following results: $p=0.2582, d . f .=65, t=1.1407$.
} 
(ITBS). While the ITBS differs in several ways from the Algebra I CST ${ }^{11}$, the results from this study adds to the body of evidence that the Algebra Project does not necessarily produce higher student test scores on these types of standardized

\section{Table 29}

\section{Research Question \#1 Trial Summaries}

\begin{tabular}{|l|c|c|c|}
\hline & Trial 1 & Trial 2 & Trial 3 \\
\hline Algebra Project group & & & \\
\hline Comparison group & Eastwood & Eastwood & Eastwood \\
\hline Sample demographics & Eastwood & District & District \\
\hline Controlled for $8^{\text {th }}$ grade mathematics & Various & Various & AA \\
\hline Controlled for instructional time in $9^{\text {th }}$ grade & No & Yes & Yes \\
\hline & & & Yes \\
\hline Algebra Project matched pair t-test $p\left(8^{\text {th }}-9^{\text {th }}\right)$ & 0.3543 & 0.3543 & 0.4433 \\
\hline Comparison matched pair t-test $p\left(8^{\text {th }}-9^{\text {th }}\right)$ & 0.3994 & $0.0001^{*}$ & 0.4968 \\
\hline & & & \\
\hline DID Independent t-test $p$ & 0.6694 & $0.0960^{* *}$ & 0.9281 \\
\hline
\end{tabular}

* Statistically significant difference at $\alpha=0.05$ level.

** Statistically significant difference at $\alpha=0.10$ level.

"The most notable difference is that the Iowa Test of Basic Skills is a norm-referenced assessment, while the Algebra I CST is a criterion-referenced test. 
assessments. Additionally, taken together, these results cast some doubt on Lee's suggestion that the culturally relevant approach embedded into the Algebra Project's curriculum results in higher test scores for traditionally underachieving student populations. Future study and investigation is recommended.

However, as important as the CST results are for individual schools and districts in California, the Algebra I CST scores represent only one method of measuring the impact of the Algebra Project on students. While practitioners place significant value on the results of this standardized assessment as an indicator of the efficacy of instruction, a singular dependency on their interpretation is limiting. Although these types of standardized exams are able to measure a snapshot of students' skills at a particular moment in time, measuring the deep understanding of concepts requires the use of additional types of assessments.

In an attempt to employ another measure for evaluating the efficacy of the Algebra Project, Sandman's MAI survey was employed. As described earlier, this survey instrument was developed to gauge students' attitudes towards the study of mathematics. The results of the survey and analysis are presented and discussed in the next section. 


\section{The Findings - Research Question \#2}

The study's second research question was:

Are there differences in students' mathematical attitudes between the instructional methodologies (Non-Algebra Project v. Algebra Project) as measured by Sandman's (1973) Mathematics Attitude Inventory (MAI) survey?

This portion of the study involved the collection and interpretation of MAI survey data from $759^{\text {th }}$ and $10^{\text {th }}$ grade students at the study site during the 2010-2011 school year. To obtain meaningful attitudinal data from a wide a spectrum of the student population from the site, the English survey instrument was also translated into Spanish and Chinese. The students were offered English, Spanish or Chinese versions of the MAI during the survey administration, with a total of 10 students requesting the non-English versions (Spanish, $\mathrm{n}=2$; Chinese, $\mathrm{n}=8$ ). After the survey administrations had been completed, results of the non-English MAI surveys were transcribed to a common form and then scanned. Two English surveys were also transcribed prior to scanning, due to inconsistent bubbling patterns by the students. ${ }^{12}$

The students (both $9^{\text {th }}$ grade and $10^{\text {th }}$ grade students enrolled in the various sections) were surveyed during their regularly scheduled algebra classes between midFebruary and early March. Students from 5 different algebra classes (2 Algebra Project classes, 3 Non-Algebra Project classes) participated in the optional survey.

\footnotetext{
${ }^{12}$ In both cases, unique student responses were clearly evident for each question. However the responses were transcribed to new Scantron forms to ensure that they were accepted by the scanner. Simply, both cases represented instances of students "coloring outside the lines" of the bubbles on the scantron forms.
} 
Additionally, these 5 sections of algebra were taught by three different teachers (1 Algebra Project teacher and 2 non-Algebra Project teachers) at the study site.

\section{Student Samples}

Self-reported demographic information collected as part of the survey provided the following breakdowns:

Table 30

Demographic profiles of Completed MAI Surveys - Non-Algebra Project and Algebra Project Classes

\begin{tabular}{|l|c|c|c|c|c|c|c|}
\hline & AA & A & L & W & O & NR & Total \\
\hline Female & 5 & 5 & 8 & 0 & 9 & 1 & 28 \\
\hline Male & 16 & 11 & 15 & 0 & 4 & 1 & 47 \\
\hline Total & 21 & 16 & 23 & 0 & 13 & 2 & 75 \\
\hline
\end{tabular}

$\begin{array}{llllll}\text { AA } & \text { African American } & \text { A } & \text { Asian } & \text { L } & \text { Latino } \\ \text { W } & \text { White } & \text { O } & \text { Other } & \text { NR } & \text { No response }\end{array}$

A demographic summary by type of algebra class is provided in Tables $31 \& 32$ : 
Table 31

Student Demographics of Algebra Project Classes at Eastwood High

\begin{tabular}{|cc|c|c|cccccc|c|}
\hline Female & Male & Teacher & Period & AA & A & L & W & O & NR & Totals \\
\hline 7 & 10 & A & 3 & 6 & 1 & 7 & 0 & 2 & 1 & 17 \\
9 & 9 & A & 6 & 5 & 0 & 10 & 0 & 3 & 0 & 18 \\
\hline \hline 16 & 19 & & & 11 & 1 & 17 & 0 & 5 & 1 & 35 \\
\hline
\end{tabular}

Table 32

Student Demographics of Non-Algebra Project Classes at Eastwood High

\begin{tabular}{|cc|c|c|cccccc|c|}
\hline Female & Male & Teacher & Period & AA & A & L & W & O & NR & Totals \\
\hline 7 & 16 & B & 7 & 8 & 6 & 3 & 0 & 6 & 0 & 23 \\
4 & 10 & C & 6 & 2 & 8 & 2 & 0 & 2 & 0 & 14 \\
1 & 2 & C & 2 & 0 & 1 & 1 & 0 & 0 & 1 & 3 \\
\hline \hline 12 & 28 & & & 10 & 15 & 6 & 0 & 8 & 1 & 40 \\
\hline
\end{tabular}

\section{Raw Data Comparisons}

A comparison of the means of the raw data for each individual question between the two groups (Non-Algebra Project v. Algebra Project) is included in Table 33 in Appendix F. However, caution should be used in the interpretation of these results. As explained earlier, the MAI employs a Likert scale, assigning scores of 1 for "Strongly Agree," 2 for "Agree," 3 for "Disagree," and 4 for "Strongly Disagree." While the negative t-scores in the table indicate lower mean scores for the Non-Algebra Project group, because 29 of the questions are reverse-scored, interpretation of the results for 
this table is dependent upon the particular wording and phrasing of each individual question.

As displayed in this table, most questions showed little variation in the means between to the two groups, with a few notable exceptions. Individual item analysis revealed differences in only four of the 48 questions. Specifically, statistically significant differences were noted at the $\alpha=0.10$ level on question 1 (Value) and 45 (Enjoyment), and at the $\alpha=0.05$ level on question 3 (Motivation) and 25 (Anxiety).

At the $\alpha=0.10$ level, the results from Question 1 indicated that Non-Algebra Project students $(\bar{X}=1.6750$ ) were more likely to agree that mathematics is useful in everyday life, compared to their Algebra Project peers $(\bar{X}=1.9143)$. Also, results from Question 45 showed that Non-Algebra Project students $(\bar{X}=2.7000)$ were more likely to agree that the study of mathematics "is more of a game than it is hard work" compared to the Algebra project group $(\bar{X}=3.0000)$.

At the $\alpha=0.05$ level, test results showed that Algebra Project students ( $\bar{X}=$ 2.0857) were more likely than their Non-Algebra Project peers $(\bar{X}=2.4500)$ to agree with the statement "It doesn't disturb me to work mathematics problems." However, at the same time the Algebra Project students ( $\bar{X}=1.4571)$ were more likely to admit that they liked the easiest mathematics problems the best, compared to their Non-Algebra Project classmates $(\bar{X}=1.900)$. 


\section{Construct Comparisons}

While statistically significant differences on a limited number of individual questions were noted, two subsequent investigations analyzed differences in the six different constructs, as described by Sandman $(1973 ; 1979)$. Specifically these tests sought to address the question:

Which of the six different affective domains measured by the MAI will detect a difference in students' attitudes between the two instructional methodologies?

After reverse scoring 29 of the 48 test items, two different construct analyses were conducted. In the first analysis, construct scores (Sandman, 1980) were first calculated for each student. Independent samples t-tests were then performed on the means between the two student cohorts. The results are summarized in Table 34 .

As shown in Table 34, although differences in the means were detected, statistically significant differences between the Algebra Project and comparison group could not be established for any of the six constructs. 
Table 34

Independent samples t-Test (Assuming Unequal Variance) Results of Mean Construct Scores Between Non-Algebra Project (Non-AP) and Algebra Project (AP) Students

\begin{tabular}{|l|c|c|c|c|c|}
\hline \multicolumn{1}{|c|}{ Domain } & $\begin{array}{c}\text { Non-AP } \\
\bar{X} \\
(S D)\end{array}$ & $\begin{array}{c}\text { AP } \\
\bar{X} \\
(S D)\end{array}$ & $t$ & d.f. & $p$ \\
\hline Perception of the Mathematics Teacher & $\begin{array}{c}24.1750 \\
(3.1451)\end{array}$ & $\begin{array}{c}24.8857 \\
(3.3235)\end{array}$ & -0.9473 & 70 & 0.3467 \\
\hline Anxiety toward Mathematics & $\begin{array}{c}13.2750 \\
(2.8374)\end{array}$ & $\begin{array}{l}13.5429 \\
(2.3053)\end{array}$ & -0.4508 & 73 & 0.6535 \\
\hline Value of Mathematics in Society & $\begin{array}{c}21.4350 \\
(3.0118)\end{array}$ & $\begin{array}{c}21.0000 \\
(2.4971)\end{array}$ & 0.6679 & 73 & 0.5063 \\
\hline Self-concept in Mathematics & $\begin{array}{c}15.8000 \\
(3.6247)\end{array}$ & $\begin{array}{l}16.0286 \\
(3.2402)\end{array}$ & -0.2883 & 73 & 0.7739 \\
\hline Enjoyment of Mathematics & $\begin{array}{l}18.5000 \\
(3.8096)\end{array}$ & $\begin{array}{l}17.6286 \\
(4.5574)\end{array}$ & 0.8911 & 67 & 0.3760 \\
\hline Motivation in Mathematics & $\begin{array}{c}\text { (2.3250 } \\
(2.1048)\end{array}$ & $\begin{array}{c}8.6857 \\
(2.5411)\end{array}$ & 1.1765 & 66 & 0.2436 \\
\hline
\end{tabular}

* Statistically significant difference at $\alpha=0.05$ level.

** Statistically significant difference at $\alpha=0.10$ level.

The second analysis attempted to limit the possible spurious results introduced from confounding linguistic or cultural variables. As several individuals have correctly argued, students from different cultural and linguistic backgrounds likely interpret the attitudinal questions (or the actual use of the survey itself) quite differently. In an attempt mitigate the unintended effects of linguistic or cultural bias, as well as those 
possibly introduced through translation, another test was conducted using the English surveys only. While the same scoring procedures were employed for this analysis, the independent samples t-test was conducted only after the Spanish and Chinese survey results had been omitted from the database. Interestingly, this procedure reduced the number of results in the comparison group by a total of ten students (two Spanish and eight Chinese), but did not reduce the size of the Algebra Project sample. The results of this second trial are shown below in Table 35 .

While differences in the means were again noted, the results in Table 35 indicate that none of the constructs showed differences between the two groups at a statistically significant level, when the sample was controlled for the English versions of the MAI. It should be noted that the results in both trials represent a snapshot of students' feelings at approximately the half-way point through the school year. While use of a pre/posttest design would have allowed for further testing, and provided insight into attitudinal changes over time, establishing the degree to which the changes were attributable to the curricula would have likely remained difficult. Having noted this, however, the results from the study indicate that statistically significant differences were not apparent between the two cohorts for any of Sandman's six attitudinal constructs. 
Table 35

Independent samples t-Test (Assuming Unequal Variance) Results of Mean Construct Scores Between Non-Algebra Project (Non-AP) and Algebra Project (AP) StudentsEnglish Language Versions Only

\begin{tabular}{|l|c|c|c|c|c|}
\hline \multicolumn{1}{|c|}{ Domain } & $\begin{array}{c}\text { Non-AP } \\
\bar{X} \\
(S D)\end{array}$ & $\begin{array}{c}\text { AP } \\
\bar{X} \\
(S D)\end{array}$ & $t$ & d.f. & $p$ \\
\hline Perception of the Mathematics Teacher & $\begin{array}{c}23.9000 \\
(3.0212)\end{array}$ & $\begin{array}{c}24.8857 \\
(3.3235)\end{array}$ & -1.2520 & 63 & 0.2152 \\
\hline Anxiety toward Mathematics & $\begin{array}{c}13.4667 \\
(3.0027)\end{array}$ & $\begin{array}{c}13.5429 \\
(2.3053)\end{array}$ & -0.1133 & 54 & 0.9102 \\
\hline Value of Mathematics in Society & 21.1000 & 21.0000 & 0.1370 & 54 & 0.8916 \\
\hline Self-concept in Mathematics & $(3.2626)$ & $(2.4971)$ & & & \\
\hline Enjoyment of Mathematics & 15.9667 & 16.0286 & -0.0698 & 57 & 0.9446 \\
& $(3.8190)$ & $(3.2402)$ & & & \\
\hline Motivation in Mathematics & 17.9000 & 17.6286 & 0.2627 & 63 & 0.7937 \\
& $(3.7724)$ & $(4.5574)$ & & & \\
\hline
\end{tabular}

* Statistically significant difference at $\alpha=0.05$ level.

** Statistically significant difference at $\alpha=0.10$ level.

Generally speaking, the results of the attitudinal inventory do not support the notion that the implementation of a culturally relevant pedagogical approach necessarily results in an improvement in students' mathematical attitudes, as suggested a number of researchers (Hines, 2008; Kamii, 1990; Leonard et al., 2010; Moses et al., 1989; 
Nelson, 1994; Sikorski et al., 1993; Silva \& Moses, 1990), Additionally, these findings contradict those presented by Nelson (1994), who reported a positive affective response to the Algebra Project. Differences in the findings between these two studies are likely attributable to issues related to sample size, differences in the tools employed to assess students' affective response, and study sites.

\section{Summary and Synthesis}

Summarizing the data from the two trials in research question \#2: individual item analysis revealed statistically significant differences in four of the 48 questions (two questions at $\alpha=0.10$ and two questions at $\alpha=0.05$ ), with three of the four results in favor of the comparison group; while analysis of the six constructs scores did not indicate statistically significant differences between the cohorts for any of the constructs.

As noted earlier, based upon the analysis of the results from the quantitative data presented in this chapter, and in keeping with the principles of Extreme Case Analysis described by Caracelli \& Greene (1993), particular questions were selected for use in the subsequent interviews and focus group sessions. Since extreme cases (defined earlier as statistically significant differences) were not detected in any of the constructs, questions were selected based upon differences in the individual questions (Value, Motivation, Anxiety and Enjoyment) and the results of the Algebra I CST quantitative 
analysis. The presentation and discussion of this qualitative data are offered in the next chapter. 


\section{Chapter Five: Qualitative Findings}

\section{Overview}

Chapter 5 is devoted to the presentation and discussion of the qualitative data from the study's third and final research question:

What additional factors impact the way students feel about their study of mathematics?

While chapter 5 was informed in part by the quantitative data and conclusions drawn from the chapter 4 , a separate presentation of the qualitative data allows for a more detailed description and thorough analysis. Additionally it provides the chance to present a number of meaningful passages from the study's participants, as well as the opportunity to discuss some of the nuances and complexities related to this data.

In order to address the third question from multiple perspectives, data were collected from both teachers and students. The findings are presented into two sections. First, after using portraiture (Lawrence-Lightfoot, 2005) to present the two Algebra Project teachers, the major findings from their interviews are presented and discussed. The second section is devoted to the results from the two student focus group sessions (Non-Algebra Project and Algebra Project). Each section concludes with a summary and synthesis of the major findings. 
The Findings - Research Question \#3

Teacher Portraitures

In addition to providing a backdrop against which the data may be viewed, these sketches provide additional insight into the teachers' backgrounds and instructional styles. The portraitures were based upon a variety of direct observations and interactions, including: data and field notes collected during several classroom observations, special presentations, and a community night from a pilot study; information collected during the personal interviews; and a number of informal conversations with each teacher over a three year period.

Cameron.

Cameron (pseudonym) is an Asian-American male in his early thirties who taught Algebra and Advanced Algebra during the year of the study. In the interview, Cameron detailed his path to becoming a mathematics teacher. After majoring in the social sciences in college, he passed the CSET exam (the state's subject matter competency assessment for teachers) in mathematics and received his teaching credential from a public university. While describing his experience studying mathematics at the collegiate level as challenging at times, during the interview he explained his love of mathematics as a high school student, his desire to work with disenfranchised student populations as a teacher, and his passion for teaching. 
At the time of the interview he had 4 years of teaching experience, including 1 year at a middle school and 3 years at the high school level. Although Cameron was not the chair of the department, he was the driving force behind the development and implementation of the Algebra Project at the site, and is viewed by his peers and administrators as an innovative and dedicated professional.

As might be expected, his instructional style is best described as progressive. While his classroom consisted of 28 individual student desks, they were typically arranged in clusters of four. Additionally, neatly constructed samples of student projects and work were prominently displayed on the walls of the classroom. Students in his classes were frequently observed to be working on discovery-based, cooperative activities during lessons; however, teacher led and directed lessons were observed on occasion.

Cameron is also active outside of the classroom, helping to lead a self-study, community of practice group of mathematics educators. As one of the founding members of this group, he has shared his experiences implementing the Algebra Project and integrating culturally relevant pedagogy with his peers. The group meets monthly during the academic year and is primarily comprised of mathematics teachers from high schools across the district. Recently several faculty members from a local community college have also joined the meetings. While these instructors are not from the mathematics department, they have expressed an interest in learning about alternative 
instructional approaches to strengthen the mathematics skills for students in their particular programs.

Finally, in addition to his role as a classroom teacher, Cameron also serves as a curriculum developer and consultant for the Algebra Project organization at the national level, receiving compensation for his work.

Mary.

Mary (pseudonym) is a White female in her mid-50s. In the interview Mary explained that prior to becoming a teacher she worked in the legal profession for 10 years. Unfulfilled with this vocation, she obtained her teaching credential and changed careers to become a middle school mathematics teacher. After six years of teaching mathematics, she accepted a district position serving as a mathematics resource across the district. Three years later she asked to return to the classroom, accepting a position as a teacher at the study site.

In terms of her style in the classroom, Mary would best be described as a progressive teacher, although somewhat more traditional in her instructional approach as compared to Cameron. The small tables in her classroom are arranged in such a way that students are seated in groups of 4-6 students and daily lessons employ a blend of cooperative activities and teacher directed micro-lessons.

Together with Cameron, Mary has also been involved in professional development at the district level, helping to promote and develop the self-study, 
community of practice group of mathematics educators. While she has helped to develop and implement the Algebra Project at the school, unlike Cameron, she is not under contract as a curriculum developer with the Algebra Project organization. Finally, in addition to her classroom duties, Mary also serves as the school's mathematics department chair. In this capacity she plans, coordinates and leads department meetings at the school site, and assists with the implementation of a number of district-wide initiatives within the department.

Although their personal life stories and professional experiences vary, both teachers have found their niche at the school, and have embraced the challenges of teaching mathematics to diverse groups of students in an urban setting. Interestingly, while it was clear from the interviews that Cameron and Mary were dedicated to closing the achievement gap in algebra through the implementation of the Algebra Project at their site, both also referred to challenges related to the program's implementation, as well as some skepticism in terms of the program's overall efficacy, particularly as it related to the improvement of students' standardized test scores.

\section{Teacher Interviews}

This section details the findings from two teacher interviews. As explained in chapter 3, after transcribing the interviews, the text was coded against Morrison's et al. framework of culturally relevant pedagogical practices. This approach was decided upon for three primary reasons. First, was the desire to take advantage of an existing 
framework. As already noted, Morrison's et al. framework was developed as a result of a meta-analysis of 45 studies on culturally relevant pedagogical practices and provides an overview of recent classroom research in the field. Additionally, because the Algebra Project has been cited as an example of a culturally relevant pedagogical approach, coding the interviews against this framework helped to establish the degree to which the Algebra Project matched with particular elements of CRP. Second, the framework was used as a lens through which to narrow the focus for additional analysis and study. After coding, the two elements receiving the largest number of tallies were subsequently analyzed in greater detail. The final reason was related to the flexibility afforded by the approach. As Morrison et al. explained, the elements within their framework could be employed as overlapping categories to describe the culturally relevant strategies and approaches of practitioners. Simply, the use of the framework provided the adaptability so that particular instances and references could be coded to multiple elements to provide a more robust and comprehensive data set. After coding, all references were tallied by element. The frequency results are presented in Table 36 .

Three observations are drawn from a review of the data in this table. The first is that the interviews contained a significant number of links to the elements of CRP, as described by Morrison et al. While a simple tally cannot be construed as proof of a 
Table 36

Frequencies of Morrison's CRP elements from teacher interviews

\begin{tabular}{|c|c|c|c|}
\hline Elements & Cameron & Mary & Totals \\
\hline High Academic Expectations & 8 & 1 & 9 \\
\hline Modeling, scaffolding, and clarification of the challenging curriculum & 5 & 28 & 33 \\
\hline Using students' strengths as instructional starting points & 5 & 18 & 23 \\
\hline Investing and taking personal responsibility for students' success & 28 & 16 & 44 \\
\hline Creating and nurturing cooperative environments & 10 & 12 & 22 \\
\hline High behavioral expectations & 2 & 6 & 8 \\
\hline Cultural Competence & 1 & 0 & 1 \\
\hline Reshaping the prescribed curriculum & 36 & 34 & 70 \\
\hline Building on students' funds of knowledge & 12 & 8 & 20 \\
\hline Encouraging relationships between school and communities & 22 & 11 & 33 \\
\hline Critical Consciousness & 5 & 0 & 5 \\
\hline Critical literacy & 7 & 5 & 12 \\
\hline Engaging students in social justice work & 4 & 5 & 9 \\
\hline Making explicit the power dynamics of mainstream society & 7 & 4 & 11 \\
\hline Sharing power in the classroom & 1 & 0 & 1 \\
\hline Totals & 153 & 148 & 301 \\
\hline
\end{tabular}

culturally relevant pedagogical approach per se, when viewed against the existing

literature base, the large number of references provides a modicum of evidence to 
indicate the interviews centered on many of the underlying concepts that undergird culturally relevant pedagogy.

Secondly, the number of references for the two teachers was approximately equal, with a total of 153 references noted for Cameron and 148 references from Mary's interview. The balance in the tallies between the two teachers is likely connected to their similar, non-traditional paths to becoming mathematics teachers, as well as their experiences working with minority student populations over an extended period of time. A closer study of the transcripts revealed that both educators had spent significant amounts of time reflecting on their instructional practices as a result of their work with different student populations.

Finally, while each teacher tended to emphasize different elements during their interviews, two were particularly noteworthy. The first - "Reshaping the prescribed curriculum" received the most tallies for both teachers, and also garnered the largest total number of references $(n=70)$ of the 15 elements. The second - "Investing and taking a personal responsibility in students' success" received the second largest total number of tallies $(n=44)$. The references from these two elements were then studied and analyzed in more detail for additional insights and connections to the quantitative data from chapter 4 . 


\section{Reshaping the prescribed curriculum}

In summarizing Banks (2001), Morrison et al. explained that this element involved the integration of non-mainstream content and learning experiences into the traditional, Eurocentric curriculum in order to develop a multicultural curriculum. As a part of this, the researchers explained the importance of implementing learning experiences that were connected to the students' identities and daily experiences to make the learning relevant and meaningful. In a similar way, the Algebra Project's emphasis in grounding learning experiences in a shared physical activity was categorized and coded as falling within this element. Further classification and analysis of each of the individual references in this element revealed two related themes: Dedication to curricular development and Content standards and standards-based exams.

\section{Dedication to curriculum development.}

Several of the passages referenced the teachers' on-going efforts to create and refine the curriculum materials so that clear, coherent lessons were presented to the students each day. While teachers are typically expected to attend workshops and develop lesson plans as part of their normal duties, the efforts described by the Algebra Project teachers pointed to a level of commitment that went far beyond that of most mathematics teachers. Here two related points are expanded upon. 
First, the teachers described needing to invest a significant amount of additional time to develop the curriculum and the related instructional materials. This included extensive participation in a variety of Algebra Project workshops and professional development sessions over a three year period. While no attempt to quantify this additional time was made, the extra commitment described by the teachers was significant, as they detailed ongoing curriculum development efforts and attending a variety of workshops and conferences, often on their own time (nights, weekends, and summers). This additional commitment was striking, especially compared with the efforts of other Non-Algebra Project teachers known to the researcher. The additional time required for this work, along with a sense of some of the underlying tensions that it created for the teachers, was highlighted in the following passage with Mary:

I: $\quad$ Yeah, and it (the Algebra Project curriculum) takes...I mean, it's...well, it's an alternative curriculum, and so I think there's an extra level of commitment that the teacher would have to have.

Mary: Ummhmmm (affirmative). And when we were working on the ninth grade, the first year we did it, I think both Cameron and I were working almost all weekend, every weekend ...

Because it (the curriculum material) wasn't...you can't just hand it to them (the students). You had to revise it and scaffold it, and you know...

I: The curriculum itself?

Mary: The curriculum itself.

I: $\quad$ Always tweaking it, refining it? 
Mary: Always, yeah. And it was hard; it was really hard.

Further analysis revealed that the teachers spent significant time on the creation of the resources that many classroom teachers often take for granted when implementing more traditional, mainstream algebra curricula. This commitment to the development of these materials was evident in a passage from Cameron's interview, in which he discussed support for Algebra Project teachers in relation to the ongoing curricular development efforts:

... But then support in the like day-to-day teaching of it (the Algebra Project curriculum materials), we created it ourselves. So Mary and I supported each other a lot during the first year where we would collaborate on ... how we planned on teaching a concept, to what's the actual homework that you're giving, to what do you think is a relevant test, and how are we going to do that. So, our support was ourselves.

There was a lot of creating that we had to do. So innately, we did a lot of curriculum support development. You know, kind of like we developed the homework, we developed the lesson plans. We developed like everything that you would almost expect in a teachers' edition, we had to come up with on our own...

None of that existed before we were introduced to it. Actually, I take that back. Pieces of it were for Road Coloring (one of the Algebra Project units). Pieces. That's what the team did before I came on board. But then, when I came on board in ... the summer of 2008, then that's when we kind of reopened up everything and we just made sure that everything had support materials...

So that's part of my role within the Algebra Project is to do that. So when I taught it the first time, there was no support. 
Interestingly, while the teachers described the development of the curricular materials as requiring significant time and effort, they also maintained that the program's novel instructional approach engaged the students at a deeper level, when compared to the use of more traditional algebra curricula. They explained that while the curriculum lacked the appropriate lesson plans and support materials it also contained activities that captured students' interest, often engaging them at a deeper level. While no difference was detected in the results of the student attitudinal inventory, corroborating evidence from the student focus group sessions supports the teachers' claim that students tended to be engaged at a deeper level with the Algebra Project curriculum.

Having noted this however, a number of the underlying challenges alluded to by the teachers are not without reference in the literature (Enyedy \& Mukhopadhyay, 2007; Gutierrez, 2009; Leonard, Napp \& Adeleke, 2009; Leonard et al., 2010; Morrison et al., 2008; Young, 2010). In writing of the difficulties that culturally relevant educators often face, Morrison et al. aptly noted:

Culturally relevant pedagogy ultimately clashes with the traditional ways in which education is carried out in our society, thus making culturally relevant teaching actions seem herculean to many teachers ... Many teachers early on in their careers discover that they lack the time and resources to do the job they hope to do, which can include enacting culturally relevant pedagogy. (p. 444)

Although some curriculum development by teachers is to be expected, the ongoing need for such extensive and continual creation and refinement of the resource 
materials prevented the teachers from developing another critical piece of the Algebra Project - the community organizing and involvement component. As already noted in the literature review, Robert Moses contends that, at its heart, the Algebra Project is first an organizing project (Moses \& Cobb, 2001a, 2001b; Moses, et al., 1989). This Freireian approach to the mobilization of the community around the improvement of students' algebra skills is rooted in Moses' civil rights work in the 1960's, and represents a key element to the Algebra Project's success. From a conceptual standpoint, this emphasis helps to ground the program in critical pedagogy, aligning it with the research and efforts of other equity-centered mathematics researchers and practitioners (Gutierrez, 2009; Gutstein, 2007; Martin, 2009; Stinson, 2008) who emphasize the actualization of the individual and the emancipation of disenfranchised groups through the study of mathematics. From a practical standpoint; however, when asked to describe their efforts at engaging the students in socially-just work in the community, Mary explained:

I: $\quad$... Another commonly referenced attribute of culturally relevant pedagogy is a commitment to engaging students in social justice work and encouraging relationships between schools and communities. Could you explain how the Algebra Project Program has attempted to foster these ideals in students?

Mary: Ours or nationally?

I: $\quad$ Here at...our, our kids. 
Mary: Okay. We're trying. This is the piece that we did neglect a bit in the first year and a half or so, because we really had to focus on the classroom. And neither Cameron nor I had any energy to expend outside. The Algebra Project, Inc., did hire a consultant or sort of a community organizer. But she didn't really make much headway ...

In this way, the additional time required for the continual work on the curriculum materials came at the expense of the full development of meaningful community partnerships. Additional evidence collected during the course of the interviews noted that despite the hard work of the teachers, the community involvement component was still a work in progress two and a half years after the implementation of the program. Various passages from both interviews suggested that teachers struggled to find the time necessary to develop and implement both the curricular and community elements of the program simultaneously. Touching on these themes, Cameron explained:

The component of community and school partnerships, my initial conceptualization of that was to have more family math nights, to have more outreach opportunities, to extend the discussion. That has since, kind of, fell from the priority list given the incredible amount of work and coordination that it takes to do. So that's kind of, like... I'm okay with not doing that.

A short while later, while describing the challenges of balancing the demands of the classroom with the coordination of a student tutoring program at a local elementary school, Cameron explained that the amount of work was overwhelming and that additional time was required to fully implement all aspects of the program successfully. 
Finally, contributing to this sense of frustration and isolation on the part of the teachers was the limited existence of a support network. While both teachers attended a number of Algebra Project workshops and conferences, these sessions were typically attended by small cadre of dedicated reformers. The limited scope of the Algebra Project's implementation at the national level, and the lack of a fully developed network of practitioners, was highlighted in the following passage with Cameron:

I: $\quad \quad \ldots$ Do you think the training, support and materials have been adequate so that you can successfully teach the Algebra curriculum?

Cameron: Umm, well, yes and no, because when we talk about support, I kind of am my own support. The other teachers that were with me at the time we taught it, the first time we taught it in $2009, \ldots 2008-2009$, that was the realm of support. So outside of Mary and myself, there was five other teachers in the country who were knowledgeable about this.

Taken together, the passages serve to underscore Morrison's et al. contention that implementing culturally relevant pedagogical practices can be overwhelming without the appropriate supports. As many curricular reformers are aware - the work of developing and implementing culturally relevant pedagogy for the mathematics classroom is challenging (Leonard et al., 2009; Young, 2010), and is often hampered by a lack of adequate time and resources (Cahnmann \& Remillard, 2002; Enyedy \& Mukhopadhyay, 2007; Morrison et al., 2008, Young, 2010). 
Content standards and standards-based exams.

The second theme within the element was related to the degree of alignment between the Algebra Project curriculum and the state's Algebra I Content Standards. Closely connected to this were the teachers' attempts to manage discrepancies between the two, particularly as they prepared students for the standards-based exams.

A study of the transcripts revealed the teachers tended to conceptualize the Algebra Project curricula, the state's content standards and the standards-based exams as discrete components. Rather than describing the relationships between these three as interconnected, and complimentary components related to mathematics instruction in their classrooms, the teachers alluded to a number of underlying tensions and inherent conflicts, as noted in the following passage with Cameron:

I: $\quad$... To what extent is the (Algebra Project) curricula aligned with the California standards?

Cameron: It's not.

I: It's not. Yeah. How do you get around that as a teacher? How do you, how do you attempt to reconcile that?

Cameron: There's a lot of standards ... I mean, we're obviously accountable to those, because we want to be in compliance and, you know, (be) responsible...

Our concept of algebra, we hope, goes much deeper than the procedural skills ... So we get around it (the standards) just by teaching them (the students) how to see some of these problems ... in a different way, deconstructed... 
I mean, they're really only given these problems on the standardized tests (Algebra I CST), and then on these benchmarks (district assessments) that we're supposed to give. But the idea is that most of these skills can be reduced to plugging it in and figuring it out, especially on a multiple choice test ...

And that's part of the reasoning skills that we want our students to develop anyway, so that's kind of ... my framework of how I can get around these things, specific things that, you know, I didn't remember, even loving math. I never remembered until I had to ... for the CSET.

Two points are of particular interest from this passage. First, the teacher acknowledged a lack of congruence between the Algebra Project's curriculum and the state's content standards. Lee's (1998) claim that students can perform at rigorous levels on standardized algebra exams via Algebra Project curriculum assumes one important and related point - that there is a strong correlation between what is taught and what is assessed on the tests. Results from this study suggest simple exposure to a culturally relevant curriculum is not enough on its own to result in higher test scores, particularly if the concepts or skills assessed on the test are not a part of the Algebra Project's curriculum.

Second, while the teacher acknowledged the importance of trying to present all of the algebra content standards to the students, at the same time he hinted at some underlying conflicts between the Algebra Project's curriculum and the types of questions typically used on standardized exams. This teacher believed that the skills evaluated on standardized assessments could often be reduced to a "plugging it in 
approach." As argued by the teacher, this is contrasted with the Algebra Project curriculum that emphasizes reasoning skills and a more conceptual understanding of topics. While it seems reasonable to assume that the development of such skills in students would translate to higher test scores on an exam, this is not necessarily true. Rather, as Cameron implied, the disconnect may be related to the limitations of the types of questions that are often employed on multiple-choice assessments used to measure academic performance. Here it should be noted that the lack of academic growth represented in the test scores does not necessarily mean that the students were not engaged in meaningful learning experiences related to algebra in the classroom.

Having noted this, however, Mary also shared similar concerns regarding the program's alignment to the state's standards. As with Cameron, she also drew connections between the curriculum, the standards and preparing students for exams, as noted in the passage below:

I: $\quad \quad \ldots$ Do you know if the Algebra curriculum from Algebra Project Program is aligned to the California state standards?

Mary: Not at all.

Not at all. And so we...that was the other sort of decision that we made when we were going to start doing it, was that we would not be aligned to California Standards.

And we spent a lot of time on test prep to try and incorporate that stuff before the CST. And that's what... why I am once again doing test prep now. 
Of interest from Mary's passage was the suggestion that the department was: a) aware of the discrepancies prior to the adoption of the program, and b) that the decision making authority for the implementation of curricular programs rested with the school site (as opposed to the district's Academics and Professional Development department). While empowering teachers to shape curriculum specific to their student population is an essential aspect of culturally relevant pedagogy, recent research has also noted the importance of ensuring that students also have access to rigorous, high quality mathematics curriculum (Horn, 2008; Lubienski, 2002b; Schiller, Schmidt, Muller, \& Houang, 2010; Schoenfeld, 2004). Of note from Schiller's et al. work was the conclusion that differences in learning opportunities (as represented via different curricular materials and course offerings) may be a major contributor to the persistent achievement gaps in mathematics. Germane to this research was their conclusion that differences in the quality of mathematics curricula are also correlated to students' socioeconomic status and their parents' level of education.

Evidence from the teacher interviews suggested that, while the teachers were aware that the Algebra Project curriculum was not aligned to the state's content standards, they also believed that the experiential approach and an embedded emphasis on reasoning skills, provided students with a deeper understanding of particular mathematical topics. Additionally, teachers were challenged with ensuring that 
standards-based content material was presented, while trying to stay true to the program's experiential and culturally relevant curriculum. Connected to this point is recent research suggesting that such challenges may be partially the result of teacher preparation programs that do not provide sufficient training for new teacher candidates on infusing cultural elements into the mathematics classroom (Gutierrez, 2009; Kress, 2005; Leonard et al., 2010; Young, 2010).

Finally, combined with the results of the test score analysis presented in chapter 4, the evidence from the teachers' interviews suggested that continued development of the Algebra Project's curriculum, particularly around the articulation and alignment with the state's Algebra I content and performance standards, might be beneficial to both practitioners and students. While a full curricular assessment and mapping is beyond the scope of this research, future investigation into the strengths and weaknesses of the Algebra Project curriculum, relative to states' algebra content standards (or the new Common Core States' Standards), might represent a significant contribution to the literature and provide meaningful guidance to those working on curricular development. Investing and taking a personal responsibility in students' success As noted in Table 37, the element with the second largest number of references from the teacher interviews was "Investing and taking a personal responsibility in students' success." This element refers to instances in which teachers go above and beyond the required classroom duties, make themselves accessible to students during 
non-school hours, and pursue professional development through self-initiated study to integrate culturally relevant practices (Morrison et al., 2008). Several of the passages from both teachers' interviews were coded to such instances.

After the initial coding, these individual references were then analyzed for further study. Although somewhat more varied than the first element, the responses displayed: the teachers' personal connection to students; the fostering of student understanding in the classroom; commitment to teaching; on-going curricular development and training; and the importance of establishing personal connections with students. For example, after being asked how his approach to working with students had changed as a result of implementing the Algebra Project curriculum, Cameron explained:

...I wasn't satisfied with the way my students were judged on the test (Algebra I CST), you know, and the labels that were put on them. And then, I also didn't like the way that I was grading them because everyone was failing my class, and it wasn't that hard. Like, I found that the students that I serve, that I work for, don't play by the rules that I played by when I was in school. And that's not to put them down, and that's not to put me on a higher pedestal, but it really is a reality check that our worlds are different. You know, within the same society, within the same geographical location, our worlds are so different, that if we're not going to impart any sort of relevant knowledge to them, then we're basically keeping them out the door. And I was affirmed the more I spoke to Algebra Project people that had been around a long time, that the goal is not to, you know, get all of the prizes at the end. The goal is to know something.

Four key points are taken from this passage to highlight the connections to this element.

The first was the teacher's lack of satisfaction with the status quo in regards to how his 
students were graded in his classes and judged by the state's assessments. Closely connected to this was his willingness to reflect upon his practice and delivery of material. After concluding that his instructional methods were not effective for his group of students, he sought to modify his instructional practice, eventually settling on the Algebra Project as a means of trying to connect the content more closely to the students' lives.

Second, was the teacher's description of his relationship to his students as one of service. While this conceptualization of the student/teacher relationship also has strong links to one of the other elements (Sharing Power in the Classroom) from the framework, and implies a more reciprocal relationship in the classroom, it also serves to underscore the level of personal commitment the teacher invested into working with his students. Interestingly, as will be detailed in the subsequent student focus group analysis, there was supporting evidence that the Algebra Project students were aware of this more equitable student/teacher power dynamic in the classroom, especially when compared to the Non-Algebra Project cohort.

Third, was the implied acknowledgement of the separate worlds that students live in, especially compared to the middle-class backgrounds of teachers and the culture of school, and how this disconnect partially contributes to the achievement gap for students from lower socio-economic backgrounds. Also of note, coupled with this 
sentiment was the understood obligation on the part of educators to offer engaging and relevant educational experiences in an attempt to bridge this gulf.

The final point from this passage was Cameron's implicit description of meaningful learning (“The goal is to know something") - a vision in which successful learners are not defined simply by the results on standardized exams or by grades, but rather by the acquisition of knowledge and the self-actualization that it engenders in the students. In this way, Cameron's conceptualization of the importance of learning algebra, particularly for his disenfranchised students, shares similarities with a number of other significant works on liberatory and emancipatory practices in the mathematics classroom (Gutierrez, 2009; Gutstein 2007; Leonard et al., 2010; Martin 2008; Stinson, 2009).

Combined, these four references from this passage serve to highlight the passion and depth of personal commitment that this teacher brought to his work. Additional analysis of the data from this element revealed that: both of the Algebra Project teachers tended to measure their own success in relation to the relative growth and personal development of their students (as opposed to test scores); the Algebra Project teachers took personal responsibility for their students' success in a variety of ways; and both teachers continued to pursue additional training and professional development to strengthen their practice. 


\section{Summary and Synthesis}

In summarizing the data; when the transcripts from the Algebra Project teachers' interviews were coded against Morrison's et al. framework of culturally relevant pedagogy, the two elements that received the largest number of references were "Reshaping the prescribed curriculum" and "Investing and taking personal responsibility for students' success."

Further analysis of the "Reshaping the prescribed curriculum" element revealed that, although the teachers had participated in several of professional development sessions on the implementation of the Algebra Project curriculum, they were required to spend significant amounts of extra time to develop and refine the curriculum materials prior to presenting them to students. Additionally, this extra time spent on curriculum development produced some measure of stress and anxiety for the teachers and came at the expense of the development of the community engagement portion of the program. Full community involvement (through the development of the site's Young People's Project, tutoring sessions at a local elementary school, and the engagement of the school's community through family math nights) represented ongoing work for the site. Additionally, in their descriptions of the articulation between the Algebra Project curriculum, the Algebra I Content Standards, and the Algebra I CST exam, the teachers reported weak connections. 
Despite these challenges and limitations of the Algebra Project's curriculum, further study of the "Investing and taking personal responsibility for students' success" element revealed that the teachers were committed to improving their students' personal and academic success and to the integration of culturally relevant practices into their classroom.

\section{Student Focus Groups}

Subsequent to the teacher interviews, two student focus groups were conducted after the results of the Algebra I CST and MAI had been analyzed. While the focus group questions were selected from a bank developed prior to the start of the study, the analysis of the qualitative data collected during the focus groups attempted to build upon the emerging understanding of the quantitative data, as well as the data from the teacher interviews. The student focus group transcripts were coded and analyzed using an open coding technique for emerging themes. After the digital recordings were transcribed, a comprehensive data index of 46 themes was developed through an iterative process in which the transcripts were carefully reviewed, highlighted, coded and finally indexed.

Through several re-readings, overlapping categories were collapsed and combined until 6 themes were identified (see Appendix F for details). Further pruning to three major themes was achieved by analyzing the frequency of responses, the strength of the relationship to the quantitative and qualitative data, and the connections 
to the existing literature. Specifically this included the knowledge that the implementation of Algebra Project did not result in statistically significant changes in the students' CST scores (Algebra I CST analysis from Question 1), but did result in differences on several individual attitudinal questions (Value, Motivation, Anxiety and Enjoyment from the MAI analysis in Question 2).

The three major themes revealed during the student focus group sessions were: Student Affect \& Voice; Curriculum \& Instruction; and Student Discipline \& Equity. Generally speaking, the student responses from these sessions pointed to affective differences between the two cohorts that were not detected in the results of the MAI survey. In an attempt to develop these differences and build upon the quantitative and qualitative data, the themes are presented in the sections that follow. Prior to this, a brief overview of the mathematics course sequence is presented.

Historically in California, the mathematics course sequence in high schools has included having students taking Algebra I in $9^{\text {th }}$ grade, followed by Geometry in $10^{\text {th }}$ grade, Advanced Algebra in $11^{\text {th }}$ grade and Pre-Calculus in $12^{\text {th }}$ grade. However, in the past decade this traditional sequence has been adjusted as educators have attempted to provide more opportunities for students to take advanced mathematics courses (primarily Advanced Placement Statistics and Calculus) by the time they complete high school. Essentially, this change has translated to shifting the mathematics course offerings down one grade level. Although the implementation of this initiative is still 
somewhat dependent upon the district or school in question, and has not taken place without a number of challenges and concerns (EdSource, 2011), students now typically begin this course sequence earlier by taking Algebra I in $8^{\text {th }}$ grade. This shift, coupled with the inclusion of Algebra I as a graduation requirement, has resulted in several interesting effects. Framed in terms of this paper, most of the students involved in this research study were already behind one full academic year in terms of the recommended course sequence ${ }^{13}$. Additionally, evidence gathered during the course of this study also indicated that some students were even further behind. Although excluded from the dataset during the quantitative analysis in chapter 4 to help ensure fair comparisons between the cohorts, several of the participants in the focus groups were taking Algebra I as $10^{\text {th }}$ grade students. While their personal circumstances and stories varied, it was alarming to discover that a number of the students were enrolled in Algebra I for a third time (having taken the same course in $8^{\text {th }}, 9^{\text {th }}$, and $10^{\text {th }}$ grades).

\section{Student Affect \& Voice}

Several of the passages and references from the focus groups pointed to differences in the students' affective response to studying mathematics between the instructional models. Although the results from MAI were inconclusive on the six affective constructs, data from the focus groups suggested that several of the students had strong feelings about the instructional methodologies.

${ }^{13} 9^{\text {th }}$ grade students at high school should be enrolled in Geometry. 
This was particularly evident with a small sub-set of the Non-Algebra Project students who had experience in both curricular approaches at the study site. During the Non-Algebra Project focus group it was discovered that two students (both African American males) had previously been enrolled in the Algebra Project as $9^{\text {th }}$ grade students $^{14}$. As a part of the conversation with these students, they indicated a clear preference for the Algebra Project's instructional approach, as detailed below:

Vance: Well, yeah, up in that class (Algebra Project) ... I was learning hecka stuff, like, but like, it's like different kind of math. It's like two different kind of math. So that's why, up in here....I feel like last year, I should have learned the same thing I'm learning up in here, so I could know more by the time I'm in tenth grade.

I: $\quad$ Are they different?

Vance: It's way different. Like up in there (Algebra Project), like, we doing some other kind of stuff, like... up in there we was doing other kind of stuff, like. Not...not even math, like. It was...it's weird.

Ronnel: Yeah, but I learned so much...

Vance: Yeah, but like...we like...we learned hecka much.

Ronnel: He had us physically doing stuff with materials.

Vance: Okay, okay! Yeah, but up in there, we learned so much. But in here we learn, too, but a different kind of math. So like, so like we don't really get it like how we... what's supposed to be like...

${ }^{14}$ These two students had been enrolled as $9^{\text {th }}$ grade students in the Algebra Project classes, but had not completed the coursework the previous school year and had to repeat the algebra course. At the time of the study, they were $10^{\text {th }}$ grade students enrolled in a Non-Algebra Project class. 
Ronnel: Exactly, that's what I tried to say. It's like the stuff that I have learned is getting thrown out. And the new stuff that he's trying to teach us is getting shoved in my brain. So I don't know which is...it's different learning ways.

Vance: Exactly.

Ronnel: It's different ways of learning. And they both teach in different ways. So I'm like...

I: $\quad$ And you think it's different material?

Vance: It's way different.

Ronnel: It's way, way, way different.

Vance: If you go up in there right now, it's different.

Ronnel: That was way fun. I had so much fun in that class, I should have passed that class with flying colors. Well, I thought I was.

While the students were unable to fully articulate the differences between the curricular approaches, the two students who had exposure to both curricular models at the high school expressed a clear preference for the Algebra Project's instructional approach. Two key points are emphasized from this passage. The first is that these students believed that they were learning more material in the Algebra Project class, compared to their experiences in the Non-Algebra Project class ("We learned hecka much"). Additionally they describe being more engaged in the learning process and that it was more enjoyable than their learning experiences in their Non-Algebra Project class ("That was way fun. I had so much fun in that class"). 
Second, while these students explained that the Algebra Project was more enjoyable and engaging, they were also cognizant that the content presented in the Algebra Project class was significantly different than that in Non-Algebra Project classes ("It's way, way, way different"). According to these students, not only did the instructional delivery differ, so did the material or content. This second point is of particular interest, especially since it offers corroborating evidence to the data presented earlier, including: a) the Algebra I CST test score analysis showed a statistically significant effect in favor of a comparison group, and b) the teachers indicated that the Algebra Project did not match with the state's Algebra I content standards. Interestingly, the students who had the opportunity to experience both instructional models at the site were also able to detect differences in the content material as well ("I feel like last year (Algebra Project), I should have learned the same thing I'm learning up in here (Non-Algebra Project), so I could know more by the time I'm in tenth grade").

However, while these students' opinions are of interest, they represent a small sub-set of the rest of the students. Since these students are not given the option between the two curricular approaches, most lack the experience necessary to compare the instructional methodologies at this school site. Future study into the experiences of those students who have had exposure to both curricula might provide additional insight into students' affective response to the program. 
In addition to this relative preference for the Algebra Project's instructional approach, the theme of student voice in the mathematics classroom was also raised at several points during the focus groups. In particular, students from the Non-Algebra Project focus group expressed feeling: that they were forced into learning particular algebraic topics; that the more traditional student/teacher roles in the classroom limited their desire to engage in the material; and that they had limited voice in their learning process. The following exchange between two students in the Non-Algebra Project focus group highlighted the students' feelings around these related themes:

Ronnel: And at the same time, it's like we...we really don't have no choice (in the material presented or learning process). And I feel like if we have a... if we have a say in what we wanna do as a math class, I think that would make it more fun because we...he (the algebra teacher) hears everybody. Like he hears everybody optional opinion of what we should...we should learn.

Alisha: I know, instead of....

Ronnel: We don't get that. We gotta do whatever he tells us.

Alisha: ...Whatever he wants to teach.

Ronnel: Whatever...yeah.

Alisha: But why... why do that? He should, like, take it upon the class like...

Ronnel: If you all say so much is about the students, then we should have a say, some of us, too. 
Interestingly, while not every student in this focus group expressed a similar opinion, this theme was not developed at all by the students in the Algebra Project session.

Why these differences in the students' feelings were not more evident in the results of the MAI survey remains unclear. One possibility, mentioned earlier, is that very few students are given the opportunity to experience both curricular models at the high school level. Implementing a survey on different cohorts of students to measure differences in their affective response to curricular programs cannot account for student choice or preference between the two models. Another possibility involves a more detailed analysis and critique of the MAI tool itself. While the MAI survey instrument has been widely used by mathematics researchers for years (Tanner \& Chism, 1996; O'Callaghan, 1998; Lodree, 2005), future attempts to measure students' mathematical attitudes might benefit from a revised survey tool that included a re-vamped set of questions and additional domains. An updated instrument that included an equity-based construct would be of interest and may have detected a difference between the cohorts during the quantitative portion of the study.

\section{Curriculum \& Instruction}

The second major theme from the student focus group sessions was connected to curriculum and instruction. Although related at times to the students' description of their affective response to the study of algebra, during the sessions the students touched upon several key aspects specific to the curriculum and instruction in their classes. A 
comparison between the two cohorts revealed that students described their experiences in relation to the curriculum quite differently. For example, when asked to comment on their experiences learning algebra, the Algebra Project students tended to frame their explanations in terms of the experiential units and activities unique to its curriculum. These descriptions included direct references to several of the well documented experiential activities, including the Tripline and Road Coloring units. Also of note was the fact that the students were able to make connections between the activities and the underlying algebraic topics that were embedded into each of these units.

However, while these students framed their experiences in terms of these experiential units, and were able to link them to particular algebraic topics, at the same time it was unclear how completely the students understood the mathematical content embedded within the experiences, as hinted at in the following passage:

Jorge: Like things we've done, like Road Coloring (Algebra Project unit), and like, Circuits (Algebra Project unit) and everything, were pretty easy. Just that to...I guess, to like, to do all the steps, is difficult.

I: $\quad$ So correct me if I'm wrong, like Road Coloring and Circuits, those are some of the activities you guys have done, right? Is that right?

Jorge: $\quad$ Yes ...

I: Pamela? How's math going for you this year? I mean, what's been easy or what's been challenging?

Pamela: Math is hard and easy. Like the Road Coloring was easy, but the whole Tripline (Algebra Project unit) was hard. 
I: Okay, and Tripline's another one of the activities, right? Okay. Tonisha?

Tonisha: ... Like you know, Tripline was hard. The exponents, it's confusing. The exponents?

... Yeah, .... (another activity) Is cool. Road Coloring was easy. The rest is just alright.

I: Okay, okay, good. Marcus?

Marcus: Math is easy when I have an example; it's hard without an example.

I: Okay.

Marcus: Like, like with the Road Coloring, like, when I didn't have an example, like sometimes, I didn't know what to do.

Evidence from this portion of the transcript suggested that the experiential approach resonated with the students, but that some of the necessary connections between the methods used to teach the concepts, and the algebraic concepts themselves would have benefited from additional scaffolding and development. As the students explained later, they developed a more complete understanding of the content material when the teachers provided examples in addition to the ones contained in the Algebra Project worksheets.

Also of interest were the students' descriptions of what they considered to be mathematics. While some claimed that the experiential approach assisted their 
understanding of concepts, there was debate within the group regarding what actually constituted mathematics, as represented in the following passage:

Pamela: I didn't like the ... Tripline!

I: $\quad$ Okay.

Pamela: I don't like that one because it like...I felt like it had nothing to do with math.

I: $\quad$ Okay.

Pamela: Like it wouldn't make any sense. But I liked Road Coloring because like we would get up and do more activities than Road Trip.

I: That's interesting to hear you say that, Pamela. So why did you think that the Tripline wasn't really about math? Why do you think that?

Pamela: Because all we did was like look at the pictures and say, "Oh, how far did we get?" or "Where did we go?" We really didn't talk about nothing with math.

I: You don't think that's math?

Pamela: Nope.

I: $\quad$... Okay, no, that's good.

Jorge: Because like although we could use numbers for that, but just like count how many spaces we moved to this way or to that way...

I: $\quad$ Yeah, so did some people think that it was too basic?

Marcus: Yeah, but it is a part of math because it's distance, and it'll tell you how far you could go. 
However, while Marcus was able to justify the Tripline activity as valid mathematics to the rest of the group, a short while later in the session, when asked if the activities helped facilitate his understanding of the mathematical concepts, he admitted, "Some of them, but not all of them."

While the Algebra Project group frequently referenced these experiential activities, the Non-Algebra Project group described their experience in a more typical fashion. For example, when asked how the study of algebra was unfolding for them the students referenced a number of traditional algebraic topics and units, including graphing, inequalities, solving equations and polynomials. Additionally, there were few references to group work, problem solving or experiential activities as a part of their explanations. Finally, at one point in the discussion a student specifically called for the inclusion of more of these types of activities in his class, as noted in the passage below:

S: $\quad \ldots$ and then the other thing I liked, is when we did ... like a project when we had to make triangles and ... squares, but only using a string, like one piece of string. And I liked that.

I: $\quad$... Do you do a lot of those (activities)?

S: $\quad$ No, we need to.

Student Discipline \& Equity

The final theme that emerged from the focus group sessions was related to student discipline \& equity issues in the mathematics classroom. While several of these references represented answers to questions regarding race and ethnicity in the 
mathematics classroom, other instances were subtle, woven into the fabric of the larger conversation, and revealed only after repeated and careful micro-analysis of the digital audio recording and the transcripts. The most interesting of these was a troubling but powerful sub-text that developed among the participants during the course of the NonAlgebra Project focus group session. Embedded within the responses were insights into how students' co-constructed a racialized mathematics classroom, and how this influenced their developing sense of agency and mathematical identities.

Through a series of answers, statements, and interactions, the students in the Non-Algebra Project focus group worked to establish, maintain and reify a number of commonly held stereotypes related to student performance in mathematics classrooms. As the students (two Chinese males, two African American males, one Pacific Islander female) participated in the discussions they worked in concert with one another to coconstruct several cultural and racial stereotypes, subconsciously taking advantage of opportunities to send powerful signals to one another as the session unfolded. Collectively, these interactions painted a picture of a polarized Non-Algebra Project classroom, in which a racial hierarchy around mathematics performance was well understood, especially when compared the Algebra Project cohort. While likely more complex than the dynamic that developed between the small sample of students that participated in the focus group, its influence on students' development of agency and mathematical identity was intriguing and noteworthy. 
Immediately after the focus group started, the Non-Algebra Project group separated itself into two main camps and along racial lines - the Chinese students and the African American students (or those who felt an affinity with them ${ }^{15}$ ). At points during the session, a palpable tension and clear division was evident between the participants.

A review of the literature suggests that many of these student interactions and responses are best described as forms of microaggressions (Sue et al., 2008; Howard, 2008). As explained in Sue et al. (2008) Sue, Bucceri, Lin, Nadal and Torino (2007) defined microaggressions as:

... brief and commonplace daily verbal, behavioral and environmental indignities, whether intentional or unintentional, that communicate hostile, derogatory, or negative racial slights and insults to the target person or group, and are expressed in three forms: microassaults, microinsults and microinvalidations. (p. 330)

According to these researchers, all three forms of microaggressions are common in everyday discourse. As a part of their work, the authors developed working definitions for each form, with microassaults (the use of racial slurs and obvious acts of omission based on race) as the most obvious and egregious expression of microaggressions. However, the researchers also postulated that subtle microinsults and microinvalidations serve to undercut the legitimacy of individuals. Because they are slight, almost innocuous, and typically woven into the fabric of conversations that center on other

\footnotetext{
${ }^{15}$ Through her statements and interactions in the focus group session, it became clear that the Pacific Islander student sympathized with the African American students.
} 
issues and topics, they can be overlooked. As a result, their cumulative effect can also be easily underestimated. In defining these two types of microaggressions, Sue et al. explained:

Microinsults can be defined as actions (verbal, nonverbal, or environmental) that convey, insensitivity, are rude, or directly demean a person's racial identity or heritage. Microinvalidations are actions that exclude, negate or nullify the psychological thoughts, feelings or experiences of people of color. (p. 332)

As part of the development of a literature-based taxonomy used to code their data, they developed four microinsult and microinvalidation themes. The microinsult themes included: a) ascription of intelligence (assigning low or high intelligence on the basis of race), b) assumption of criminal status (belief a group is more prone to crime), c) pathologizing cultural values/communication styles, and d) second-class citizenship (treating others as lesser beings). Microinvalidation themes included: a) being alien in one's own land, b) color blindness, c) denial of personal racism, and d) the myth of meritocracy.

Close analysis of the transcripts and audio revealed several instances of microinsults and microinvalidations in the Non-Algebra Project cohort, beginning with the first question. The session began as Derrick, a Chinese-American student who happened to be seated immediately to the researcher's left, was asked to respond to the initial question of the session. 
I: $\quad$... How's math going for ya? What's been easy or what's been challenging in Algebra? Derrick, do you want to start us off?

(... African American student knocks three times on his desk ...)

Derrick: Uh...well, Algebra is going good for me. And some challenging things are, uh...doing hard problems....

(...interrupted by the Pacific Islander female student ....)

Alisha: They be hecka smart. They hecka smart.

(... Derrick ignores her attempting to answer the question ...)

Derrick: And uh...something easy for me is graphing.

I: $\quad$ Something easy is graphing?

Derrick: Right.

I: Okay. What's been hard for you, did you say?

Alisha: (... whispers to African American students ...) ... No ... (answering the interviewer's question...)

(...laughter and snickering from African American students...).

Derrick: Oh, uhhh...Doing those ...equality things.

I: Inequalities?

Derrick: Something like that.

Four points are highlighted in this microanalysis of this interaction. The first is the importance of the sub-text of the conversation between the participants. 
Immediately after the first question is posed, the participants worked to establish a clearly discernable non-verbal communication channel between the members of the group (signaled by the knocking on the desk). Here, the rapping seems to have served two primary purposes. First, the knocking was offered as a signal to others within the group that an element of the discussion was connected to part of a previously established and ongoing conversation between some of the group members. In this way, at least a few students in the group were alerted, while others were excluded beginning at the very start of the focus group session. Second, additional data collected during the course of the focus group suggested this knowing knock was connected to the order in which the students were asked to respond. ${ }^{16}$ The knock served notice to the rest of the members that this issue would be in play during the course of the interview. And in fact, it presented itself subtly several times over the course of the interview.

Second, the pattern of the students' responses was of interest. Simply, interruptions appeared to be an accepted norm within the group. While it is perhaps not surprising for adolescents to interrupt one another in the course of conversation, when compared to the student interactions in the Algebra Project group, this represented a striking difference between the cohorts. Interestingly, the session with the Non-Algebra Project comparison group actually begins with an interruption (via the knocking).

Close study of other portions of the transcripts and digital recording revealed several

\footnotetext{
${ }^{16}$ Derrick, the first student asked to respond, was a Chinese male. In some way the knocking may have also served as a mild protest directed towards the interviewer for selecting this student first.
} 
other instances of students interrupting, cutting other students short, or engaging in other non-verbal interactions designed to silence others in the group. Of additional interest was the fact that, almost without exception, these interruptions were initiated by the African American student group, who tended to dominate and control large portions of the focus group session. In this way, and somewhat paradoxically, the African American students used the focus group as a third space to air a number of grievances and concerns that they felt were not being addressed in the regular classroom setting. Additionally, their responses were contrasted by those from the Chinese students, who were more likely to describe themselves as successful in the algebra classroom, but who were also more reserved in sharing their thoughts and opinions in the focus group session.

The third was the subsequent interaction that took place after the Chinese student had responded to the initial question. Immediately after Derrick's answer, another student (Alisha) interjects, interrupting the student again. She begins by grouping the two Chinese students together, (indicated by the use of the word "they" and pointing during the session), even though the question had been posed to a single individual in the group. Closely connected to her declaration ("They be hecka smart") was the inherent stereotyping with the ascription of intelligence and ability in mathematics. This microinsult served to acknowledge an assumed privileged status on the part of some members in the group - with an implied connection to their racial 
identities. Also of interest from Alisha's statement was her unvoiced message to the rest of the group - that some members were not "hecka smart."

Finally, a few moments later, after the interviewer had asked the Chinese male if aspects of the algebra course had been challenging for him, the female student interrupted again, answering "No" for this student in a whisper to other participants. Her answer was met with laughter and snickering from the African American male students in the group, and resulted in a muted and truncated explanation by Derrick.

However, this was not the only instance in which the students worked in concert with one another to co-construct a picture of a racialized mathematics classroom. The microaggressions continued as a short while later the second Chinese student was posed with the same question:

I: $\quad$... What's been hard? Nothing? Okay.

(...African American student laughs...)

Alisha: Told you he's smart.

I: $\quad$ And you think Algebra's pretty easy?

(... Wright - Chinese male student nods silently....)

Okay.

Alisha: He isn't even supposed to be in our class. He's supposed to be in geometry.

I: $\quad$ Okay.... 


\section{(...”Oooouhhhh" by African American student)}

Again in this passage the students appeared to work in concert to help reinforce a number of well established stereotypes with the ascription of proficiency in mathematics to the Chinese students in the group. In this instance this sentiment was also coupled with the female student's assertion that this second Chinese student did not even belong in the class. The inappropriateness of her comment, as well as an acknowledgement of the tone in her voice, was captured in the response of one of the other African American students in the group, as noted by the "Oooouhhhh".

This tension among the group members continued during the course of the conversation, ebbing and flowing depending upon the question and the student responding. The microaggressions became most pointed later during the session as the female student (Alisha) again brought up race in the context of differential treatment by the teacher. As with the previous passages, several microaggressions are evident in the following exchange:

I: He's (the algebra teacher) got a good sense of humor?

Alisha: Yeah. And then he helps us individually. But then, other parts I don't like. There's specific stuff I don't like. It's like when we (table of African American and Pacific Islander students) talk, and then... Like, oh, of course, like, we talk like 'cause it's the end of the day. Like that's all we want to do. You know? It's our last period of the day. So every time we talk and stuff, like he'll bother...like tell us and tell us, like yeah, constantly. But we'll stop at a point. But it's like, he'll always tell 
us, like, keep ragging up on us, and send us out of class, when it'll be like...a...a table like with them (Chinese students). Their table. Like they be making the most noise, and he don't do nothing. He don't...

I: Who's table? Who's ...

Alisha: THEIR TABLE (pointing to the Chinese students). It be like...I don't want to say, like, that's just rude, like....

I: Okay.

Alisha: ... Like a table full of Chinese people...

(... laughter and snickering from African American students...)

And then there'll be a table full of like, of the quiet people, but then they'll be...they'll make hecka noise, and he won't do nothing!

I: $\quad$ So if I understand it correctly, you think , uh,... you think there's some difference in how the teacher responds... responds to students from different racial backgrounds somehow?

Alisha: Yeah ....

Additional examples of microinsults and microinvalidations were evident throughout the transcript. While most of these instances involved inappropriate interruptions, asides to other members in the group, and laughter and snickering they culminated in an interesting difference between the group members by the end of the interview session. When this group of students was asked if they felt that race mattered in the mathematics classroom, all students in the African American camp adamantly agreed. However, when the two Chinese students were asked the same question, they 
both maintained that race had no influence. As Wright explained, "Well, you just come in the classroom and do the work and that's all."

Race and related discipline issues also presented themselves in the Algebra Project focus group; however, the discussion was significantly more balanced and equitable between the participants. While these students also alluded to differential treatment by teachers on classroom discipline matters, and made reference to race-based hierarchical stereotypes, instances of microaggressions among the participants were not evident. Interruptions were almost non-existent; students took turns as the conversation unfolded, and there were no documented instances of microassaults or microinvalidations between the students. Compared to the Non-Algebra Project focus group, the Algebra Project group's answers to the final question also revealed interesting differences:

I: Do you think it matters what race or ethnicity you are when it comes to learning math? Why or why not?

Tonisha: ( ... laughs ...)

Marcus: Yeah, because people come from different places. So like, yeah, so they might not...they might not have a better education before, like. So they probably didn't learn this before. It's new to them. It's basically new to them, like another language to them.

I: Okay. Like another language?

Marcus: Yeah, so they don't understand it. 
I: $\quad$ Okay.

Pamela: I'd say, no, it don't matter, because math is math. You get to all the...Some people have different ways of teaching it, but it still has to involve numbers and things. So if somebody is from another country or like, have similar things to what they do over there in their country.

I: $\quad$ Again, the question here is this: Do you think it matters what race or ethnicity you are when it comes to learning math? Why or why not?

Tonisha: No, because you're learning the same thing.

I: You're learning the same thing, you think?

Jorge: Sometimes...

Myron: What you mean by race?

Jorge: Some people are like...Some people are like fast. They're like...

Tonisha: Fast learners.

Jorge: They learn...fast learners. And other ones are kind of like slow. So they have to take things step by step.

I: $\quad$ Do you think it's connected to race, somehow, Jorge?

Jorge: It don't matter.

Tonisha: I don't think it matters.

Marcus: No, just 'cause we're different colors. We all got the same stuff, so it don't matter.

Three points are noted from this passage. First, Marcus (African American male) initially agreed that race mattered in the classroom, but linked the differences to the quality of the students' previous educational experiences. By the end of the 
discussion however, his interpretation of the question shifted from an understanding of systemic racism (as the result of differences in the quality of schools) to the conclusion that race was not connected to differences in an individual's cognitive ability.

Second, with the exception of one student (Myron - African American male), the students in the Algebra Project group indicated that race did not influence the study of mathematics. While the students acknowledged the importance and influence race in the classrooms, at some level the unanimity suggested that the group believed that they could all be successful in the mathematics classroom, regardless of race.

The third and final point is, that although the group had an active discussion about race in the mathematics classroom at points during the session, microaggressions were absent from the conversation. Also of note was the fact that the absence of microaggressions coincided with the unanimity on the lack of influence that race played in the mathematics classroom.

The differences in the microaggression patterns also have several connections to recent research on establishing equitable mathematics classrooms (Bartell, 2011; Boaler, 2008; Esmonde, 2009; Gresalfi et al., 2008; Howard, 2008). As part of a longitudinal study into efforts to implement group work and de-track mathematics classes at a high school, Boaler (2008) developed the concept of relational equity. In defining the term she wrote: 
This conception of equity (relational equity) also goes further than students' test results in schools and considers the ways students are acting in school and the ways they learn to regard and relate to one another. Unlike Anderson's conception of equity, relational equity is about students' relationships with other students and with subjects and with the intersection of the two ... (p. 14)

Boaler explained how the use of a cooperative grouping structures and the integration of a problem solving approach fostered relational equity between the students in the school's mathematics classes. Additionally, and of note to this study, were the connections between relational equity and culturally relevant practices. As she noted in her work, the commonly held assumption is that culturally relevant strategies and examples help to foster relational equity in classrooms. While her work did show that a well structured and uniformly implemented constructivist approach at a site could achieve the same effect, she noted:

It is commonly believed that students will learn respect for people from different cultures and circumstances if they learn through culturally relevant examples, or consider the history of different cultures. (p. 41)

As noted in the examples above, evidence collected during the course of the focus group sessions suggested that the culturally relevant approaches employed in the Algebra Project helped to foster more inclusive and positive relationships between students from different racial backgrounds and contributed to the absence of microaggressions. Continued study is recommended to discern which elements of the 
Algebra Project's program specifically contributed to the development of this important type of equity in the classroom.

\section{Summary and Synthesis}

Combined, the evidence from the student focus groups pointed to several affective differences between the two cohorts that were not detected through the quantitative measures. The first was that students who had experiences in both instructional methodologies at the site expressed a preference for the types of experiential learning activities contained in the Algebra Project classroom. However, at the same time, evidence suggested that while some preferred this instructional approach, they were also aware that the different methodologies did not present the same course content.

Second, when the Algebra Project students were asked to comment on their experiences in the classroom, they tended to frame their descriptions in terms of the experiential units. At points, they also hinted at difficulty in making connections to the underlying algebraic concepts embedded in these activities. Additionally, there was some debate over what constituted legitimate mathematical topics within this cohort. The Non-Algebra Project cohort was more likely to describe their experiences in terms of traditional algebraic units, and called for the inclusion of more engaging activities in their classes. Additionally, the Non-Algebra Project group expressed feeling limited voice in their classrooms, compared to the Algebra Project cohort. 
Finally, a significant difference was detected in the patterns of responses and relationships between the individuals in the two cohorts. The interactions among the Non-Algebra Project students contained several instances of microaggressions, and painted a picture of a racially polarized classroom in which stereotypes and were being reinforced. In clear contrast, the discussion with students in the Algebra Project cohort contained no examples of microaggressions among the participants. 
Chapter Six: Discussion and Recommendations

\section{Overview}

This study investigated the efficacy of the Algebra Project, cited in the literature as an example of a culturally relevant pedagogical approach used to teach students algebra. The research was conducted at a four-year college preparatory high school that serves a diverse student body in a metropolitan area in northern California.

Specifically, the study addressed three research questions:

1. Are there differences in students' performance between the instructional methodologies (Algebra Project v. non-Algebra Project) as measured by the Algebra I CST?

2. Are there differences in students' mathematical attitudes between the instructional methodologies (Algebra Project v. non-Algebra Project) as measured by Sandman's $(1973,1979)$ Mathematics Attitude Inventory (MAI) survey?

3. What additional factors impact the way students feel about the study of mathematics?

To answer these questions, the study employed a quasi-experimental, sequential, explanatory mixed-methods design, consisting of a retrospective analysis of standardized test scores and an investigation into students' affective responses.

\section{Interpretation of Findings}

Findings from the first research question revealed no evidence that the Algebra Project produced a statistically significant difference in the results on the Algebra I CST 
assessment, when compared to the Non-Algebra Project approach at the study site. Additionally, when controlled for the amount of instructional time, the Non-Algebra Project students at other high schools obtained statistically significant higher test scores compared to Algebra Project students. When controlled for the amount of instructional time and race, African American students did not show a statistically significant difference on the Algebra I CST, compared to those enrolled in a Non-Algebra Project curriculum. Therefore, the study's original hypothesis (that the Algebra Project would result in a favorable, statistically significant difference on students' Algebra I CST scores) was not substantiated for the three different trials.

From the second research question, individual item analysis of the Mathematics Attitudinal Inventory (MAI) results revealed statistically significant differences in four of the 48 questions (two questions at $\alpha=0.10$ and two questions at $\alpha=0.05$ ), with three of the four results in favor of the Non-Algebra Project group. In contrast, analysis did not indicate a statistically significant difference between the cohorts (Non-Algebra Project v. Algebra Project) for any of Sandman's six attitudinal constructs. This trend was established for both student trials: a) all language versions (English, Chinese and Spanish), and b) English Language versions only. The original hypothesis that a statistically significant difference on the MAI would be established in favor of the Algebra Project group was not substantiated for either trial. 
In summarizing the data from the Algebra Project teachers' interviews, generally speaking the data mapped onto Morrison's et al. framework to a high degree, Additionally, the two elements that received the largest number of references were a) "Reshaping the prescribed curriculum," and b) "Investing and taking personal responsibility for students' success.”

Further analysis of the first element revealed that teachers were spending significant amounts of extra time developing and refining the curriculum materials. The additional time required for this work resulted in elevated levels of stress and anxiety for the teachers and came at the expense of the development of the community engagement portion of the program. Finally, the teachers described poor articulation between the Algebra Project curriculum, the Algebra I Content Standards, and the Algebra I California Standards Test.

The second element revealed that despite these challenges with the curriculum materials, the Algebra Project teachers were committed to the integration of culturally relevant practices in their classrooms, as well as to improving their students' personal and academic success.

Evidence from the student focus groups pointed to several affective differences that were not detected in Mathematics Attitudinal Inventory results. Specifically, differences were found in three major themes: a) Student Affect \& Voice; b) Curriculum \& Instruction; and c) Student Discipline \& Equity. 
In the first theme, several students (from the Non-Algebra Project and Algebra Project cohorts) expressed a preference for the types of experiential learning activities contained in the Algebra Project program. However, some students were also aware that there were differences in the content between the two instructional methodologies. Additionally, the students in the Non-Algebra Project cohort were more likely to feel that they had limited voice in their classrooms, when compared to the Algebra Project cohort.

In the second theme, the Algebra Project students tended to describe their experiences in the algebra classroom in terms of the experiential units embedded in the curriculum. At the same time however, this group also expressed some difficulty in making connections to the underlying algebraic concepts. Additionally, at points some participants in this group expressed reservation over what constituted a legitimate mathematical topic. The Non-Algebra Project students, on the other hand, described their experiences in more typical terms, referencing several traditional algebraic topics and units.

In the third and final theme, a significant difference was detected in the patterns of responses and relationships between the members of the two cohorts. The interactions between the Non-Algebra Project students contained several instances of microaggressions among the participants, and painted a picture of a racially polarized mathematics classroom where racial stereotypes and hierarchies were reinforced. This 
was contrasted with the discussion in the Algebra Project cohort which contained no examples of microaggressions among the members, who instead displayed a higher degree of relational equity with one another.

The hypothesis that students would identify race as a factor related to their achievement and developing mathematical identities was proved to be partially true. However, data indicated that this hypothesis was likely conceptualized too narrowly prior to the start of the study. The evidence suggested that while some students believed that race played a role in the mathematics classroom, it was woven into several other factors that contributed to their feelings towards the study of algebra, including: the types of activities used to present the algebraic concepts; students' sense of the student/teacher power dynamic; student voice in the classroom; the strength of the curriculum relative to the content standards; the perceived differences related to student discipline in the mathematics classroom; and the extent to which these factors worked in combination with one another to develop strong connections among the students and to the algebra curricula.

Set against the existing research literature, the results from this study contradicted those presented in other studies that investigated the efficacy of the Algebra Project's curriculum, most notably those of Adair (1996), Carson \& Day (1995) and Nelson (1997). Additionally, the data confirmed the results reported by Sikorski et al. (1993), who described less favorable outcomes. 
From the standpoint of the study's conceptual frame, the data suggested that while the Algebra Project was grounded in several of the principles of culturally relevant pedagogy and critical pedagogy, a number of practical limitations precluded the program's full impact for students. Specifically, the students in the program had difficulty meeting high academic expectations (as measured on the Algebra I CST). Additionally, there was no effect on students' attitudinal responses (as measured via the MAI survey) when compared to students in the comparison group. Finally, issues related to ongoing curricular development for the teachers prevented students from fully participating in the types of community activities that may have promoted more libratory and emancipatory experiences by involving them in a variety of ways including: the Young People's Project, tutoring opportunities, and family math nights.

Having noted these connections, however, a number of delimitations to this study exist, including the relatively short history of the program in this school district, and the fact that the study rested on the efforts of a small group of teachers from a single site. Additional limitations were connected to data access issues. Future studies would benefit from access to students' socio-economic status (SES), attendance rates, students' discipline and transcript data, and parents' education levels. A longitudinal investigation into the long-term (persistence in mathematics) and cumulative effects of the Algebra Project (agency and mathematical identity) for students would benefit from 
access to these additional data-fields, and would help to fill the gaps left by this research.

\section{Implications}

The results of this study have several important implications for researchers, practitioners, and educational leaders. The first is that researchers continue to study the underlying factors related to the algebra achievement gap, and continue to work towards the identification of strategies and interventions that narrow this gap. While this study centered on the effects of a particular curricular approach designed to narrow the algebra achievement gap, as Boaler (2002) has noted, a singular approach is likely too limited for the complexities related to this challenge.

The second is that practitioners continue curricular reform efforts with an eye towards strengthening the articulation between process and content. While the results from this study revealed inherent challenges in the balance between the instructional strategies used to engage the students and a comprehensive coverage of the algebraic concepts, efforts to strengthen the Algebra Project's curriculum would likely translate to different results if this study was replicated or re-conceptualized as a design experiment (Cobb, Confrey, diSesa, Lehrer \& Schauble, 2003; Cobb, 2004; Gorard, Roberts, \& Taylor, 2004; Labato, 2003). Related to this point, the Algebra Project organization will likely have to re-work portions of their curricular materials, if one of their objectives is to improve students' academic achievement as measured by standardized 
exams. Here, specific emphasis is recommended on the alignment and articulation between the topics and curricular materials and the new Common Core States' Standards for algebra. Finally, in terms of implementing culturally relevant practices in mathematics classrooms, practitioners should carefully consider balancing how materials are presented with what concepts are included in the presentations. While the incorporation of culturally relevant, experiential activities into lessons should be considered, at the same time practitioners must also work to ensure that all concepts in the state's standards are presented to students.

The third implication is that educational leaders within school districts establish, and periodically review, the protocols and criteria for the evaluation, adoption, and implementation of curricula in their systems. Evidence from this study suggested that such review is especially important during the evaluation and adoption phases. Districts and schools should consider curricula carefully prior to their implementation to ensure that materials are aligned with strategic objectives and priorities (Lubienski, 2002b; Schiller et al., 2010). Finally, an increased emphasis on supporting and developing the community outreach components would likely serve to benefit the African American, Latino, and Pacific Islander students involved in the program.

\section{Recommendations for Action and Further Study}

Three specific recommendations are offered as a result of this study. The first recommendation is that the Algebra Project organization continues to allocate resources 
towards the development of their algebra curricular materials. Although their curriculum has been in existence for over 25 years, the data collected in this study (CST test scores, teacher and student transcripts) indicated that the materials lacked alignment with the California algebra standards and often required significant re-working by teachers. A more focused and deliberate attempt to produce a complete set of standards-aligned materials would strengthen curriculum significantly.

Although attempting to align the curriculum with the algebra content standards of 50 different states represents a daunting task, the timing of events at the national level actually offers a great opportunity for the organization. To date, the new Common Core States' Standards have been adopted by 47 states and territories. Although full implementation is still a few years away, teams of educators in districts across the country are currently studying how this change will impact their systems and practices. Perhaps more importantly, they are also beginning to analyze which curricular materials will best support the implementation of these new standards. If the organization were to capitalize on this transition with an update of their curricular materials, they stand to position themselves favorably in light of this coming reform. At the same time, in doing so they would increase the likelihood of the program's adoption by schools across the country. Finally, from a teacher's perspective, such a concerted effort to develop and fully align the curriculum would free teachers to focus their efforts on the development of the community involvement component of the program. 
The second recommendation is geared toward individual school sites, and is related to two systemic supports inherent in the Algebra Project's implementation at this site. Although not reported in the course of this research paper, additional data suggested that the Algebra Project students benefited from two tertiary support structures: a) student cohorts, and b) teacher looping. According to one of the teachers, the Algebra Project students benefited by progressing through the mathematics course sequence with the same student cohort for a period of several years, including through algebra, geometry and advanced algebra courses. The evidence suggested that this helped to provide the students with a support network as they progressed to more challenging mathematics content. Mary noted:

\author{
Mary: I think that's a big piece of it (student success in understanding a \\ particular math problem), is that they've been with the same kids in the \\ same room for three years. \\ I: $\quad$ With the same teacher? \\ Mary: With the same teacher. They feel safe.
}

Additionally, teacher looping offered another means of support, as several of the teachers moved with the student cohorts to the next course the following year (geometry or advanced algebra). Because of the way the program was implemented at this school site, it was not uncommon for the students to remain with the same teacher for multiple 
years. As Mary explained, both supports combined to benefit the students, making it more likely that they were promoted to the next course, as teachers knew what the students had mastered and where they had struggled the previous year. As such the teachers were in an excellent position to continue to provide additional scaffolding and support without losing students along the way.

Since these two strategies are not necessarily dependent upon the implementation a particular curriculum, practitioners may want to consider this recommendation as stand-alone support strategy designed to assist all students. Continued study into the benefits of student cohorts and teacher looping are also recommended.

The third and final recommendation is a call for continued investigation. Due in part to the limited accessibility to student data, continued study of the Algebra Project's full effect for students is recommended. Specifically, investigation into the program's connections to: a) students' attendance patterns, b) students' SES status, c) student discipline, d) parents' level of education, and e) persistence in studying mathematics all represent important avenues for continued study and research.

\section{Conclusion}

The persistence of the algebra achievement gap represents a significant challenge for students, practitioners, and researchers alike. Moses' point that students require strong algebra skills to participate as citizens in a modern, technologically 
driven world is even more urgent today than it was in the 1980's. While this investigation did not produce the results that had been hoped for, the persistent gap represented in students' test scores necessitates that researchers and practitioners continue to collaborate as they work to implement effective programs and instructional practices for all students. 


\section{References}

Adair, J. (1996). Priming the pump: A study of the Algebra Project and its impact on student achievement in mathematics. Unpublished doctoral dissertation, Michigan: UMI.

Andrew, L. (2007). Comparison of teacher educators' instructional methods with the constructivist ideal. The Teacher Educator, 42(3), 157-184.

Anderson, S. (1990). Worldmath curriculum: Fighting Eurocentrism in mathematics. The Journal of Negro Education, 59(3), 348-359.

Bartell, T. (2011). Caring, race, culture and power: A research synthesis toward supporting mathematics teachers in caring with awareness. The Journal of Urban Mathematics Education, 4(1), 50-74.

Berry, R. (2005). Voices of success: Descriptive portraits of two successful African American male middle school mathematics students. Journal of African American Studies, 8(4), 46-62.

Boaler, J. (1993). Encouraging the transfer of 'school' mathematics to the 'real world' through the integration of process and content, context and culture. Educational Studies in Mathematics, 25(1), 341-373.

Boaler, J. (2002). Learning from teaching: Exploring the relationship between reform curriculum and equity. The Journal for Research in Mathematics Education, 33(4), 239-258. 
Boaler, J. (2008). Promoting 'relational equity' and high mathematics achievement through an innovative mixed-ability approach. The British Educational Research Journal, 34(2), 167-194.

Boaler, J., \& Staples, M. (2008). Creating mathematical futures through an equitable teaching approach: The case of Railside school. Teachers College Record, $110(3), 608-645$.

Boaler, J., William, D., \& Zevenbergen, R. (2000). The construction of identity in secondary mathematics education. Unpublished paper delivered at the International Mathematics Education and Society Conference. Montechoro, Portugal.

Brenner, M. (1998). Adding cognition to the formula for culturally relevant instruction in mathematics. Anthropology \& Education Quarterly, 29(2), 214-244.

Cahnmann, M., \& Remillard, J. (2002). What counts and how: Mathematics teaching in culturally, linguistically, and socioeconomically diverse urban settings. The Urban Review, 34(3), 179-204.

California School District. (2010). Student achievement data 2009-2010 CD\#1. (Research and Accountability Department, CD-ROM, 2010 release).

Caracelli ,V., \& Green, J. (1993). Data analysis strategies for mixed-method evaluation designs. Educational Evaluation and Policy Analysis, 15(2), 195-207 
Carson, R., \& Rowlands, S. (2007). Strategies for Affecting the Necessary Course of Cognitive Growth as an Integral Part of Curricular and Instructional Planning. Interchange, 38(2), 137-165.

Carson, C., \& Day, J. (1995). Annual report on promising practice: How the Algebra Project eliminates the "game of signs" with negative numbers. San Francisco, California: Far West Regional Laboratory for Educational Research and Development.

Cervone, B. (2002). Learning outside the lines: Six innovative programs that reach youth. Office of Research and Improvement. W.K. Kellogg Foundation.

Checkley, K. (2001). Algebra and Activism: Removing the shackles of low expectations - A conversation with Robert P. Moses, Educational Leadership, 59(2), 6-11.

Clarke, D., Breed, M., \& Fraser, S. (2004). The consequences of a problem-based mathematics curriculum. The Mathematics Educator, 14(2), 7-16.

Cobb, N. (1994). The Chicago Algebra Project: A historical organizational case study. Unpublished doctoral dissertation, Michigan: Xerox University Microfilms.

Cobb, P. (2004). Mathematics, literacies, and identity. Reading Research Quarterly, 39(3), 333-337.

Cobb, P., Confrey, J., diSesa, A., Lehrer, R., \& Schauble, L. (2003). Design experiments in educational research. Educational Researcher, 32(1), 9-13. 
Corey, D., \& Bower, B. (2005). The experiences of an African American male learning mathematics in the traditional and the online classroom: A case study. The Journal of Negro Education, 74(4), 321-331.

Creswell, J., \& Plano-Clark, V. (2007). Designing and conducting mixed methods research. Thousand Oaks: Sage Publications.

Davis, F., Greene, J., \& West, M. (Undated). Improvement of Mathematics Literacy in African-American Students: Preparation for Algebra and High Mathematics. Unpublished project proposal, 1-13.

Davis, F. (2004). The Algebra Project - Social Movement \& Educational Intervention. Unpublished paper presented at the $10^{\text {th }}$ International Congress of Mathematics Education. Denmark.

Davis, J., \& Martin, D. (2008). Racism, assessment, and instructional practices: Implications for mathematics teachers of African American students. The Journal of Urban Mathematics Education, 1(1), 10-34.

Diamond, J., Randolph, A., \& Spillane, J. (2004). Teachers' expectations and sense of responsibility for student learning: The importance of race, class and organizational habitus. Anthropology and Education Quarterly, 35(1), 25-98.

Enyedy, N., \& Mukhopadhyay, S. (2007). They don't show nothing I didn't know: Emergent tensions between culturally relevant pedagogy and mathematics pedagogy. The Journal of the Learning Sciences, 16(2), 139-174. 
Esmonde, I. (2009). Ideas and identities: Supporting equity in cooperative mathematics learning. The Review of Educational Research, 79(2), 1008-1043.

Fraenkel, J., \& Wallen, N. (2009). How to design and evaluate research in education. Boston: McGraw-Hill Higher Education.

Freire, P. (2009). Pedagogy of the Oppressed. New York: Continuum International Publishing.

Funkhouser, C. (2003). The Effects of Computer-Augmented Geometry Instruction on Student Performance and Attitudes. Journal of Research on Technology in Education, 35(2), 163-175.

Gadanidis, G. (1994). Deconstructing Constructivism. The Mathematics Teacher, 87(2), 91-97.

Gay, G. (2000). Culturally responsive teaching: Theory, research and practice. New York: Teachers College Press.

Gee, J. (2004). Discourse analysis: What makes it critical? In R. Rogers (Ed.), An introduction to discourse analysis in education (p. 19-50). New Jersey: Lawrence Erlbaum Associates Inc.

Gorard, S., Roberts, K., \& Taylor, C. (2004). What kind of creature is a design experiment? The British Educational Research Journal, 30(4), 577-590.

Greeno, J. (2002). Students with competence, authority, and accountability. Affording intellective identities in classrooms. New York, New York: The College Board. 
Gresalfi, M., Martin, T., Hand, V., \& Greeno, J. (2009). Constructing competence: An analysis of student participation in the activity systems of mathematics classrooms. Educational Studies in Mathematics, 70(1), 49-70.

Gutstein, E. (2007). "And that's just how it starts": Teaching mathematics and developing student agency. Teachers College Record, 109(2), 420-448.

Gutstein, E., \& Peterson B. (2006). Introduction [Introduction]. In E. Gutstein \& B. Peterson, Rethinking mathematics: Teaching social justice by the number (p. 1-6). Wisconsin: Rethinking Schools.

Gutierrez, R. (2000). Advancing African American, urban youth in mathematics: Unpacking the success of one math department. The Journal of Education, 109(1), $63-111$.

Gutierrez, R. (2008). A 'gap-gazing' fetish in mathematics education? Problematizing research on the achievement gap. The Journal for Research in Mathematics Education, 39(4), 357-364.

Gutierrez, R. (2009). Embracing the inherent tensions in teaching mathematics from an equity stance. Democracy \& Education, 18(3), 9-16.

Hand, V. (2010). The co-construction of opposition in a low-track mathematics classroom. American Education Research Journal. 47(1), 97-132. 
Hines, M. (2008). African American children and mathematical problem solving in Texas: An analysis of meaning making in review. The National Forum of Applied Educational Research Journal, 21(3), 1-27.

Horn, I. (2008). Turnaround students in high school mathematics: Constructing identities of competence through mathematical worlds. Mathematical Thinking and Learning, 10(3), 201-239.

Howard, T. (2008). Who really cares? The disenfranchisement of African American males in preK-12 schools: A Critical Race Theory Perspective. Teachers College Record, 110(5), 954-985.

Hughes, S. (2003). An Early Gap in Black-White Mathematics Achievement: Holding School and Home Accountable in an Affluent City School District. The Urban Review, 35(4), 297-322.

Jacobson, K. (2000, April). Central tensions: A critical framework for examining high school mathematics and mathematics education. Unpublished paper presented at the Annual Meeting of the American Educational Research Association. New Orleans, LA.

Jones, E., \& Southern, T. (2003). Balancing Perspectives on Mathematics Instruction. Focus on Exceptional Children, 35(9), 1-16.

Kamii, M. (1990). Opening the algebra gate: Removing obstacles to success in college preparatory mathematics courses. Journal of Negro Education, 59(3), 392-406. 
Kamii, C., \& Ewing, J. (1996). Basing teaching on Piaget's constructivism. Childhood Education, 72(5), 260-264.

Kress, H. (2005). Math as a civil right: Social and cultural perspectives on teaching and teacher education. American Secondary Education, 34(1), 48-56.

Labato, J. (2003). How design experiments can inform a rethinking of transfer and vice versa. The Educational Researcher, 32(1), 17-20.

Ladson-Billings, G. (1995). But that's just good teaching: The case for culturally relevant pedagogy. Theory into Practice, 34(3), 159-165.

Ladson-Billings, G., \& Tate, W. (1995). Toward a critical race theory of education. Teachers College Record, 97(1), 47-68.

Ladson-Billings, G. (1997). It doesn't add up: African American students' mathematics achievement. The Journal for Research in Mathematics Education, 28(6), 697-708.

Lauzon, D. (2001, November). Gender differences in large scale, quantitative assessments of mathematics and science achievement. Unpublished paper presented at the Statistics Canada-John Deutsch Institute- WRNET conference on Empirical Issues in Canadian Education. Ottawa, Canada.

Lawrence-Lightfoot, S. (2005). Reflections on portraiture: A dialogue between art and science. Qualitative Inquiry, 11(1), 3-15.

Le, V., Stecher, B., Lockwood, R., Hamilton, L., Robyn, A., Williams, V., Ryan, G., Kerr, K., Martinez, J., \& Klein, S. (2006). Improving mathematics and science 
education: A longitudinal investigation of the relationship between reform-oriented instruction and student achievement. Santa Monica, CA: RAND

Lee, C. (1998). Culturally responsive pedagogy and performance-based assessment. The Journal of Negro Education, 67(3), 268-279.

Leonard, J., Napp, C., \& Adeleke, S. (2009). The complexities of culturally relevant pedagogy: A case study of two secondary mathematics teachers and their ESOL students. The High School Journal, 93(1), 3-22.

Leonard, J., Brooks, W., Barnes-Johnson, J., \& Berry, R. (2010). The nuances and complexities of teaching mathematics for cultural relevance and social justice. The Journal of Teacher Education, 61(3), 261-270.

Levine, D. (2001). Radical Equations. [Review of the book Radical Equations: Math Literacy and Civil Rights]. Rethinking Schools. Retrieved from http:// www.rethinkingschools.org/restrict.asp?path=archive/15_04/Mose154.shtml.

Lodree, A. (2005). The effects of animated agents with verbal audio on mathematics comprehension and attitudes towards mathematics and computers. Unpublished doctoral dissertation, University of Missouri - Columbia, United States.

Lubienski, S. (2002a). A closer look at Black-White mathematics gaps: Intersections of race and SES in NAEP achievement and instructional practices data. Journal of Negro Education, 71(4), 269-287. 
Lubienski, S. (2002b, April). Traditional or problem-centered mathematics? The choices of students and parents in one district. Unpublished paper presented at the Annual Meeting of the American Educational Research Association.

Lubienski, S., \& Bowen, A. (2000). Who's counting? A survey of mathematics education research 1982-1998. Journal for Research in Mathematics Education, 31(5), 626-634.

Martin, D. (2009). Researching race in mathematics education. Teachers College Record, 111(2), 295-338.

Matusov, E., \& Hayes, R. (2000). Sociocultural critique of Piaget and Vygotsky. New Ideas in Psychology, 18, 215-239.

Morrison, K., Robbins, H., \& Rose, D. (2008). Operationalizing culturally relevant pedagogy: A synthesis of classroom-based research. Equity \& Excellence in Education, 41(4), 433-452.

Moses, R., \& Cobb, C. (2001a). Radical equations: Civil rights from Mississippi to the Algebra Project. Boston: Beacon Press.

Moses, R., \& Cobb, C. (2001b). Organizing algebra: The need to voice a demand. Social Policy. 4-12.

Moses, R., Kamii, M., Swap, S., \& Howard, J. (1989). The Algebra Project: Organizing in the spirit of Ella. Harvard Educational Review, 59(4), 423- 443. 
National Center for Education Statistics (2009). The nation's report card: Mathematics 2009. (NCES 2010-451). Institute of Education Sciences, US Department of Education, Washington, DC.

Nelson, T. (1997). A case study analysis of Bob Moses' Algebra Project: A mathematics program for African-American middle school boys. Unpublished doctoral dissertation, Michigan: UMI.

Normore, A., Rodriguez, L., \& Wynne, J. (2007). Making all children winners: confronting social justice issues to redeem American's soul. Journal of Educational Administration, 45(6), 653-671.

O'Callaghan, B. (1998). Computer-intensive algebra and students' conceptual knowledge of functions. The Journal for Research in Mathematics Education, 29(1), 21-40.

Rech, J. (1994). A comparison of the mathematics attitudes of Black students according to grade level, gender and academic achievement. Journal of Negro Education, 63(2), 212-220.

Reeves, C. (2002). The Algebra Project - Improving Educational Outcomes for African American Students in the Rural South. Unpublished article in Gaining Ground: Council of Chief State School Officers, Washington, DC, 1-7. 
Reimer, M. (2009a). The achievement gulf in mathematics: There's no such thing as a free lunch effect. Unpublished paper, San Francisco State University, San Francisco, CA.

Reimer, M. (2009b). The mathematics achievement gulf: Sex, race \& numbers. Unpublished paper, San Francisco State University, San Francisco, CA.

Reimer, M. (2009c). Algebra attitudes - A mixed-methods study: "Because somehow the math is not liking my people": Capital D discourse, student agency and students ' mathematical attitudes at Taft Middle School. Unpublished paper, San Francisco State University, San Francisco, CA.

Reimer, M. (2009d). The Algebra Project - A Case Study: "Jackie talk too much" Capital D-Discourse, Developing Student Agency, and Students' Mathematical Identities at Sample High School. Unpublished paper, San Francisco State University, San Francisco, CA.

Riegle-Crumb, C. (2006). The pathway through math: Course sequences and academic performance at the intersection of race-ethnicity and gender. American Journal of Education, 113(11), 101-122.

Roach, R. (2004). From Mississippi to Miami - Florida International University recruits legendary civil rights activist Bob Moses and his nationally recognized math literacy project. Black Issues in High Education, 21(18), 28-31. 
Rosen, M., \& Wilson, K. (2008). Raising African American student achievement: California goals, local outcomes. Palo Alto, California: EdSource.

Sanders, R. (1995). A case study analysis of the Algebra Project's community development component. Unpublished doctoral dissertation, Teachers College: Columbia University.

Sandman, R. (1973). The development, validation, and application of a multidimensional mathematics attitude instrument. Michigan: Xerox University Microfilms.

Sandman, R. (1979). Mathematics Attitude Inventory User's Manual. Unpublished paper, Minnesota Research and Evaluation Center: University of Minnesota.

Sandman, R. (1980). The mathematics attitude inventory: Instrument and user's manual. Journal for Research in Mathematics Education, 11(2), 148-149.

Schiller, K., Schmidt, W., Muller, C., \& Houang, R. (2010). Hidden disparities: How courses and curricula shape opportunities in mathematics during high school. Equity \& Excellence in Education, 43(4), 414-433.

Schoenfeld, A. (1985, April). Students' beliefs about mathematics and their effects on mathematical performance. Unpublished paper presented at the Annual Meeting of the American Educational Research Association. Chicago. 
Schoenfeld, A. (2002, March). Looking for leverage: Issues of classroom research on "Algebra for All". Unpublished paper presented at the International Conference on the Teaching of Mathematics. Hersonissos, Greece.

Schoenfeld, A. (2004). The math wars. Educational Policy, 18(1), 253-286.

Sikorski, M., Wallace, R., Stariha, W., \& Rankin, V. (1993). School reform and the curriculum. New Directions for Program Evaluation, 1993(59), 81-93.

Silva, C., \& Moses, R. (1990). The Algebra Project: Making Middle School Mathematics Count. Journal of Negro Education, 59(3), 375-91.

Snipes, V., \& Waters, R. (2005). The mathematics education of African Americans in North Carolina: From the Brown decision to No Child Left Behind. Negro Educational Review, 56(2/3), 107-126.

Stinson, D. (2008). Negotiating sociocultural discourses: The counter-storytelling of academically (and mathematically) successful African American male students. American Educational Research Journal, 45(4), 975-1010.

Sue, D., Nadal, K., Capodilupo, C., Lin, A., Torino, G., \& Rivera, D. (2008). Racial microaggressions against Black Americans: Implications for counseling. The Journal of Counseling and Development, 86(3), 330-338.

Tanner, K., \& Chism, P. (1996). The effects of administrative policy on mathematics curricula, student achievement and attitudes. The High School Journal, 79(4), 315323. 
Tate, W. (1995). Returning to the root: A culturally relevant approach to mathematics pedagogy. Theory into Practice, 34(3), 166-174.

Tate, W. (2008). The political economy of teacher quality in school mathematics: African American males, opportunity structures, politics, and method. American Behavioral Scientist. 51(7), 953-971.

Telese, J. (1999a). Mexican American high school students' perceptions of mathematics and mathematics teaching. Hispanic Journal of Behavioral Sciences, 21(2), 154169.

Telese, J. (1999b, April). Social constructivism: Its role in algebra classrooms. Paper presented at the Annual Meeting of the Association of Mathematics Teacher Educators. Chicago, Illinois.

Terry, L., \& Rosen, M. (2011). Preparation, placement, proficiency: Improving middle grades math performance. Palo Alto, California: EdSource

Weinstein, G. (2004). Their side of the story: Remedial college algebra students. Mathematics and Computer Education, 38(2), 230-239.

West, M. (2007). The Algebra Project: Overview of research \& evaluation. Unpublished report, 1-5.

West, M., \& Davis, F. (2005). Research related to the Algebra Project's intervention to improve student learning in mathematics. Report prepared for the State of Virginia Department of Education, 1-8. 
White-Clark, R., DiCarlo, M., \& Gilchriest, N. (2008). "Guide on the side": An instructional approach to meet mathematics standards. The High School Journal, 91(4), 40-44.

Williams, A. (1994). An analysis of intervention programs used for the recruitment and retention of minority students in high school mathematics. Unpublished doctoral dissertation, Michigan: UMI.

Yates, D., Moore, D., \& Starnes, D. (2008). The practice of statistics. New York: W. H. Freeman and Company.

Young, E. (2010). Challenges to conceptualizing culturally relevant pedagogy: How viable is the theory in classroom practice? The Journal of Teacher Education, 61(3), 248-260. 
Appendices 
Appendix A

$9^{\text {th }}$ Grade Algebra I CST Test Scores from a California School District 
Table 1

Percentage of $9^{\text {th }}$ Grade Students Testing At or Above Proficient on the Algebra I CSTs from a California School District by Race/Ethnicity

\begin{tabular}{|c|c|c|c|c|c|c|c|}
\hline & 2004 & 2005 & 2006 & 2007 & 2008 & 2009 & 2010 \\
\hline African American & $\begin{array}{c}5.6 \% \\
(324)\end{array}$ & $\begin{array}{c}4.8 \% \\
(293)\end{array}$ & $\begin{array}{c}8.7 \% \\
(403)\end{array}$ & $\begin{array}{c}6.9 \% \\
(403)\end{array}$ & $\begin{array}{c}5.2 \% \\
(363)\end{array}$ & $\begin{array}{c}5.6 \% \\
(375)\end{array}$ & $\begin{array}{c}5.6 \% \\
(285)\end{array}$ \\
\hline Chinese & $\begin{array}{c}47.9 \% \\
(894)\end{array}$ & $\begin{array}{c}55.3 \% \\
(1020)\end{array}$ & $\begin{array}{c}51.2 \% \\
(955)\end{array}$ & $\begin{array}{c}46.6 \% \\
(872)\end{array}$ & $\begin{array}{c}51.6 \% \\
(924)\end{array}$ & $\begin{array}{c}50.7 \% \\
(827)\end{array}$ & $\begin{array}{c}50.2 \% \\
(596)\end{array}$ \\
\hline Latino & $11.2 \%$ & $\begin{array}{c}10.4 \% \\
(618)\end{array}$ & $\begin{array}{c}11.8 \% \\
(723)\end{array}$ & $\begin{array}{c}9.9 \% \\
(761)\end{array}$ & $\begin{array}{c}13.5 \% \\
(830)\end{array}$ & $\begin{array}{c}11.3 \% \\
(791)\end{array}$ & $\begin{array}{c}12.1 \% \\
(651)\end{array}$ \\
\hline White & $\begin{array}{c}40.0 \% \\
(200)\end{array}$ & $\begin{array}{c}36.3 \% \\
(251)\end{array}$ & $\begin{array}{c}41.0 \% \\
(212)\end{array}$ & $\begin{array}{c}41.0 \% \\
(212)\end{array}$ & $\begin{array}{c}43.8 \% \\
(203)\end{array}$ & $\begin{array}{c}37.8 \% \\
(193)\end{array}$ & $\begin{array}{c}32.4 \% \\
(173)\end{array}$ \\
\hline
\end{tabular}

Note: Actual counts stated in parentheses in each cell.

Table 2

Change in $9^{\text {th }}$ Grade Students Testing At or Above Proficient on the Algebra I CSTs from a California School District by Race/Ethnicity

\begin{tabular}{|c|c|c|c|}
\hline & 2004 & 2010 & Change \\
\hline African American & $5.6 \%$ & $5.6 \%$ & $0.0 \%$ \\
\hline Chinese & $47.9 \%$ & $50.2 \%$ & $3.7 \%$ \\
\hline Latino & $11.2 \%$ & $12.1 \%$ & $2.3 \%$ \\
\hline White & $40.0 \%$ & $32.4 \%$ & $-7.6 \%$ \\
\hline
\end{tabular}


Table 3

African American Achievement Gap Between $9^{\text {th }}$ Grade Students Testing At or Above Proficient on the Algebra I CSTs from a California School District

\begin{tabular}{|c|c|c|c|c|c|c|c|}
\hline & 2004 & 2005 & 2006 & 2007 & 2008 & 2009 & 2010 \\
\hline Chinese - African American & $42.3 \%$ & $50.3 \%$ & $42.5 \%$ & $39.7 \%$ & $46.4 \%$ & $45.1 \%$ & $44.6 \%$ \\
\hline Latino - African American & $5.6 \%$ & $5.6 \%$ & $3.1 \%$ & $3.0 \%$ & $8.3 \%$ & $5.7 \%$ & $6.5 \%$ \\
\hline White - African American & $34.4 \%$ & $31.5 \%$ & $32.3 \%$ & $34.1 \%$ & $38.6 \%$ & $32.2 \%$ & $26.8 \%$ \\
\hline
\end{tabular}


Appendix B

Mathematics Attitudinal Inventory (MAI) Survey

Spanish Version

Chinese Version 


\begin{tabular}{|c|c|c|c|c|}
\hline & $\begin{array}{l}\text { Totalmente } \\
\text { Acuerdo }\end{array}$ & Acuerdo & $\begin{array}{l}\text { No de } \\
\text { Acuerdo }\end{array}$ & $\begin{array}{l}\text { Totalmente } \\
\text { no de } \\
\text { Acuerdo }\end{array}$ \\
\hline $\begin{array}{l}\text { 1. Las matemáticas son útiles para los problemas que } \\
\text { pasan cada día. }\end{array}$ & $\mathrm{O}$ & $\mathrm{O}$ & $\mathrm{O}$ & $\mathrm{O}$ \\
\hline 2. Las matemáticas son algo que disfruto mucho. & $\mathrm{O}$ & 0 & $\mathrm{O}$ & $\mathrm{O}$ \\
\hline $\begin{array}{l}\text { 3. Me gustan los problemas de matemáticas que sean } \\
\text { fácil. }\end{array}$ & O & $\mathrm{O}$ & $\mathrm{O}$ & $\mathrm{O}$ \\
\hline 4. Yo no saco muy buenos grados en matemáticas. & $\mathrm{O}$ & $\mathrm{O}$ & $\mathrm{O}$ & $\mathrm{O}$ \\
\hline $\begin{array}{l}\text { 5. Mi maestro de matemáticas muestra poco interés en } \\
\text { sus estudiantes. }\end{array}$ & $\mathrm{O}$ & $\mathrm{O}$ & $\mathrm{O}$ & $\mathrm{O}$ \\
\hline 6. Calcular problemas de matemáticas es fácil para mi. & $\mathrm{O}$ & $\mathrm{O}$ & $\mathrm{O}$ & $\mathrm{O}$ \\
\hline 7. Me siento a gusto en una clase de matemáticas. & O & $\mathrm{O}$ & $\mathrm{O}$ & $\mathrm{O}$ \\
\hline 8. Me gustaría leer sobre matemáticas a fuera de clase. & $\mathrm{O}$ & $\mathrm{O}$ & $\mathrm{O}$ & $\mathrm{O}$ \\
\hline $\begin{array}{l}\text { 9. Hay poca necesidad para matemáticas en la mayoría } \\
\text { de los trabajos. }\end{array}$ & $\mathrm{O}$ & $\mathrm{O}$ & $\mathrm{O}$ & $\mathrm{O}$ \\
\hline 10. Las matemáticas son fáciles para mi. & $\mathrm{O}$ & $\mathrm{O}$ & $\mathrm{O}$ & $\mathrm{O}$ \\
\hline $\begin{array}{l}\text { 11. Cuando oigo la palabra matemáticas, yo siento } \\
\text { disgusto. }\end{array}$ & $\mathrm{O}$ & $\mathrm{O}$ & $\mathrm{O}$ & $\mathrm{O}$ \\
\hline $\begin{array}{l}\text { 12. La mayoría de las personas deben estudiar las } \\
\text { matemáticas. }\end{array}$ & $\mathrm{O}$ & $\mathrm{O}$ & $\mathrm{O}$ & $\mathrm{O}$ \\
\hline $\begin{array}{l}\text { 13. Me gustaría dedicar menos tiempo en la escuela } \\
\text { estudiando las matemáticas. }\end{array}$ & $\mathrm{O}$ & $\mathrm{O}$ & $\mathrm{O}$ & $\mathrm{O}$ \\
\hline $\begin{array}{l}\text { 14. A veces yo me adelanto leyendo nuestro libro de } \\
\text { matemáticas. }\end{array}$ & $\mathrm{O}$ & $\mathrm{O}$ & $\mathrm{O}$ & $\mathrm{O}$ \\
\hline $\begin{array}{l}\text { 15. Las matemáticas nos ayudan entender el mundo de } \\
\text { hoy. }\end{array}$ & $\mathrm{O}$ & $\mathrm{O}$ & $\mathrm{O}$ & $\mathrm{O}$ \\
\hline $\begin{array}{l}\text { 16. Generalmente yo entiendo de lo que hablamos en la } \\
\text { clase de matemáticas. }\end{array}$ & O & $\mathrm{O}$ & $\mathrm{O}$ & $\mathrm{O}$ \\
\hline $\begin{array}{l}\text { 17. Mi maestro de matemáticas hace que las clases sean } \\
\text { interesante. }\end{array}$ & $\mathrm{O}$ & $\mathrm{O}$ & $\mathrm{O}$ & $\mathrm{O}$ \\
\hline 18. Yo no disfruto ni una cosa de las matemáticas. & $\mathrm{O}$ & $\mathrm{O}$ & $\mathrm{O}$ & $\mathrm{O}$ \\
\hline $\begin{array}{l}\text { 19. No importa cuanto esfuerzo le ponga, yo no } \\
\text { entiendo las matemáticas. }\end{array}$ & 0 & 0 & 0 & 0 \\
\hline
\end{tabular}




\begin{tabular}{|c|c|c|c|c|}
\hline & $\begin{array}{l}\text { Totalmente } \\
\text { Acuerdo }\end{array}$ & Acuerdo & $\begin{array}{l}\text { No de } \\
\text { Acuerdo }\end{array}$ & $\begin{array}{l}\text { Totalmente } \\
\text { no de } \\
\text { Acuerdo }\end{array}$ \\
\hline $\begin{array}{l}\text { 20. Yo me siento tenso cuando alguien habla conmigo } \\
\text { sobre las matemáticas . }\end{array}$ & $\mathrm{O}$ & $\mathrm{O}$ & $\mathrm{O}$ & $\mathrm{O}$ \\
\hline $\begin{array}{l}\text { 21. Mi maestro de matemáticas presenta la materia } \\
\text { claramente. }\end{array}$ & $\mathrm{O}$ & $\mathrm{O}$ & $\mathrm{O}$ & $\mathrm{O}$ \\
\hline $\begin{array}{l}\text { 22. Muchas veces yo pienso, "Yo no puedo," cuando un } \\
\text { problema matemático parezca difícil. }\end{array}$ & $\mathrm{O}$ & $\mathrm{O}$ & $\mathrm{O}$ & $\mathrm{O}$ \\
\hline $\begin{array}{l}\text { 23. Las matemáticas son de gran importancia en el } \\
\text { desarrollo de un país. }\end{array}$ & $\mathrm{O}$ & $\mathrm{O}$ & $\mathrm{O}$ & O \\
\hline $\begin{array}{l}\text { 24. Es importante conocer las matemáticas para obtener } \\
\text { un buen trabajo. }\end{array}$ & $\mathrm{O}$ & $\mathrm{O}$ & $\mathrm{O}$ & $\mathrm{O}$ \\
\hline 25. No me molesta resolver problemas de matemáticas. & $\mathrm{O}$ & $\mathrm{O}$ & $\mathrm{O}$ & $\mathrm{O}$ \\
\hline $\begin{array}{l}\text { 26. Me gustaría un trabajo que no hace uso de las } \\
\text { matemáticas. }\end{array}$ & $\mathrm{O}$ & $\mathrm{O}$ & $\mathrm{O}$ & $\mathrm{O}$ \\
\hline $\begin{array}{l}\text { 27. Mi maestro de matemáticas sabe cuando estamos } \\
\text { teniendo problemas con la tarea. }\end{array}$ & $\mathrm{O}$ & $\mathrm{O}$ & $\mathrm{O}$ & $\mathrm{O}$ \\
\hline $\begin{array}{l}\text { 28. Me gusta hablar con otras personas acerca de las } \\
\text { matemáticas. }\end{array}$ & $\mathrm{O}$ & O & $\mathrm{O}$ & $\mathrm{O}$ \\
\hline 29. Me gusta jugar los juegos que utilizan números. & $\mathrm{O}$ & $\mathrm{O}$ & O & $\mathrm{O}$ \\
\hline $\begin{array}{l}\text { 30. Soy bueno para resolver los problemas de } \\
\text { matemáticas. }\end{array}$ & $\mathrm{O}$ & $\mathrm{O}$ & $\mathrm{O}$ & $\mathrm{O}$ \\
\hline $\begin{array}{l}\text { 31. Mi maestro no parece disfrutar el enseño de las } \\
\text { matemáticas. }\end{array}$ & $\mathrm{O}$ & $\mathrm{O}$ & O & $\mathrm{O}$ \\
\hline $\begin{array}{l}\text { 32. A veces trabajo mas problemas de matemáticas que } \\
\text { son asignados en la clase. }\end{array}$ & $\mathrm{O}$ & $\mathrm{O}$ & $\mathrm{O}$ & $\mathrm{O}$ \\
\hline $\begin{array}{l}\text { 33. Se puede vivir perfectamente bien la vida sin las } \\
\text { matemáticas. }\end{array}$ & $\mathrm{O}$ & $\mathrm{O}$ & $\mathrm{O}$ & $\mathrm{O}$ \\
\hline 34. Trabajar con números me molesta. & $\mathrm{O}$ & $\mathrm{O}$ & O & $\mathrm{O}$ \\
\hline $\begin{array}{l}\text { 35. Me acuerdo la mayor parte de cosas que aprendo en } \\
\text { mis clases de matemáticas. }\end{array}$ & O & O & O & $\mathrm{O}$ \\
\hline $\begin{array}{l}\text { 36. Me pone nervioso no mas pensar en hacer las } \\
\text { matemáticas. }\end{array}$ & $\mathrm{O}$ & $\mathrm{O}$ & $\mathrm{O}$ & $\mathrm{O}$ \\
\hline $\begin{array}{l}\text { 37. Yo prefiero que me den la repuesta correcta a un } \\
\text { problema de matemáticas que resolverlo yo mismo. }\end{array}$ & $\mathrm{O}$ & $\mathrm{O}$ & O & $\mathrm{O}$ \\
\hline $\begin{array}{l}\text { 38. La mayoría de las ideas en matemáticas no son muy } \\
\text { útiles. }\end{array}$ & 0 & O & O & 0 \\
\hline
\end{tabular}




\begin{tabular}{|c|c|c|c|c|}
\hline & $\begin{array}{l}\text { Totalmente } \\
\text { Acuerdo }\end{array}$ & Acuerdo & $\begin{array}{l}\text { No de } \\
\text { Acuerdo }\end{array}$ & $\begin{array}{l}\text { Totalmente } \\
\text { no de } \\
\text { Acuerdo }\end{array}$ \\
\hline 39. Me da miedo a tomar clases de matemáticas. & $\mathrm{O}$ & $\mathrm{O}$ & $\mathrm{O}$ & O \\
\hline $\begin{array}{l}\text { 40. Mi maestro de matemáticas esta dispuesto a dar } \\
\text { ayuda individual. }\end{array}$ & $\mathrm{O}$ & $\mathrm{O}$ & $\mathrm{O}$ & $\mathrm{O}$ \\
\hline $\begin{array}{l}\text { 41. La única razón que tomo clases de matemáticas es } \\
\text { porque tengo que. }\end{array}$ & $\mathrm{O}$ & $\mathrm{O}$ & $\mathrm{O}$ & $\mathrm{O}$ \\
\hline $\begin{array}{l}\text { 42. Para mi es importante entender el trabajo que hago } \\
\text { en mi clase de matemáticas. }\end{array}$ & $\mathrm{O}$ & $\mathrm{O}$ & $\mathrm{O}$ & $\mathrm{O}$ \\
\hline 43. Tengo un sentimiento bueno hacia las matemáticas. & $\mathrm{O}$ & $\mathrm{O}$ & $\mathrm{O}$ & $\mathrm{O}$ \\
\hline $\begin{array}{l}\text { 44. Mi maestro de matemáticas sabe mucho sobre las } \\
\text { matemáticas. }\end{array}$ & O & $\mathrm{O}$ & $\mathrm{O}$ & $\mathrm{O}$ \\
\hline $\begin{array}{l}\text { 45. Las matemáticas son mas como un juego, que } \\
\text { trabajo. }\end{array}$ & $\mathrm{O}$ & $\mathrm{O}$ & O & $\mathrm{O}$ \\
\hline $\begin{array}{l}\text { 46. Mi maestro de matemáticas no quiere que } \\
\text { estudiantes hagan preguntas. }\end{array}$ & $\mathrm{O}$ & $\mathrm{O}$ & $\mathrm{O}$ & $\mathrm{O}$ \\
\hline $\begin{array}{l}\text { 47. Tengo un deseo verdadero para aprender las } \\
\text { matemáticas. }\end{array}$ & $\mathrm{O}$ & $\mathrm{O}$ & $\mathrm{O}$ & $\mathrm{O}$ \\
\hline $\begin{array}{l}\text { 48. Si yo no puedo resolver un problema de } \\
\text { matemáticas en manera rápida, nunca lo podré } \\
\text { resolver. }\end{array}$ & $\mathrm{O}$ & 0 & 0 & 0 \\
\hline
\end{tabular}




\begin{tabular}{|c|c|c|c|c|}
\hline & 非常同意 & 同意 & 反對 & 非常反對 \\
\hline 1. 㜢學可以用來椑动解䏐日常生活的的題。 & 0 & 0 & 0 & 0 \\
\hline 2. 數學是我非常喜嚾的科目。 & 0 & 0 & 0 & O \\
\hline 3. 我最喜歡容易的嘍㙾題。 & O & 0 & 0 & 0 \\
\hline 4. 我的數學不是很子。 & 0 & 0 & O & 0 \\
\hline 5. 我的數學老的秛學生的覞趣不大。 & 0 & 0 & 0 & O \\
\hline 6. 做數㙾題是很有趣的。 & O & O & O & O \\
\hline 7. 我上數學堂時感受得很舒通 & O & 0 & 0 & O \\
\hline 8. 除了堂上的書本我也想琴讀些其他的數㙾書。 & $\mathrm{O}$ & 0 & $\mathrm{O}$ & 0 \\
\hline 9. 有大部分的工作都不需要用㜢學。 & 0 & 0 & 0 & 0 \\
\hline 10. 數㙾㩘我來講是最容易的。 & 0 & O & O & O \\
\hline 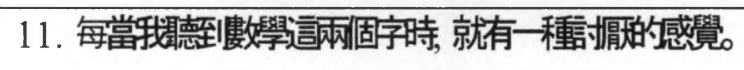 & O & O & $\mathrm{O}$ & O \\
\hline 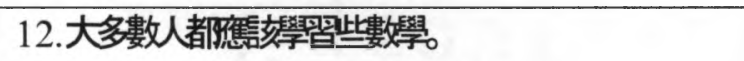 & 0 & 0 & 0 & 0 \\
\hline 13. 我不想化態多的時間在學校做娆㙾。 & 0 & 0 & $\mathrm{O}$ & 0 \\
\hline 14. 我有時是前閱櫝我的數㙾畫本。 & O & $\mathrm{O}$ & 0 & 0 \\
\hline 15. 數㙾可以嘟助你明白今日的世界。 & O & 0 & 0 & O \\
\hline 16. 我通常容易明白老皈在數學課堂上所講的。 & 0 & 0 & 0 & 0 \\
\hline 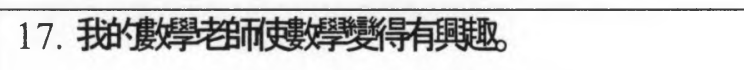 & 0 & 0 & 0 & 0 \\
\hline 18. 我一點都不喜歡僂鸡。我無去故 & 0 & 0 & O & O \\
\hline 19. 無脸我怎榢努力我還是不明白數㙾 & 0 & 0 & 0 & 0 \\
\hline
\end{tabular}




\begin{tabular}{|c|c|c|c|c|}
\hline & 非常同意 & 同意 & 反對 & 非常反對 \\
\hline 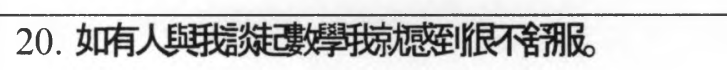 & $\mathrm{O}$ & $\mathrm{O}$ & 0 & 0 \\
\hline 21. 我的櫢㙾老師的的教導方式使我容易明白。 & O & O & 0 & 0 \\
\hline 22. 每當做㜢㙾遇臸困蜼持手我通常都险想'我無去做'。 & 0 & 0 & 0 & 0 \\
\hline 23 數學㦠國家的發展是非常重要。 & 0 & 0 & 0 & 0 \\
\hline 24. 敗噚找一份好工作㜢學是很重要的。 & 0 & O & O & 0 \\
\hline 25. 解答數㙾題是不會難到牫的。 & $\mathrm{O}$ & 0 & 0 & 0 \\
\hline 26.我喜歡的工作是不需要用任何數學。 & 0 & 0 & $\mathrm{O}$ & O \\
\hline 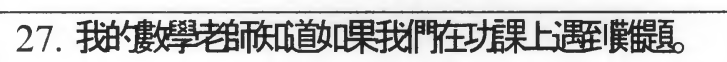 & $\mathrm{O}$ & 0 & 0 & 0 \\
\hline 28. 我很臬放食與其他人談验關下數學題 & 0 & 0 & 0 & O \\
\hline 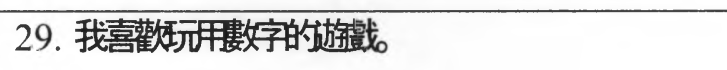 & 0 & 0 & 0 & 0 \\
\hline 30. 我存做傮㙾題方面比較效子。 & 0 & O & 0 & O \\
\hline 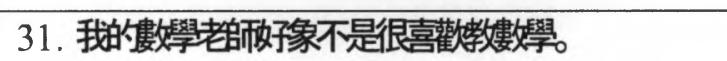 & 0 & 0 & 0 & $\mathrm{O}$ \\
\hline 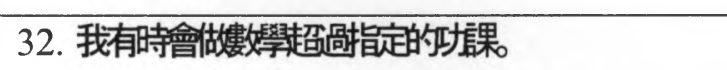 & 0 & O & 0 & 0 \\
\hline 33. 在日常的生活中沒有數學也可以過著完美的生活。 & 0 & 0 & O & $\mathrm{O}$ \\
\hline 34. 每噹我做有數字功锞持就會感到川不開し。 & 0 & $\mathrm{O}$ & 0 & 0 \\
\hline 35. 我記得大部分我所學過的數學 & $\mathrm{O}$ & O & O & $\mathrm{O}$ \\
\hline 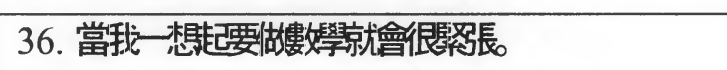 & O & O & $\mathrm{O}$ & $\mathrm{O}$ \\
\hline 37. 宁愿別人給我正碓的㜢㙾答案而自己去做。 & 0 & 0 & 0 & 0 \\
\hline
\end{tabular}




\begin{tabular}{|c|c|c|c|c|}
\hline & 非常局意 & 同意 & 反對 & 非常反對 \\
\hline 38. 大部分的數學理念是很不實用的。 & $\mathrm{O}$ & O & $\mathrm{O}$ & $\mathrm{O}$ \\
\hline 39. 我很害怕我們一定要選數學科。 & $\mathrm{O}$ & $\mathrm{O}$ & O & $\mathrm{O}$ \\
\hline 40. 我的數學老師䋺意給我門一對一的赭助。 & $\mathrm{O}$ & $\mathrm{O}$ & O & O \\
\hline 41. 唯 的理由我選睪數學科是因為我必須要選。 & $\mathrm{O}$ & $\mathrm{O}$ & $\mathrm{O}$ & $\mathrm{O}$ \\
\hline 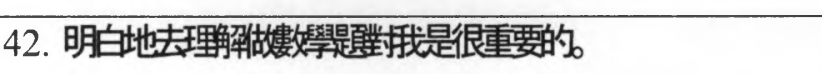 & $\mathrm{O}$ & $\mathrm{O}$ & $\mathrm{O}$ & $\mathrm{O}$ \\
\hline 43. 我對數學有好感 & $\mathrm{O}$ & $\mathrm{O}$ & 0 & O \\
\hline 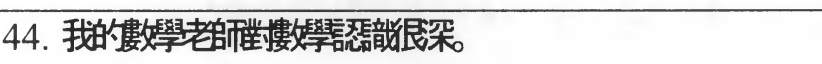 & $\mathrm{O}$ & 0 & $\mathrm{O}$ & $\mathrm{O}$ \\
\hline 45. 數學是趣耕生多於黑罢版練習。 & $\mathrm{O}$ & $\mathrm{O}$ & $\mathrm{O}$ & O \\
\hline 46. 我的數學老師不喜歡學生發問鲖題。 & $\mathrm{O}$ & $\mathrm{O}$ & O & O \\
\hline 47. 我有一個學習數學的獂望。 & $\mathrm{O}$ & $\mathrm{O}$ & $\mathrm{O}$ & $\mathrm{O}$ \\
\hline 48. 如果我現在不理解數學题的解初去 我将會永遠都不會明白。 & $\mathrm{O}$ & O & $\mathrm{O}$ & $\mathrm{O}$ \\
\hline
\end{tabular}


Appendix C

Teacher Interview Questions 


\section{Teacher Interview Questions}

Could you start by giving me an overview of your educational and teaching background and how you came to become a mathematics teacher here at Eastwood High School?

How long have you taught?

How long have you taught algebra?

How long have you worked with minority student populations?

Can you tell me a little about how you became interested and involved in the Algebra Project?

School wide decision?

Department decision?

How long have you been involved in the project?

Could you talk about some of the training or support you've received to implement the program at your school?

Training?

On-going PD over the summer?

Additional workshops or supports?

Do you feel the training, support and materials have been adequate so you that you can successfully teach the algebra curriculum?

What have been some of challenges or difficulties with implementing the program at your site?

How have the students responded to the program? Have they commented on similarities or differences to mathematics instruction they've received in the past?

Could you describe the Algebra Project students' level of "enjoyment" compared to Non-Algebra Project students? 
Do you think the Algebra Project curriculum has impacted students' motivation to learn algebra? If so, in what ways? Can you share some evidence or an anecdote?

What has the impact been on students' standardized test scores? (CSTs, CAHSEE, etc). Has the site notice any significant changes since the Algebra Project's introduction? Have some groups of students responded to the curriculum differently when compared to other groups? (gender, race, SES)

From your perspective, how is the Algebra Project curriculum similar/different from other algebra curricula?

In the research literature, the Algebra Project is often cited as an example of a culturally relevant pedagogical approach to teaching mathematics. How has the Algebra Project curriculum attempted to build upon students' prior funds of knowledge? How successful has it been in this regard?

The Algebra Project curriculum builds in several experiential activities over the course of the year to try to engage learners. Could you talk about a few of these? How effective have these activities been in engaging the students? Connecting to the algebra topics?

Have you found yourself using the Algebra Project materials in Non-Algebra Project classes and vice-versa?

Have you changed your approach to teaching or working with students as a result implementing the algebra project curriculum?

Can you describe the support you've received from the site administration or district personnel around implementing the program? 
Another commonly referenced attribute of CRP is a commitment to engaging students in social justice work and encouraging relationships between schools and communities. Could you explain how the AP program has attempted to foster these ideals in the students?

How has the AP impacted the development of students' mathematical identities and sense of agency?

What have been the major positives from implementing the AP?

What have been the major challenges from implementing the AP?

Are there any additional thoughts you'd like to share - important issues or topics that we haven't addressed? 
Appendix D

Student Focus Group Questions 


\section{Student Focus Group Questions}

Perception of the Mathematics Teacher

What are the characteristics of an effective math teacher? Does your math teacher exhibit these characteristics?

Is your math teacher's teaching style similar or different to teachers you've had in the past? How are they similar/different? Could you explain more?

How do you feel about the way your math teacher teaches the algebra class? Why?

Do you think it is important for a math teacher to be interested in the students? Student learning? Could you provide an example?

Do you think it is more important for a math teacher to know the subject matter, or to be interested in teaching? Could you provide an example?

Does your math teacher talk to you about your progress in math? How does this communication take place? Do you feel this is important? Why/why not?

Does your math teacher talk to your family about your progress in math? How does this communication take place? Do you feel this is important? Why/why not?

Do you think a strong student/teacher relationship is important to learning?

Learning math? Why/why not?

Could you describe a typical lesson in your algebra class?

Could you describe an activity from your math class that you thought was good or interesting? What made it a good or interesting activity?

How do you think your classmates feel about math? About your teacher? Why? Could you provide an example? 
Anxiety toward Mathematics

How do you feel about math? About studying math? About your math class?

* Do you get nervous or anxious when working on math problems? When (during class, homework, quizzes, tests)? How does this compare to how you feel about other subjects?

* Do you feel differently towards math this year compared to previous years?

How? Why do you think these feelings have changed (or stayed the same)?

Are you becoming more or less confident in math? Why?

Do you think your classmates feel the same way? Why or why not?

Value of Mathematics in Society

Do you think math is a valuable or important subject to study? Why or why not?

Have your feelings about the importance of math changed because of this year's math class? How? Why/why not?

Do you think it helps you in life to learn math? How? Why/why not?

Do you think it helps you to do well in math? How? Why/why not?

Do you think that it helps you in other subjects to learn math? How? Why/why not?

Do you think you will use math later in life? How? A little or a lot?

Are there certain topics or ideas in math that you are interested in studying in the future?

Do you think your classmates would feel the same way? Why or why not? 


\section{Self-Concept in Mathematics}

How would you describe yourself as a math student? Has this changed during this school year?

What activities have you enjoyed or connected with in math this year? Why?

What have these activities taught you about being a math student? Besides the mathematics?

What do you think you've gained from studying math this year? Why?

Do you think your classmates would feel the same way? Why or why not?

Are you more or less confident of your math skills as a result of your math class this year?

\section{Enjoyment of Mathematics}

Do you enjoy studying math? To what extent? Has this changed over time? Why/why not?

Do you get a sense of satisfaction from working on math problems? Has this changed over time? How? Why/why not?

Are you interested in math or science related topics outside of class (television shows, internet sites, museums, news items, etc)? Has your math class this year contributed to this? How? Why/why not?

Have you enjoyed mathematics this year more or less than in previous years?

Why? How has your math class contributed to this?

Do you think your classmates would feel the same way? Why/why not?

Can you describe how your math teacher has tried to make math more enjoyable for students this year? Has it worked? How? Why? 
Are there any math related topics that you'd like to learn more about? Which ones?

Motivation in Mathematics

Do you think you're a motivated math student? Why or why not? Could you give me an example?

*** Can you tell me about a time when motivation was challenging for you in math? What was the situation? How did you cope? Was this different from previous years? How?

How motivated are your friends who are in different math classes? Do you think they are more or less motivated to study math? Why/why not? Can you provide me with an example? What are some of the reasons for the differences?

*** Has studying math this year changed your motivation to study math in the future? How about its impact on your motivation to study other subjects?

* Do you think you'll continue to study math? At high school? College? Why/why not? How has your experience in math this year influenced this?

How do you think your classmates would answer? Why?

Algebra Project

*** Could you share any specific things that you've liked/disliked about Algebra Project? How have they have helped/hurt your learning of mathematics this year?

What do your friends in other classes think about the Algebra Project? How do you know? What do your parents think about the Algebra Project? How do you know? 
*** How has the Algebra Project been different from other math classes you've taken? How have these differences affected your learning? Could you provide an example?

Do you think the Algebra Project is a good method of instruction? Do you think the Algebra Project should continue at your school?

Do you think it matters how math is taught? Do you think it matters who decides how math is taught?

If you had a choice between an Algebra Project class and a non-Algebra Project class which would you choose? Why? Do you think students should be allowed to pick what type of algebra class they take?

General

*** How's math going for you this year? What has been challenging/easy for you?

What other factors have affected learning math this year? Do you have other thoughts or feelings you'd like to share about studying math?

If you were in charge of picking math activities or topics to study - what types of things would you pick? Why? What types of things would you leave out? Why? Give me some examples.

* Do you think it matters if you're male or female in the math classroom? Why/why not? How? Do you think it matters in other subjects? Could you give me an example?

*** Do you think it matters what race/ethnicity you are when it comes to learning math? Why/why not? How? What about in other subjects? Could you give me an example?

* Do you think it matters what race/ethnicity your math teacher is? Does it matter if they are male or female? Why? 
How has the math you've studied this year in the Algebra Project compare to math classes you've had in the past? Why? What types of things have been similar/different?

* $\quad$ Algebra Project Focus Group

** Non-Algebra Project Focus Group 
Appendix E

Algebra I CST Technical Report 
The following explanation on the validity and reliability of the 2008 Algebra I

CST is taken from the California Department of Education's Technical Analysis

Report:

Content validity refers to the degree to which the content of a test samples, as determined by subject-matter experts. CST items were developed to align with the content standards that are representative of the broader content domains: English-language arts, mathematics, history-social science, and science. Thus, the content-related evidence of validity concerns the extent to which the test items represent these specified content domains and cognitive dimensions.

Content validity also provides information about how well an item measures its intended construct. Such validity is determined by a critical review of the items by experts in the field. For the CSTs, these reviews are conducted by experts in their designated areas from both the CDE and ETS. For these reviews, ETS senior content staff work directly with CDE content consultants.

The CDE content consultants each have extensive experience in $\mathrm{K}-12$ assessments, particularly in their subject of expertise, and many are former teachers. At minimum, each CDE content consultant holds a bachelor's degree; most have an advanced degree in their area of expertise. All ETS content and test development staff have extensive experience with $\mathrm{K}-12$ assessments, experience in teaching students with a broad range of abilities, and an understanding of the California content standards. They each hold, at minimum, a bachelor's degree; most have an advanced degree within their area of expertise.

After the CST items were written by ETS-trained item writers, a series of reviews, including reviews by ETS content assessment specialists and the external ARPs, were conducted to ensure that each item was measuring the appropriate California content standard and was matched to the item specifications.

Additionally, analyses of the relationship of test scores to variables external to the test provide an important source of validity evidence. The analyses address questions about the degree to which these relationships are consistent with the construct underlying the proposed test interpretations. Relationships between test scores and other measures intended to measure similar constructs provide criterion validity evidence. For the CSTs, the criterion evidence can be 
collected through an examination of the relationship between the CSTs and their CAT/6 Survey counterparts (see Table 8).

Table 8: Correlations Between End-of-Course CSTs for Mathematics and CAT/6 Survey Mathematics Tests

\begin{tabular}{ccccccccc}
\cline { 2 - 8 } Grade & \multicolumn{2}{l}{ GM (CST) / } & \multicolumn{2}{c}{ Algebra I (CST) / } & \multicolumn{2}{c}{ Geometry (CST) / } & \multicolumn{2}{c}{ Algebra II (CST) / } \\
MTH (CAT/6) & \multicolumn{2}{l}{ MTH (CAT/6) } & \multicolumn{2}{c}{ MTH (CAT/6) } & \multicolumn{2}{c}{ MTH (CAT/6) } \\
\cline { 2 - 9 } & N & Correl. & N & Correl. & N & Correl. & N & Correl. \\
\hline 8 & 269,630 & 0.73 & 188,563 & 0.72 & 12,432 & 0.64 & 453 & 0.72 \\
9 & 133,382 & 0.64 & 215,774 & 0.63 & 89,036 & 0.66 & 13,161 & 0.61 \\
10 & N/A & N/A & 128,604 & 0.49 & 124,253 & 0.61 & 77,970 & 0.65 \\
11 & N/A & N/A & 61,488 & 0.43 & 68,306 & 0.50 & 87,167 & 0.60 \\
\hline
\end{tabular}

Reliability focuses on the extent to which differences in test scores reflect true differences in the knowledge, ability, or skill being tested rather than fluctuations due to chance or random factors. The variance in the distributions of test scores-essentially, the differences among individuals - is partly due to real differences in the knowledge, skill, or ability being tested (true score variance) and partly due to random unsystematic errors in the measurement process (error variance). The number used to describe reliability is an estimate of the proportion of the total variance that is true score variance. Several different ways of estimating this proportion exist. The estimates of reliability reported here are internal-consistency measures, which are derived from analysis of the consistency of the performance of individuals on items within a test (internalconsistency reliability). Therefore, they apply only to the test form being analyzed. They do not take into account form-to-form variation due to equating limitations or lack of parallelism, nor are they responsive to day-to-day variation due, for example, to state of health or testing environment. Reliability coefficients may range from 0 to 1 . The higher the reliability coefficient for a set of scores, the more likely individuals would be to obtain very similar scores if they were retested. The internal consistency reliability is measured by Cronbach's Alpha (Cronbach, 1951).

The reliability analyses were conducted for all valid cases of the overall P1 examinee population with valid scores $(99.6$ percent of the data that was used for the August 15 reporting and more than 99 percent of the total examinee population). The table presents the results of reliability analyses on the Algebra I CST with the number of items and examinees upon which the analysis was performed (see Table 9) (California Department of Education, 2008). 
Table 9: Reliability Analysis of 2008 Algebra I CST

\begin{tabular}{|l|c|c|c|c|c|c|c|c|c|}
\hline \multicolumn{2}{|c|}{} & \multicolumn{3}{c|}{ Scale } & \multicolumn{3}{c|}{ Raw } \\
Score & Score \\
\hline CST & Items & Students & Reliability & Mean & Std. Dev. & SEM & Mean & Std. Dev. & SEM \\
\hline Algebra I & 65 & 742,363 & 0.91 & 315 & 67 & 20.10 & 29.75 & 12.15 & 3.64 \\
\hline
\end{tabular}


Appendix F

MAI Raw Data Results 
Table 33

Independent $t$-test of individual questions from MAI - Non-Algebra Project (Non-AP) v. Algebra Project (AP)

\begin{tabular}{|c|c|c|c|c|c|}
\hline & $\begin{array}{c}\text { Non-AP } \\
\bar{X} \\
(S D)\end{array}$ & $\underset{(S D)}{\stackrel{\mathrm{AP}}{\bar{X}}}$ & $t$ & d.f. & $p$ \\
\hline $\begin{array}{l}\text { 1. Mathematics is useful for the problems of every } \\
\text { day life. } * *\end{array}$ & $\begin{array}{c}1.6750 \\
(0.6938)\end{array}$ & $\begin{array}{c}1.9143 \\
(0.5071)\end{array}$ & -1.7188 & 71 & 0.0900 \\
\hline $\begin{array}{l}\text { 2. Mathematics is something which I enjoy very } \\
\text { much. }\end{array}$ & $\begin{array}{c}2.3250 \\
(0.8883)\end{array}$ & $\begin{array}{c}2.5714 \\
(0.8501)\end{array}$ & -1.2264 & 72 & 0.2240 \\
\hline 3. I like the easy mathematics problems the best. * & $\begin{array}{c}1.9000 \\
(0.8412)\end{array}$ & $\begin{array}{c}1.4571 \\
(0.6108)\end{array}$ & 2.6301 & 71 & 0.0105 \\
\hline 4. I don't do very well in mathematics. & $\begin{array}{c}2.5250 \\
(1.0125)\end{array}$ & $\begin{array}{c}2.4571 \\
(0.8521)\end{array}$ & 0.3151 & 73 & 0.7536 \\
\hline $\begin{array}{l}\text { 5. My mathematics teacher shows little interest in } \\
\text { the students. }\end{array}$ & $\begin{array}{c}2.8500 \\
(0.6998)\end{array}$ & $\begin{array}{c}2.7941 \\
(0.9138)\end{array}$ & 0.2913 & 61 & 0.7718 \\
\hline 6. Working mathematics problems is fun. & $\begin{array}{c}2.3500 \\
(0.8930)\end{array}$ & $\begin{array}{c}2.4000 \\
(0.8812)\end{array}$ & -0.2436 & 72 & 0.8082 \\
\hline 7. I feel at ease in a mathematics class. & $\begin{array}{l}2.3500 \\
(0.7974)\end{array}$ & $\begin{array}{c}2.4571 \\
(0.7800)\end{array}$ & -0.5972 & 71 & 0.5523 \\
\hline $\begin{array}{l}\text { 8. I would like to do some outside reading in } \\
\text { mathematics. }\end{array}$ & $\begin{array}{c}2.5000 \\
(0.7511) \\
\end{array}$ & $\begin{array}{c}2.7143 \\
(0.9258) \\
\end{array}$ & -1.0908 & 65 & 0.2794 \\
\hline 9. There is little need for mathematics in most jobs. & $\begin{array}{c}2.7000 \\
(1.0427)\end{array}$ & $\begin{array}{l}2.8000 \\
(0.7194)\end{array}$ & -0.4881 & 69 & 0.6270 \\
\hline 10. Mathematics is easy for me. & $\begin{array}{c}2.6500 \\
(0.8638)\end{array}$ & $\begin{array}{c}2.5882 \\
(0.8916)\end{array}$ & 0.3013 & 69 & 0.7641 \\
\hline $\begin{array}{l}\text { 11. When I hear the word mathematics, I have a } \\
\text { feeling of dislike. }\end{array}$ & $\begin{array}{c}2.7500 \\
(0.8397)\end{array}$ & $\begin{array}{c}2.5429 \\
(0.8859) \\
\end{array}$ & 1.0350 & 70 & 0.3042 \\
\hline 12. Most people should study some mathematics. & $\begin{array}{c}1.8250 \\
(0.6360) \\
\end{array}$ & $\begin{array}{c}2.0000 \\
(0.5941) \\
\end{array}$ & -1.2314 & 73 & 0.2221 \\
\hline $\begin{array}{l}\text { 13. I would like to spend less time in school doing } \\
\text { mathematics. }\end{array}$ & $\begin{array}{c}2.5250 \\
(0.7157) \\
\end{array}$ & $\begin{array}{c}2.5429 \\
(0.6084) \\
\end{array}$ & -0.1028 & 70 & 0.9184 \\
\hline $\begin{array}{l}\text { 14. Sometimes I read ahead in our mathematics } \\
\text { book. }\end{array}$ & $\begin{array}{l}2.7500 \\
(0.8086)\end{array}$ & $\begin{array}{c}2.8571 \\
(0.8096)\end{array}$ & -0.5721 & 72 & 0.5690 \\
\hline $\begin{array}{l}\text { 15. Mathematics is helpful in understanding today's } \\
\text { world. }\end{array}$ & $\begin{array}{c}2.1250 \\
(0.7574) \\
\end{array}$ & $\begin{array}{c}2.1429 \\
(0.6482) \\
\end{array}$ & -0.1100 & 73 & 0.9127 \\
\hline $\begin{array}{l}\text { 16. I usually understand what we are talking about in } \\
\text { mathematics class. }\end{array}$ & $\begin{array}{c}2.1750 \\
(0.8130) \\
\end{array}$ & $\begin{array}{c}2.0571 \\
(0.7253) \\
\end{array}$ & 0.6635 & 73 & 0.5091 \\
\hline $\begin{array}{l}\text { 17. My mathematics teacher makes mathematics } \\
\text { interesting. }\end{array}$ & $\begin{array}{c}2.2250 \\
(0.7675) \\
\end{array}$ & $\begin{array}{c}2.0286 \\
(0.7470) \\
\end{array}$ & 1.1216 & 72 & 0.2657 \\
\hline 18. I don't like anything about mathematics. & $\begin{array}{c}2.9744 \\
(0.8732)\end{array}$ & $\begin{array}{c}2.8571 \\
(0.9121)\end{array}$ & 0.5632 & 70 & 0.5751 \\
\hline & & & & & \\
\hline
\end{tabular}




\begin{tabular}{|c|c|c|c|c|c|}
\hline & $\begin{array}{c}\text { Non-AP } \\
\bar{X} \\
(S D)\end{array}$ & $\begin{array}{c}\mathrm{AP} \\
\bar{X} \\
(S D)\end{array}$ & $t$ & d.f. & $p$ \\
\hline $\begin{array}{l}\text { 19. No matter how hard I try, I cannot understand } \\
\text { mathematics. }\end{array}$ & $\begin{array}{c}2.8000 \\
(0.9392)\end{array}$ & $\begin{array}{c}2.9412 \\
(0.9192) \\
\end{array}$ & -0.6519 & 71 & 0.5166 \\
\hline $\begin{array}{l}\text { 20. I feel tense when someone talks to me about } \\
\text { mathematics. }\end{array}$ & $\begin{array}{c}2.8750 \\
(0.7906)\end{array}$ & $\begin{array}{c}2.7576 \\
(0.7513) \\
\end{array}$ & 0.6491 & 70 & 0.5184 \\
\hline $\begin{array}{l}\text { 21. My mathematics teacher presents material in a } \\
\text { clear way. }\end{array}$ & $\begin{array}{c}2.1250 \\
(0.6864)\end{array}$ & $\begin{array}{c}1.9429 \\
(0.5913)\end{array}$ & 1.2346 & 73 & 0.2210 \\
\hline $\begin{array}{l}\text { 22. I often think, "I can't do it," when a mathematics } \\
\text { problem seems hard. }\end{array}$ & $\begin{array}{c}2.5000 \\
(0.9608)\end{array}$ & $\begin{array}{c}2.3714 \\
(0.8431)\end{array}$ & 0.6172 & 73 & 0.5390 \\
\hline $\begin{array}{l}\text { 23. Mathematics is of great importance to a country's } \\
\text { development. }\end{array}$ & $\begin{array}{c}1.6500 \\
(0.7355)\end{array}$ & $\begin{array}{c}1.8286 \\
(0.6177)\end{array}$ & -1.1426 & 73 & 0.2569 \\
\hline $\begin{array}{l}\text { 24. It is important to know mathematics in order to } \\
\text { get a good job. }\end{array}$ & $\begin{array}{c}1.5750 \\
(0.5943)\end{array}$ & $\begin{array}{c}1.5429 \\
(0.6108)\end{array}$ & 0.2302 & 71 & 0.8186 \\
\hline $\begin{array}{l}\text { 25. It doesn't disturb me to work mathematics } \\
\text { problems. } *\end{array}$ & $\begin{array}{c}2.4500 \\
(0.7144)\end{array}$ & $\begin{array}{c}2.0857 \\
(0.7425)\end{array}$ & 2.1576 & 71 & 0.0343 \\
\hline $\begin{array}{l}\text { 26. I would like a job which doesn't use any } \\
\text { mathematics. }\end{array}$ & $\begin{array}{c}2.5641 \\
(0.7879)\end{array}$ & $\begin{array}{c}2.3429 \\
(0.8725)\end{array}$ & 1.1399 & 69 & 0.2583 \\
\hline $\begin{array}{l}\text { 27. My mathematics teacher knows when we are } \\
\text { having trouble with our work. }\end{array}$ & $\begin{array}{c}2.0250 \\
(0.7675)\end{array}$ & $\begin{array}{c}1.9429 \\
(0.8023)\end{array}$ & 0.4514 & 71 & 0.6531 \\
\hline $\begin{array}{l}\text { 28. I enjoy talking to other people about } \\
\text { mathematics. }\end{array}$ & $\begin{array}{c}2.7000 \\
(0.8227)\end{array}$ & $\begin{array}{c}2.7429 \\
(0.9185)\end{array}$ & -0.2116 & 69 & 0.8331 \\
\hline 29. I like to play games that use numbers. & $\begin{array}{c}2.3000 \\
(0.6869)\end{array}$ & $\begin{array}{c}2.4000 \\
(0.8471)\end{array}$ & -0.5564 & 65 & 0.5798 \\
\hline 30. I am good at working mathematics problems. & $\begin{array}{c}2.4750 \\
(0.8161)\end{array}$ & $\begin{array}{c}2.4571 \\
(0.8521)\end{array}$ & 0.0923 & 71 & 0.9267 \\
\hline $\begin{array}{l}\text { 31. My mathematics teacher doesn't seem to enjoy } \\
\text { teaching mathematics. }\end{array}$ & $\begin{array}{c}3.1250 \\
(0.8530)\end{array}$ & $\begin{array}{c}3.2000 \\
(0.8677)\end{array}$ & -0.3764 & 71 & 0.7077 \\
\hline $\begin{array}{l}\text { 32. Sometimes I work more mathematics problems } \\
\text { than are assigned in class. }\end{array}$ & $\begin{array}{c}2.7250 \\
(0.7507)\end{array}$ & $\begin{array}{c}3.0000 \\
(0.8044)\end{array}$ & -1.5237 & 70 & 0.1321 \\
\hline $\begin{array}{l}\text { 33. You can get along perfectly well in everyday life } \\
\text { without mathematics. }\end{array}$ & $\begin{array}{c}2.5750 \\
(0.8130)\end{array}$ & $\begin{array}{c}2.6286 \\
(0.8075)\end{array}$ & -0.2857 & 72 & 0.7759 \\
\hline 34. Working with numbers upsets me. & $\begin{array}{c}2.8750 \\
(0.6864)\end{array}$ & $\begin{array}{c}2.9714 \\
(0.7854)\end{array}$ & -0.5624 & 68 & 0.5757 \\
\hline $\begin{array}{l}\text { 35. I remember most of the things I learn in } \\
\text { mathematics. }\end{array}$ & $\begin{array}{c}2.2250 \\
(0.6598) \\
\end{array}$ & $\begin{array}{c}2.2571 \\
(0.7006)\end{array}$ & -0.2037 & 70 & 0.8392 \\
\hline $\begin{array}{l}\text { 36. It makes me nervous to even think about doing } \\
\text { mathematics. }\end{array}$ & $\begin{array}{c}2.7500 \\
(0.8397) \\
\end{array}$ & $\begin{array}{c}2.8571 \\
(0.6011) \\
\end{array}$ & -0.6408 & 70 & 0.5237 \\
\hline $\begin{array}{l}\text { 37. I would rather be given the right answer to a } \\
\text { mathematics problem than to work it out myself. }\end{array}$ & $\begin{array}{c}2.6000 \\
(0.7779) \\
\end{array}$ & $\begin{array}{c}2.3143 \\
(0.7960) \\
\end{array}$ & 1.5672 & 71 & 0.1215 \\
\hline $\begin{array}{l}\text { 38. Most of the ideas in mathematics aren't very } \\
\text { useful. }\end{array}$ & $\begin{array}{c}2.8750 \\
(0.6864)\end{array}$ & $\begin{array}{c}2.6571 \\
(0.6835)\end{array}$ & 1.3743 & 72 & 0.1736 \\
\hline 39. It scares me to have to take mathematics. & $\begin{array}{c}2.9250 \\
(0.7971)\end{array}$ & $\begin{array}{c}3.0000 \\
(0.6417) \\
\end{array}$ & -0.4511 & 73 & 0.6533 \\
\hline $\begin{array}{l}\text { 40. My mathematics teacher is willing to give us } \\
\text { individual help. }\end{array}$ & $\begin{array}{c}1.8750 \\
(0.6480)\end{array}$ & $\begin{array}{c}1.8571 \\
(0.6482)\end{array}$ & 0.1190 & 72 & 0.9056 \\
\hline
\end{tabular}




\begin{tabular}{|l|c|c|c|c|c|}
\hline & Non-AP & $\overline{A P}$ & $t$ & d.f. & $p$ \\
& $\begin{array}{c}\bar{X} \\
(S D)\end{array}$ & $\begin{array}{c}\bar{X} \\
(S D)\end{array}$ & & & \\
\hline 41. The only reason I'm taking mathematics is & 2.2250 & 2.1471 \\
because I have to. & $(0.9470)$ & 0.3641 & 71 & 0.7169 \\
\hline $\begin{array}{l}\text { 42. It is important to me to understand the work I do } \\
\text { in mathematics. }\end{array}$ & $\begin{array}{c}1.8500 \\
(0.7355)\end{array}$ & $\begin{array}{c}1.8571 \\
(0.6921)\end{array}$ & -0.0433 & 73 & 0.9656 \\
\hline 43. I have a good feeling toward mathematics. & $\begin{array}{c}2.2750 \\
(0.7507)\end{array}$ & $\begin{array}{c}2.3143 \\
(0.8321)\end{array}$ & -0.2135 & 69 & 0.8316 \\
\hline $\begin{array}{l}\text { 44. My mathematics teacher knows a lot about } \\
\text { mathematics. }\end{array}$ & $\begin{array}{c}1.7500 \\
(0.6304)\end{array}$ & $\begin{array}{c}1.6571 \\
(0.7253)\end{array}$ & 0.5877 & 68 & 0.5587 \\
\hline 45. Mathematics is more of a game than it is hard & $\begin{array}{c}2.7000 \\
(0.7579)\end{array}$ & $\begin{array}{c}3.0000 \\
(0.7669)\end{array}$ & -1.6993 & 71 & 0.0936 \\
\hline work. ** & $\begin{array}{c}3.2000 \\
(0.8227)\end{array}$ & $\begin{array}{c}3.3143 \\
(0.7582)\end{array}$ & -0.6259 & 73 & 0.5334 \\
\hline $\begin{array}{l}\text { 46. My mathematics teacher doesn't like students to } \\
\text { ask questions. }\end{array}$ & $\begin{array}{c}2.4000 \\
(0.8412)\end{array}$ & $\begin{array}{c}2.5143 \\
(0.9195)\end{array}$ & -0.5587 & 70 & 0.5782 \\
\hline 47. I have a real desire to learn mathematics. & $\begin{array}{c}2.6923 \\
(0.9502)\end{array}$ & $\begin{array}{c}2.5429 \\
(0.7414)\end{array}$ & 0.7582 & 71 & 0.4508 \\
\hline 48. If I don't see how to work a mathematics \\
problem right away, I never get it.
\end{tabular}

* Statistically significant difference at $\alpha=0.05$ level.

$* *$ Statistically significant difference at $\alpha=0.10$ level. 


\section{Appendix G}

Student Focus Groups Data Indexing 


\section{$\underline{\text { Student Affect \& Voice }}$}

1. Negative disposition/response to studying mathematics

2. Positive disposition/response of studying mathematics

8. Feeling of forced to learn mathematics

9. Feeling of lack of choice/student voice (in class or interview)

22. Feeling of learning "hecka stuff" in AP

24. Enjoyment of AP

25. Motivated

26. Lack of motivation

27. Desire to be motivated

28. Positionality of teacher/students in class

30. Perseverance

32. Ease

33. Repetition of AP topics

36. Apprehension/fear - "hard"

37. Good grades/performance

41. Frustrated/anxious/nervous

\section{Homework}

5. Challenges of doing homework

6. Challenges of turning homework in

20. Call for more homework

\section{$\underline{\text { Race. Discipline \& Equity }}$}

3. Acknowledging others/reinforcing racial stereotypes

10. Discipline/trouble
$\mathrm{A} 7, \mathrm{~A} 12, \mathrm{~A} 13, \mathrm{~A} 14, \mathrm{~A} 14, \mathrm{~A} 28, \mathrm{~B} 21$,

$\mathrm{A} 7, \mathrm{~A} 10, \mathrm{~A} 11, \mathrm{~A} 33, \mathrm{~B} 18$,

$\mathrm{A} 12, \mathrm{~A} 13, \mathrm{~A} 13$,

$\mathrm{A} 13, \mathrm{~A} 13, \mathrm{~A} 13, \mathrm{~A} 13, \mathrm{~A} 14, \mathrm{~A} 14, \mathrm{~A} 15$, $\mathrm{A} 20, \mathrm{~A} 29, \mathrm{~A} 30, \mathrm{~A} 30, \mathrm{~A} 37$, $\mathrm{A} 24, \mathrm{~A} 25, \mathrm{~A} 25, \mathrm{~A} 25, \mathrm{~A} 34, \mathrm{~B} 16, \mathrm{~B} 31$, A26, A34, A34, B9, B10 (lack of for Road Trip/Tripline), B11, B24, B18, B18

A27, A28, A29 (w. AP), A31

(requisite for), A33 (to not learn math), B17 (due to ease of pacing), B17, B18 (due to ease and fun), B18 (due to facilitation of understanding), B22 (lukewarm reference to future math in college), B22 (x2, to continue at high school),

$\mathrm{A} 28, \mathrm{~A} 29, \mathrm{~A} 35$ (for future use of math), A35, B21 (for future use), B22, B23 (for high school)

A29, A29,

A31,

$\mathrm{B} 5$ ( $\mathrm{x} 2)$

B9, B9, B12, B13 (lack of ease), B13,

$\mathrm{B} 13, \mathrm{~B} 14, \mathrm{~B} 15, \mathrm{~B} 17, \mathrm{~B} 18, \mathrm{~B} 19$,

B10 (lack of enjoyment of), B21

B17,

B18, B22, B23 (importance of grades to motivation)

B23 (due lack of understanding), B24

(lack of due to increased comprehension), B24,

$\mathrm{A} 11, \mathrm{~A} 12$,

A11, A12,

A23, B18 (less than regular algebra)
A9, A9, A10, A16, A36, A15, A16, A18, A20, A21, A30, A36, B28, 
3.

Differential treatment in math class based on race

Laughter/teasing/inappropriate behavior between

7. students (Microaggressions)

43. Influence of Race

42. Equity between genders in math

\section{$\underline{\text { Teacher/Student Relations }}$}

11. Sense of humor w. teacher

12. Individual help from teacher

14. Suspicion/concerns with sharing feelings

18. Tension between teacher and students

\section{Curriculum \& Instruction}

4. Algebra topics

15. Math/constructivist activities

16. Desire for more constructivist activities

19. Importance of teacher pacing and re-teaching concepts

23. Differences between AP and traditional algebra

AP activities

9.

Importance of examples/materials

1.

34. Lack of connection between AP and math

35. Advantages of additional time in class

39. Interdisciplinary connections

44. Attention/1-1/class size

45. Benefits of heterogeneous class
A16, A36 (x3 all Blacks), A36, A36, $\mathrm{A} 36, \mathrm{~A} 37, \mathrm{~A} 37$ (x 2 equality in math classroom from Chin. students), B28, B28, B28 \& B29 (tension w. Asians), B29

A8, A9 (x 5), A10 (x 2), A15 (x2), A17

(x4), A18, A18, A19, A21, A22, A27

(x2), A36, A37,

B26 (connection to different previous educational backgrounds), B26 (no influence), B27 (learning the same thing), B27 (x3, equitable between races) B 25, B25 (in seating), B25 (in classroom in general), B26 (difference than in the gym classes),

A15, A18, A19, A20, A21

A16,

$\mathrm{A} 17, \mathrm{~A} 38$

$\mathrm{A} 21, \mathrm{~A} 21, \mathrm{~A} 21$,

$\mathrm{A} 9, \mathrm{~A} 10, \mathrm{~A} 10, \mathrm{~A} 17, \mathrm{~B} 6, \mathrm{~B} 9, \mathrm{~B} 10, \mathrm{~B} 11$,

B14,

A17

A17, A18, A25, A29

A22

A25, A25, A25, A25, A26, A26, A26, A34,

B5, B5, B6, B6, B8, B9, B11, B12

(importance of), B12 (trouble with Tripline), B13 (recommended changes to sequence of curricula), B13 (helped to learn)

B6, B7, B15 (step-by-step), B15 (enough, step by step examples), B15 (more steps) B11

B16, B19 (less homework due to)

B20,

B29, B30 (afterschool), B30, B30, 


\section{Miscellaneous}

7. Math/money connection
A12, A35
A24,
B20, B22,
B20,
B30,

21. Algebra Project

38. College reference

46. Harder

\section{A Non-Algebra Project \\ B Algebra Project}


